\title{
High-Performance Polymer Ion Conductors Enabled by Decoupled Fast Ions in Molecular Channels
}

\section{Liangbing Hu ( $\nabla$ binghu@umd.edu )}

University of Maryland at College Park https://orcid.org/0000-0002-9456-9315

\section{Chunpeng Yang}

University of Maryland at College Park

\section{Qisheng Wu}

Brown University https://orcid.org/0000-0001-9123-1864

\section{Weiqi Xie}

University of Maryland at College Park

\section{Xin Zhang}

University of Maryland at College Park

Jin Zheng

Florida State University

\section{Mounesha Garaga}

City University of New York

\section{Byung Hee Ko}

University of Delaware https://orcid.org/0000-0002-0934-5182

\section{Yimin Mao}

National Institute of Standards and Technology

\section{Alexandra Brozena}

University of Maryland at College Park https://orcid.org/0000-0002-5045-2123

\section{Shuaiming He}

University of Maryland at College Park

Jiaqi Dai

University of Maryland at College Park

\section{Madhu Sudan Tyagi}

National Institute of Standards and Technology

\section{Feng Jiao}

University of Delaware https://orcid.org/0000-0002-3335-3203

\section{Steve Greenbaum}

Hunter College and Graduate Center of the City University of New York

\section{Yan-Yan Hu}

Florida State University

Robert Briber 
University of Maryland College Park

\section{Akira Isogai}

The University of Tokyo

\section{Kang Xu}

United States Army Research Laboratory https://orcid.org/0000-0002-6946-8635

\section{Yue Qi}

Brown University

\section{Physical Sciences - Article}

Keywords: Nanocellulose, Ion coordination, Polymer electrolyte, Super ion conductor, Solid-state 53 batteries

Posted Date: December 1st, 2020

DOl: https://doi.org/10.21203/rs.3.rs-114732/v1

License: (c) (i) This work is licensed under a Creative Commons Attribution 4.0 International License. Read Full License

Version of Record: A version of this preprint was published at Nature on October 20th, 2021. See the published version at https://doi.org/10.1038/s41586-021-03885-6. 
1 High-Performance Polymer Ion Conductors Enabled by Decoupled

Fast Ions in Molecular Channels

3 Chunpeng Yang ${ }^{1 \mathrm{a}}$, Qisheng Wu ${ }^{2 \mathrm{a}}$, Weiqi Xie ${ }^{1 \mathrm{a}}$, Xin Zhang ${ }^{1}$, Jin Zheng ${ }^{3}$, Mounesha N. Garaga $^{4}$, 4 Byung Hee $\mathrm{Ko}^{5}$, Yimin Mao ${ }^{1,6}$, Alexandra Brozena ${ }^{1}$, Shuaiming $\mathrm{He}^{1}$, Jiaqi Dai ${ }^{1}$, Madhusudan 5 Tyagi $^{1,6}$, Feng Jiao ${ }^{5}$, Steven Greenbaum ${ }^{4}$, Yan-Yan $\mathrm{Hu}^{3,7}$, Robert Briber ${ }^{1}$, Akira Isogai ${ }^{8}$, Kang Xu ${ }^{9}$, 6 Yue $\mathrm{Qi}^{2 *}$, and Liangbing $\mathrm{Hu}^{1 *}$

$7{ }^{1}$ Department of Materials Science and Engineering, University of Maryland, College Park, 8 Maryland 20742, USA

$9 \quad{ }^{2}$ School of Engineering, Brown University, Providence, Rhode Island 02912, USA

$10{ }^{3}$ Department of Chemistry and Biochemistry, Florida State University, Tallahassee, Florida 32306, 11 USA

$12{ }^{4}$ Department of Physics and Astronomy, Hunter College, City University of New York, New York, 13 NY, 10065 USA

$14{ }^{5}$ Center for Catalytic Science and Technology, Department of Chemical and Biomolecular 15 Engineering, University of Delaware, Newark, Delaware 19716, USA

$16{ }^{6}$ NIST Center for Neutron Research, National Institute of Standards and Technology (NIST), 17 Gaithersburg, Maryland 20899, USA

$18{ }^{7}$ Center of Interdisciplinary Magnetic Resonance, National High Magnetic Field Laboratory, 19 Tallahassee, Florida 32310, USA

$20{ }^{8}$ Laboratory of Cellulose Chemistry, Department of Biomaterial Sciences, The University of 21 Tokyo, Tokyo 113-8657, Japan

$22{ }^{9}$ Battery Science Branch, Energy and Biomaterials Division, Sensor and Electron Devices 23 Directorate, Army Research Laboratory, Adelphi, Maryland 20783, USA

$24{ }^{a}$ These authors contributed equally.

$25 *$ Email: binghu@umd.edu, yueqi@brown.edu 


\section{Abstract:}

27 While solid-state batteries are tantalizing for achieving improved safety and higher energy density, 28 solid ion conductors currently available fail to satisfy the rigorous requirements for battery 29 electrolytes and electrodes. Inorganic ion conductors allow fast ion transport, but their rigid and 30 brittle nature prevents good interfacial contact and impedes device integration and stability.

31 Conversely, flexible polymeric ion conductors provide better interfacial compatibility and

32 mechanical tolerance, but suffer from inferior ionic conductivity $\left(<10^{-5} \mathrm{~S} \mathrm{~cm}^{-1}\right.$ at room

33 temperature) due to the coupling of ion transport with the polymer chain motion ${ }^{1-3}$. In this work,

34 we report a general design strategy for achieving one-dimensional (1D), high-performance

35 polymer solid-state ion conductors through molecular channel engineering, which we demonstrate

36 via $\mathrm{Cu}^{2+}$-coordination of cellulose nanofibrils. The cellulose nanofibrils by themselves are not

37 ionic conductive; however, by opening the molecular channels between the cellulose chains

38 through $\mathrm{Cu}^{2+}$ coordination we are able to achieve a Li-ion conductivity as high as $1.5 \times 10^{-3} \mathrm{~S} \mathrm{~cm}^{-1}$

39 at room temperature - a record among all known polymer ion conductors. This improved

40 conductivity is enabled by a unique $\mathrm{Li}^{+}$hopping mechanism that is decoupled from the polymer

41 segmental motion. Also benefitted from such decoupling, the cellulose-based ion conductor

42 demonstrates multiple advantages, including a high transference number (0.78 vs. $0.2-0.5$ in other

43 polymers $\left.^{2}\right)$, low activation energy $(0.19 \mathrm{eV})$, and a wide electrochemical stability window $(4.5 \mathrm{~V})$

44 that accommodate both Li metal anode and high-voltage cathodes. Furthermore, we demonstrate

45 this 1D ion conductor not only as a thin, high-conductivity solid-state electrolyte but also as an

46 effective ion-conducting additive for the solid cathode, providing continuous ion transport

47 pathways with a low percolation threshold, which allowed us to utilize the thickest $\mathrm{LiFePO}_{4}$ solid-

48 state cathode ever reported for high energy density. This approach has been validated with other 
49 polymers and cations (e.g., $\mathrm{Na}^{+}$and $\mathrm{Zn}^{2+}$ ) with record-high conductivities, offering a universal

50 strategy for fast single-ion transport in polymer matrices, with significance that could go far

51 beyond safe, high-performance solid-state batteries.

52 Keywords: Nanocellulose, Ion coordination, Polymer electrolyte, Super ion conductor, Solid-state

53 batteries

54 One Sentence Summary: A four-decade-long challenge of low ionic conductivity in polymer 55 electrolytes is overcome by engineering fast ion-conduction channels between polymer chains. 


\section{Introduction}

57 Solid-state batteries are attractive for next-generation energy-storage systems with high energy

58 density and safety, but the realization of these promises depends largely on the development of

59 superior ion conductors as the solid-state electrolyte as well as additives for ion-insulating cathode

60 materials. Recent advances in inorganic solid electrolytes based on ceramic materials have

61 achieved fast ion transport, but their rigidity and brittleness present new challenges for battery

62 integration and stability. Solid polymer electrolytes (SPEs) are a promising alternative due to their

63 mechanical flexibility and facile processibility compared with inorganic solid-state electrolytes ${ }^{4-6}$.

64 However, $\mathrm{Li}$ ion $\left(\mathrm{Li}^{+}\right)$transport in SPEs, which are typically ether-based represented by

65 poly(ethylene oxide) $(\mathrm{PEO})^{3,7}$, is highly coupled with the segmental relaxation of the polymer

66 chains, resulting in limited ionic conductivity $(\sigma)$ (generally $<10^{-5} \mathrm{~S} \mathrm{~cm}^{-1}$ at room temperature ${ }^{2}$ )

67 and low $\mathrm{Li}^{+}$transference numbers $\left(0.2-0.5\right.$ in most SPEs) ${ }^{8,9}$.

68 Recent studies have generally focused on improving the ionic conductivity of SPEs by

69 increasing the mobile $\mathrm{Li}^{+}$concentration $(n)$ or mobility $(\mu)$, given that $\sigma=e n \mu(e$ : elementary

70 charge). However, the concentration of mobile $\mathrm{Li}^{+}$is limited by the low solubility of salts in

71 polymers ${ }^{10,11}$. To improve the $\mathrm{Li}^{+}$mobility, a common practice is to increase the temperature of

72 SPEs, even above their melting point (e.g., $\sim 60{ }^{\circ} \mathrm{C}$ for $\mathrm{PEO}$ ), to promote the polymer segmental

73 motion for faster ion movement. But increasing the temperature deteriorates the mechanical

74 strength of the SPE and compromises the safety of the battery. Other efforts to improve the $\mathrm{Li}^{+}$

75 conductivity and transference number include modifying the polymer matrix with crosslinked

76 polymers ${ }^{12-14}$, block copolymers ${ }^{15}$, single-ion-conducting polymers ${ }^{16}$, and the addition of inorganic

77 fillers ${ }^{7,17,18}$. Despite these approaches, the tradeoff between the ion conduction, transference

78 number, and mechanical strength in SPEs has persisted for over four decades, with the room- 
79 temperature ionic conductivity barely approaching a ceiling value of $10^{-4} \mathrm{~S} \mathrm{~cm}^{-1}$, mainly because

80 the $\mathrm{Li}^{+}$movement has remained coupled to the polymer segmental motion. Additionally, SPEs

81 feature poor ionic percolation when used as additives to improve the ionic conductivity in cathode

82 materials, requiring a threshold content of $\sim 25 \mathrm{wt} \% \mathrm{SPE}^{19,20}$, which further reduces the energy

83 density of the battery. Clearly, the conventional SPE structure and $\mathrm{Li}^{+}$transport mechanism must

84 be drastically transformed in order to meet future energy storage needs.

85 In this work, we explore a new SPE design strategy based on expanding the inter-molecular

86 polymer structure and decoupling the $\mathrm{Li}^{+}$transport from the polymer segmental relaxation to

87 produce polymer ion conductors with record-high ionic conductivity. We first demonstrate this

88 approach using cellulose nanofibrils (CNFs). CNFs are abundantly available from various biomass

89 sources (e.g., wood, bamboo, grass, etc.) and feature an aligned, one-dimensional (1D) hierarchical

90 structure rich in oxygen-containing polar functional groups (e.g., hydroxyl) in the form of

91 repeating anhydroglucose units (AGUs) that make up the cellulose molecular chains (Fig. 1a) ${ }^{21-23}$.

92 Such polar functionalities could solvate $\mathrm{Li}^{+}$and aid in its fast movement. Through $\mathrm{Cu}^{2+}-$

93 coordination of the CNFs (Cu-CNF) via a scalable solvent exchange process, we show the spacing

94 between the polymer chains can be expanded into molecular channels that enable rapid $\mathrm{Li}^{+}$

95 transport (Fig. 1a). In such 1D conduction passages, the abundant oxygen-containing functional

96 groups of cellulose, along with bound water, assist in the $\mathrm{Li}^{+}$movement in a manner independent

97 of the polymeric segmental relaxation. As a result, the $\mathrm{Li}^{+}$-intercalated $\mathrm{Cu}-\mathrm{CNF}$ ( $\mathrm{Li}-\mathrm{Cu}-\mathrm{CNF}$ ) ion

98 conductor features a high ionic conductivity of $1.5 \times 10^{-3} \mathrm{~S} \mathrm{~cm}^{-1}(10-1000$-times that of other

99 SPEs) and a high transference number of 0.78 at room temperature (Fig. 1b). Furthermore, the

100 amorphous $\mathrm{Li}-\mathrm{Cu}-\mathrm{CNF}$ ion conductor demonstrates extremely low activation energy of $0.19 \mathrm{eV}$,

101 compared to $\sim 1 \mathrm{eV}$ for $\mathrm{PEO}^{3}$ and $\sim 0.6 \mathrm{eV}$ for PEO-inorganic composites ${ }^{7}$, allowing utilization at 
102 room temperature as well as a wide electrochemical stability window $\left(0-4.5 \mathrm{~V} \mathrm{vs.} \mathrm{Li}^{+} / \mathrm{Li}\right)$, on top 103 of the material's fundamental low cost, scalability, and flexibility (Fig. 1c). In addition to serving 104 as a thin and dense solid-state electrolyte film, the 1D structure of Li-Cu-CNF also makes it an 105 effective ion-conducting additive for composite solid-state electrodes where low ionic 106 conductivity has been a key hurdle. Indeed, the effective ionic percolation of Li-Cu-CNF allowed 107 us to fabricate the thickest $\mathrm{LiFePO}_{4}$ solid-state cathode ever reported, suggesting the material's 108 potential as an additive for increasing battery energy density. This design principle based on facile 109 coordination chemistry and expansion of the polymer molecular channels to provide fast diffusion 110 pathways for uncoupled $\mathrm{Li}^{+}$can be applied to other polymers and cations, enabling the 111 development of highly conductive solid-state ion conductors that may go far beyond high-energy112 density and safe all-solid-state batteries. 
a
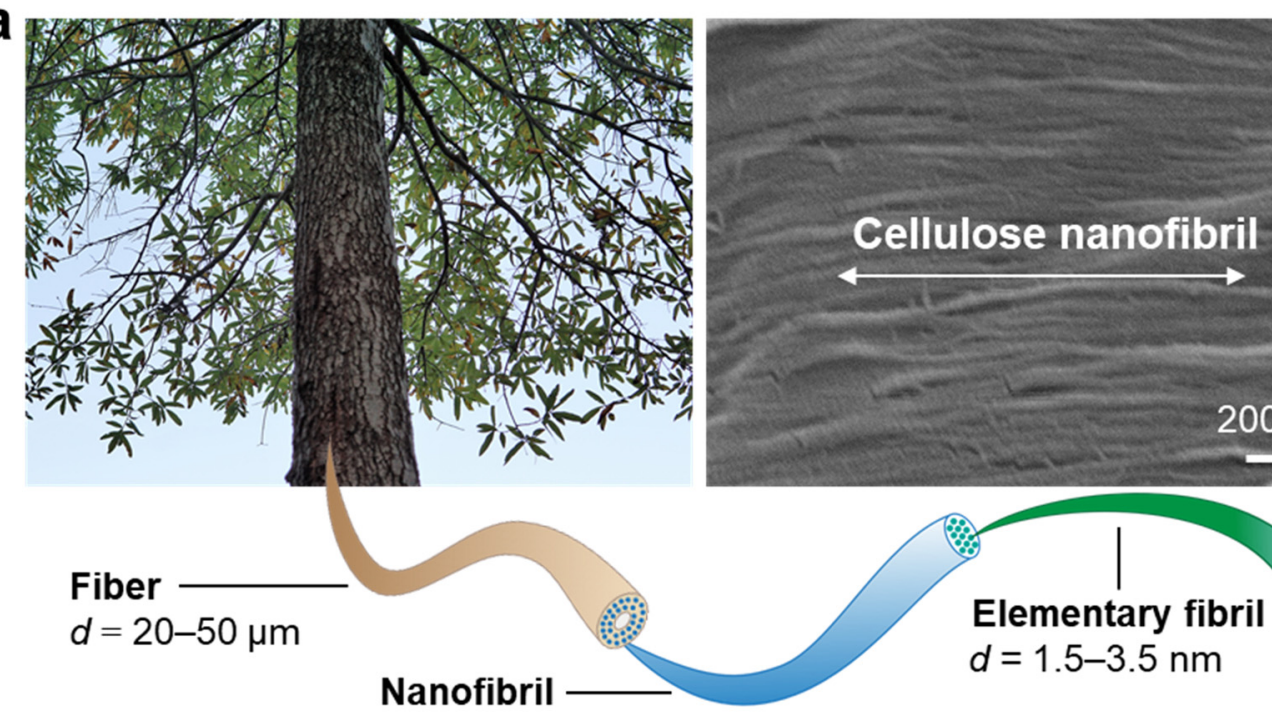

$d=10-15 \mathrm{~nm}$

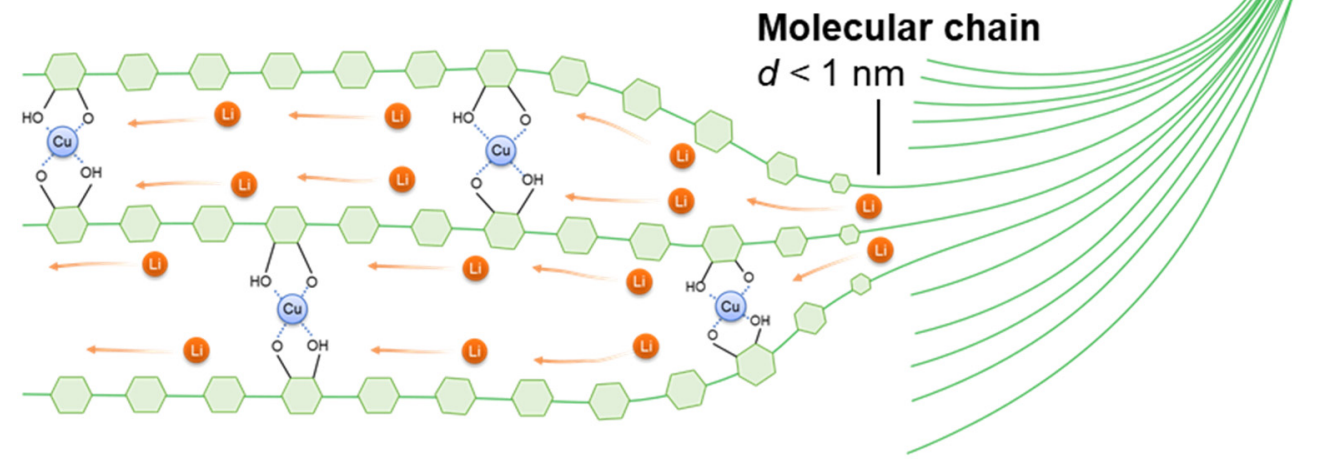

b

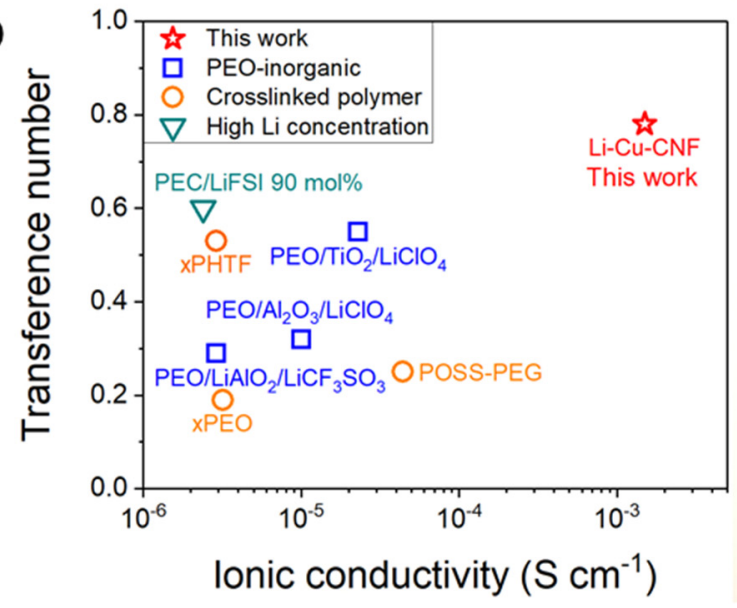

C

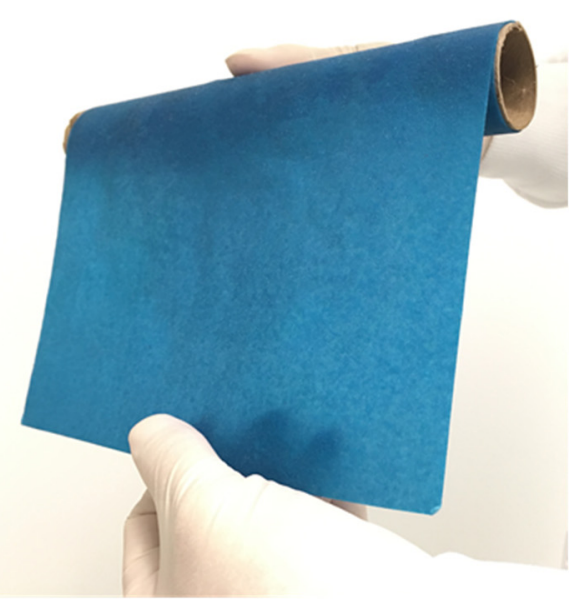

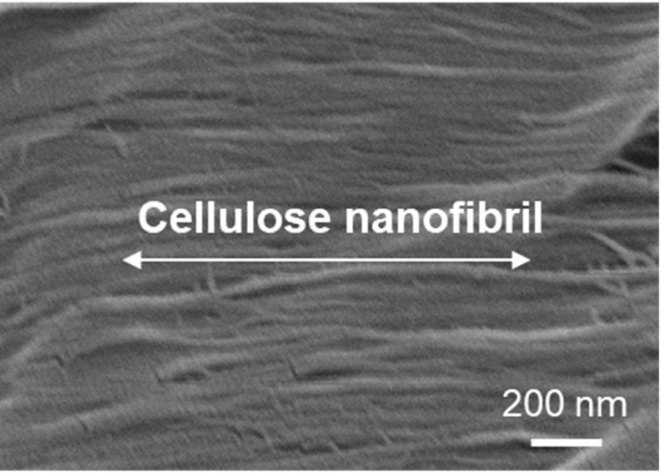

Elementary fibril

$d=1.5-3.5 \mathrm{~nm}$

114 Fig. 1 The structure and performance of the Li-Cu-CNF solid-state ion conductor. a,

115 Schematic illustration of the hierarchical structure of CNFs, which are derived from wood

116 cellulose fibers and are composed of elementary fibrils, each of which is comprised of individual 
117 cellulose molecular chains. Cu-ion coordination with the hydroxyl groups of cellulose opens the

118 spacing between molecular chains, creating cellulose molecular channels in the CNFs that serve

$119 \mathrm{as}^{+}$conducting pathways in the resulting $\mathrm{Li}-\mathrm{Cu}-\mathrm{CNF}$ ion conductor. The scanning electron

120 microscopy (SEM) image shows the morphology of the CNFs, which are naturally aligned in the

121 cellulose fibers. $\mathbf{b}$, A plot of the transference number and ionic conductivity of Li-Cu-CNF and

122 other SPEs ${ }^{13,14,17,24}$. c, A digital photo of a 1-meter long Li-Cu-CNF roll.

123 We fabricated the solid-state $\mathrm{Li}-\mathrm{Cu}-\mathrm{CNF}$ ion conductor using a simple ion-coordination and

124 solvent-exchange process. The CNFs, obtained by oxidization of commercial wood pulp, were

125 first immersed in $\mathrm{Cu}^{2+}$-saturated alkaline solution $(20 \% \mathrm{NaOH})$, where gradual $\mathrm{Cu}$-ion

126 coordination with the cellulose molecular chains occurs, forming a blue-colored $\mathrm{Cu}-\mathrm{CNF}-\mathrm{NaOH}$

127 complex material filled with $\mathrm{NaOH}$ solution (Fig. 2a). After washing the $\mathrm{NaOH}$ from $\mathrm{Cu}-\mathrm{CNF}-$

$128 \mathrm{NaOH}$ with water, displacing the water with dimethylformamide (DMF), and finally evaporating

129 the $\mathrm{DMF}$ under vacuum, we obtained the solid-state $\mathrm{Cu}-\mathrm{CNF}$ material. $\mathrm{Li}^{+}$was then intercalated

130 into the $\mathrm{Cu}-\mathrm{CNF}$ by soaking in $\mathrm{LiPF}_{6}$ electrolyte and subsequently evaporating the solvent,

131 producing the polymeric $\mathrm{Li}-\mathrm{Cu}-\mathrm{CNF}$ ion conductor (Fig. 2a).

132 We applied fiber X-ray diffraction (XRD, Fig. 2b-e and Extended Data Fig. 1a-d) and X-ray

133 absorption spectroscopy (XAS, Extended Data Fig. 1e-h) to track the structural evolution during

134 the fabrication process. Additionally, we constructed the material structures by molecular

135 dynamics (MD) simulations (details in Methods and Extended Data Fig. 2) based on the fiber XRD

136 results. The pristine CNFs featured a typical monoclinic diffraction pattern of cellulose $\mathrm{I}_{\beta}$, with

137 diffraction peaks at (110), (200), etc. (Fig. 2b), showing a cellulose molecular spacing $\left(d_{200}\right)$ of

$1380.39 \mathrm{~nm}^{25}$. The corresponding simulation of the crystalline CNF (Fig. 2c) suggests the material

139 cannot accommodate the intercalation of $\mathrm{Li}^{+}$between the inter-molecular spacing due to the 
140 closely packed cellulose chains. In contrast, the $\mathrm{Cu}-\mathrm{CNF}-\mathrm{NaOH}$ obtained from the $\mathrm{Cu}^{2+}$-saturated

141 alkaline solution featured a hexagonal crystal structure, with threefold symmetry along the

142 cellulose chain direction (Fig. 2d), consistent with the crystal structure of alkaline-cellulose-Cu

143 reported in the literature ${ }^{26}$. In the simulated structure of the $\mathrm{Cu}-\mathrm{CNF}-\mathrm{NaOH}$ (Fig. 2e), each

144 cellulose chain has three neighboring chains with an inter-chain distance of $0.87 \mathrm{~nm}$, which are

145 bridged by $\mathrm{Cu}^{2+}$ via four coordinated $\mathrm{Cu}-\mathrm{O}$ bonds, opening the close molecular packing of the

146 CNFs. We note the spaces between the less densely packed cellulose chains of $\mathrm{Cu}-\mathrm{CNF}-\mathrm{NaOH}$

147 are filled with $\mathrm{NaOH}$ aqueous solution. After $\mathrm{NaOH}$ removal and water displacement by DMF,

148 the crystalline $\mathrm{Cu}-\mathrm{CNF}-\mathrm{NaOH}$ becomes amorphous $\mathrm{Cu}-\mathrm{CNF}$ (Fig. 2f, 2g). Such amorphous

149 structure has a much lower cellulose packing density (4.7 AGU/nm ${ }^{3}$, Fig. 2 g) than the pristine

$150 \mathrm{CNF}$ material (6.1 AGU/nm ${ }^{3}$, Fig. 2c), with the molecular channels open for $\mathrm{Li}^{+}$intercalation. The

151 final $\mathrm{Li}-\mathrm{Cu}-\mathrm{CNF}$ structure with $\mathrm{Li}^{+}$intercalated maintains the amorphous state (Fig. $2 \mathrm{~h}$ ) with a low

152 packing density (4.4 AGU/nm ${ }^{3}$, Fig. 2i). These XRD and simulations results are also consistent

153 with the XAS data (Extended Data Fig. 1e-h), which confirm that in the amorphous Cu-CNF and

$154 \mathrm{Li}-\mathrm{Cu}-\mathrm{CNF}$ materials the $\mathrm{Cu}^{2+}$ ions are bonded with $\mathrm{O}$ atoms, with an average bonding distance of $1551.97 \AA$.

156 Interestingly, thermogravimetric analysis (TGA, Extended Data Fig. 3a) shows the pristine

$157 \mathrm{CNF}$ and $\mathrm{Li}-\mathrm{Cu}-\mathrm{CNF}$ contain the same amount of water ( $\sim 6 \mathrm{wt} \%)$, which is bound to the cellulose

158 molecules through multiple hydrogen bonding according to the Fourier-transform infrared spectra

159 (FTIR, Extended Data Fig. 3b, 3c). Quasi-elastic neutron scattering (QENS, Extended Data Fig.

$1603 \mathrm{~d}, 3 \mathrm{e}$ ) experiments also confirm the absence of free water or solvent in the $\mathrm{Li}-\mathrm{Cu}-\mathrm{CNF}$. We also

161 note the solid 1D Li-Cu-CNF material features high tensile stress of $29.2 \mathrm{MPa}$, among the strongest

162 SPEs (Extended Data Fig. 3f), possibly due to its amorphous nature. 
a
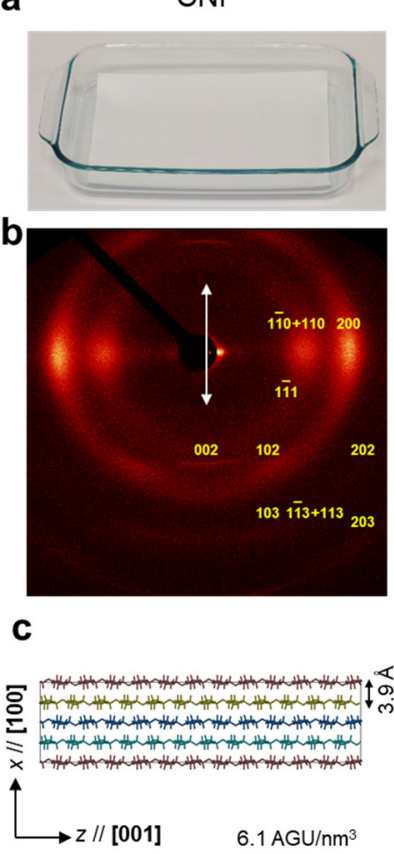

Cu-CNF-NaOH
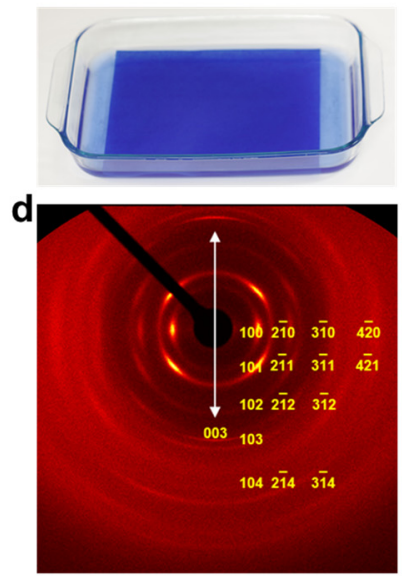

e

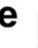

\section{롱}
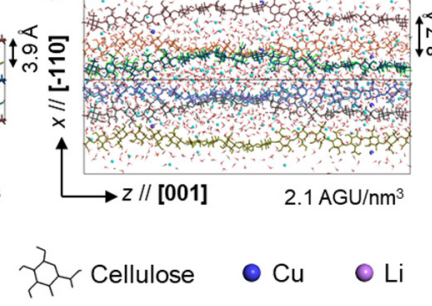

Cu-CNF
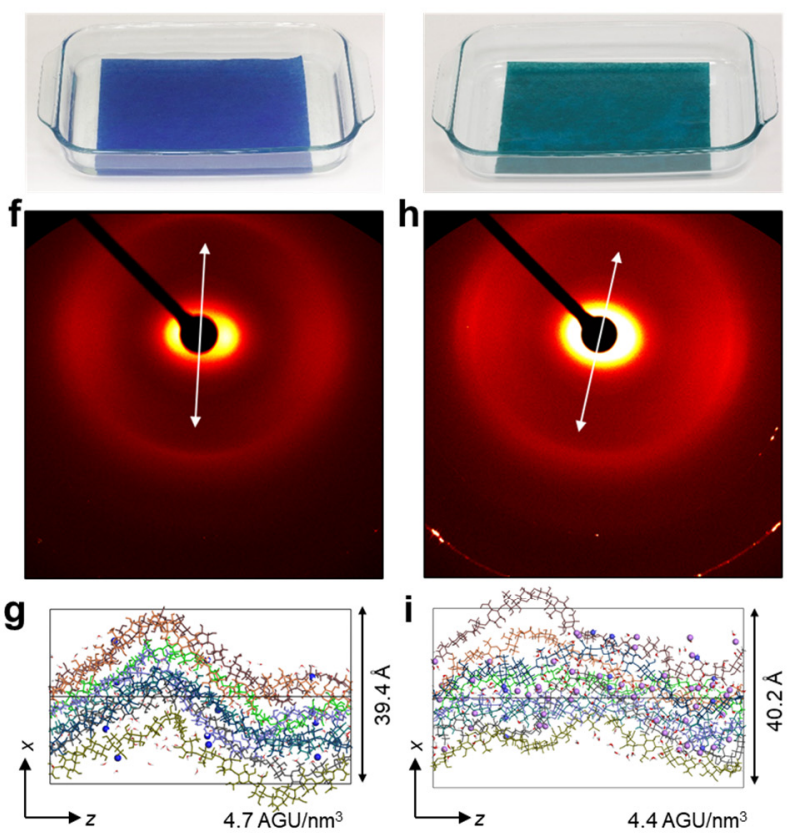

$\mathrm{Na}=\mathrm{OH} \vee \mathrm{H}_{2} \mathrm{O}$

164 Fig. 2 | Structural evolution during the synthesis of Li-Cu-CNF. a, Digital images showing the

165 fabrication process of $\mathrm{Li}-\mathrm{Cu}-\mathrm{CNF}$, during which the $\mathrm{CNF}$ starting material was immersed in $\mathrm{Cu}^{2+}$

166 alkaline solution to produce $\mathrm{Cu}-\mathrm{CNF}-\mathrm{NaOH}$. The aqueous solution in $\mathrm{Cu}-\mathrm{CNF}-\mathrm{NaOH}$ was then

167 displaced with DMF to obtain $\mathrm{Cu}-\mathrm{CNF}$, and finally exchanged with LiPF6 organic electrolyte for

$168 \mathrm{Li}^{+}$intercalation and then dried to form Li-Cu-CNF. The fiber XRD patterns (middle row) and

169 simulated structures (bottom row) of $\mathbf{b}$ and $\mathbf{c}$, the pristine CNFs showing cellulose I $\beta$ structure; $\mathbf{d}$

170 and $\mathbf{e}, \mathrm{Cu}-\mathrm{CNF}-\mathrm{NaOH}$, with coordinated cellulose chains packed in a hexagonal unit cell consistent

171 with the literature ${ }^{26}$; $\mathbf{f}$ and $\mathbf{g}, \mathrm{Cu}-\mathrm{CNF}$, in a largely amorphous state; and $\mathbf{h}$ and $\mathbf{i}, \mathrm{Li}-\mathrm{Cu}-\mathrm{CNF}$, which

172 features an amorphous structure (with some weak diffraction signals of cellulose $\mathrm{II}^{25}$ ). The white

173 arrows in the fiber XRD patterns indicate the fiber direction. Different cellulose chains in the

174 simulated structures are denoted by different colors. 
The amorphous $\mathrm{Li}-\mathrm{Cu}-\mathrm{CNF}$ material, featuring $1 \mathrm{D}$ cellulose molecular chains opened by $\mathrm{Cu}^{2+}$ 176 coordination, serves as an excellent $\mathrm{Li}^{+}$conductor. At $25{ }^{\circ} \mathrm{C}$, $\mathrm{Li}-\mathrm{Cu}-\mathrm{CNF}$ has a high $\mathrm{Li}^{+}$ 177 conductivity of $1.5 \times 10^{-3} \mathrm{~S} \mathrm{~cm}^{-1}$ along the cellulose molecular chain direction (measured by 178 galvanostatic cycling and electrochemical impedance spectroscopy (EIS), Extended Data Fig. 4a179 d), which is higher by orders of magnitude compared to that of all known SPEs, including PEO180 inorganic composites ${ }^{7}$, crosslinked polymers ${ }^{12,13}$, single-ion-conducting polymers ${ }^{15,16}$, and high Li 181 concentration electrolytes ${ }^{24}$ (Fig. 3a). Such high ionic conductivity along with the observed high 182 mechanical strength (Extended Data Fig. 3f) strongly suggests the ion transport is completely 183 decoupled from the polymer segmental relaxation. Additionally, the temperature dependence of 184 the ionic conduction in Li-Cu-CNF follows an Arrhenius-like behavior (i.e., linear conductivity 185 vs. 1/T) (Fig. 3a), which typically reflects an ion hopping mechanism through crystalline or 186 ordered matrices, and is distinctly different from the so-called Vogel-Tammann-Fulcher-like 187 behavior observed for ion transport in other amorphous materials, such as SPEs, gel polymer 188 electrolytes (GPEs), and liquid electrolytes ${ }^{1,27}$. According to the Arrhenius equation, the activation 189 energy of Li-Cu-CNF is $0.19 \mathrm{eV}$, which is much lower compared with PEO $(\sim 1 \mathrm{eV})^{3}$ and PEO190 inorganic composite electrolytes $(\sim 0.6 \mathrm{eV})^{7}$. In addition, the Li-Cu-CNF shows a high $\mathrm{Li}^{+}$ 191 transference number of 0.78 (measured by the Bruce-Vincent method ${ }^{28}$, Extended Data Fig. 4e, 192 4f), which is much higher than that of other SPEs (0.2-0.5, Fig. 1b), except single-Li-ion 193 conducting polymers ${ }^{15,16}$ (close to 1.0 , although achieved at the impractical expense of the ionic 194 conductivity at room temperature). As a control experiment, we synthesized Li-CNF using the 195 same procedure shown in Fig. 2a but in absence of $\mathrm{Cu}$-ion coordination, and found it displayed a $196 \mathrm{Li}^{+}$conductivity of just $7 \times 10^{-7} \mathrm{~S} \mathrm{~cm}^{-1}$ at $25^{\circ} \mathrm{C}$ (Fig. 3a) and a low transference number of 0.35 197 (Extended Data Fig. 4g-i), confirming the indispensable role of $\mathrm{Cu}^{2+}$ in promoting $\mathrm{Li}^{+}$-transport. 
198 We also note the $\mathrm{Cu}^{2+}$ coordinated in $\mathrm{Li}-\mathrm{Cu}-\mathrm{CNF}$ contribute negligible ionic conductivity $\left(5 \times 10^{-7}\right.$

$199 \mathrm{~S} \mathrm{~cm}^{-1}$, Extended Data Fig. 4j, 4k) but are critical for maintaining the open cellulose molecular

200 spacing necessary for the high $\mathrm{Li}^{+}$conductivity.

201 Fig. 3b compares the ionic conductivity of Li-Cu-CNF with other types of solid-state 202 electrolytes. Li-Cu-CNF offers a similar ionic conductivity $\left(\sim 10^{-3} \mathrm{~S} \mathrm{~cm}^{-1}\right)$ as oxide-based 203 electrolytes (e.g., $\left.\mathrm{Li}_{7} \mathrm{La}_{3} \mathrm{Zr}_{2} \mathrm{O}_{12}(\mathrm{LLZO})\right)$ but at much lower $\mathrm{Li}$ concentration $\left(1.2 \mathrm{~mol} \mathrm{~L}^{-1}\right.$ in $\mathrm{Li}^{-}$ $204 \mathrm{Cu}-\mathrm{CNF}$ vs. $41.3 \mathrm{~mol} \mathrm{~L}^{-1}$ in $\mathrm{LLZO}^{29}$ ), which is preferential for lower cost. Such Li concentration 205 is similar to PEO $\left(\sim 1.1 \mathrm{~mol} \mathrm{~L}^{-1}\right)^{29}$, but Li-Cu-CNF features a $\sim 500$-times higher $\mathrm{Li}^{+}$diffusion 206 coefficient $\left(D_{\mathrm{Li}}=6.1 \times 10^{-7} \mathrm{~cm}^{2} \mathrm{~s}^{-1}\right.$, as measured by pulse field gradient NMR $)$ and over two207 times the cation transference number. Thus, we attribute the high ionic conductivity of Li-Cu-CNF 208 entirely to the high-mobility of the $\mathrm{Li}^{+}$in the material due to the opening of the cellulose molecular 209 channels.

$210 \quad \mathrm{The}^{+}{ }^{+}$in the $\mathrm{Li}-\mathrm{Cu}-\mathrm{CNF}$ molecular channels can form multiple $\mathrm{Li}-\mathrm{O}$ coordination bonds that 211 are critical for the $\mathrm{Li}^{+}$migration, as we demonstrate via NMR and simulations. We used solid-state $212{ }^{6} \mathrm{Li}$ NMR to probe the local environment of $\mathrm{Li}^{+}$(Extended Data Fig. 5a-d), which revealed the $\mathrm{Li}^{+}-$ 213 mobility in the Li-Cu-CNF molecular channels derives from multiple Li-O coordination bonds. In $214 \mathrm{Li}-\mathrm{Cu}-\mathrm{CNF}$, the $\mathrm{Li}^{+}$are mainly bonded to the rich oxygen-containing functional groups of 215 cellulose, including hydroxyl (ROH), carboxyl (COO), alkoxy (RO), and ether (EO) moieties, as 216 well as bound water and some residual LiPF6 (schematically shown in Fig. 3c). Chemically, the 217 molar ratio of $\mathrm{Cu}: \mathrm{Li}: \mathrm{AGU}$ is approximately 1:6:18 based on the inductively coupled plasma (ICP) 218 analysis of the contents of $\mathrm{Li}^{+}(1.3 \mathrm{wt} \%)$ and $\mathrm{Cu}^{+}(1.9 \mathrm{wt} \%)$ in the $\mathrm{Li}-\mathrm{Cu}-\mathrm{CNF}$, which indicates 219 the number of oxygen atoms is $\sim 20$-times the number of $\mathrm{Li}^{+}$. Compared with $\mathrm{Li}-\mathrm{CNF}$, the $\mathrm{Li}-\mathrm{Cu}-$ 220 CNF material shows a drastically increased number of $\mathrm{Li}^{+}$coordinated with oxygen atoms 
$221\left(\mathrm{RO} \cdots \mathrm{Li}, \mathrm{COO} \cdots \mathrm{Li}\right.$, and $\mathrm{ROH} / \mathrm{H}_{2} \mathrm{O} \cdots \mathrm{Li}$ ) (Fig. 3d), further suggesting the $\mathrm{Li}^{+}$is intercalated in the 222 opened molecular channels of $\mathrm{Li}-\mathrm{Cu}-\mathrm{CNF}$ where more $\mathrm{Li}-\mathrm{O}$ coordination can occur. To further 223 investigate the $\mathrm{Li}^{+}$transport pathways, we performed ${ }^{6} \mathrm{Li}$ tracer-exchange $\mathrm{NMR}$, which is a 224 combination of ${ }^{6} \mathrm{Li}$ isotope replacement of ${ }^{7} \mathrm{Li}$ and high-resolution solid-state ${ }^{6} \mathrm{Li} \mathrm{NMR}$ (Extended 225 Data Fig. 5e-g) ${ }^{30}$. We electrochemically cycled the Li-Cu-CNF electrolyte (natural abundance: $22692.4 \%{ }^{7} \mathrm{Li}$ and $7.6 \%{ }^{6} \mathrm{Li}$ ) between two ${ }^{6} \mathrm{Li}$-rich metal electrodes, during which the ${ }^{6} \mathrm{Li}^{+}$from the 227 electrodes partially replaced ${ }^{7} \mathrm{Li}^{+}$in the ion diffusion pathway of the electrolyte. After the ${ }^{6} \mathrm{Li}$ tracer 228 exchange, the number of ${ }^{6} \mathrm{Li}^{+}$coordinated with $\mathrm{COO}^{-}, \mathrm{RO}^{-}$, and $\mathrm{ROH} / \mathrm{H}_{2} \mathrm{O}$ in $\mathrm{Li}-\mathrm{Cu}-\mathrm{CNF}$ increased 229 by 15-, 20-, and 25-times, respectively, compared to Li-Cu-CNF prior to cycling (Fig. 3e), 230 suggesting that the $\mathrm{Li}^{+}$coordinated with these oxygen-containing functional groups are not "dead $231 \mathrm{Li}^{\dagger}$, but remain active to diffusion and migration.

232 MD simulations further revealed that in $\mathrm{Li}-\mathrm{Cu}-\mathrm{CNF}$ each $\mathrm{Li}^{+}$is coordinated with 4.5 oxygen 233 atoms on average, a number much larger than that in Li-CNF (3.0) (Fig. 3f). The relatively low 234 coordination number in the closely packed $\mathrm{Li}-\mathrm{CNF}$ is due to the spatially forbidden of $\mathrm{Li}^{+}$to access 235 these oxygens within the cellulose channels. Hence the $\mathrm{Li}^{+}$can only absorb on the external surface 236 of the CNFs (Extended Data Fig. 6), whereas in $\mathrm{Li}-\mathrm{Cu}-\mathrm{CNF}$, intercalated $\mathrm{Li}^{+}$are fully coordinated 237 by the rich oxygen groups in the open cellulose channels (Fig. 2i). DFT calculations (Extended 238 Data Fig. 2a and 2b) demonstrate the importance of coordination number for $\mathrm{Li}^{+}$-mobility: if $\mathrm{Li}^{+}$ 239 is coordinated with just 1 or 2 anionic oxygen species, the Li-O binding energy $(2.9-5.5 \mathrm{eV})$ is 240 prohibitively high for $\mathrm{Li}-\mathrm{O}$ dissociation; whereas the $\mathrm{Li}^{+}$migration energy barrier can be 241 significantly reduced $(\sim 0.3 \mathrm{eV})$ if a 5-oxygen-coordinated $\mathrm{Li}^{+}$moves in inorganic materials, 242 because this $\mathrm{Li}^{+}$can dissociate from just 1-2 bonded oxygen atoms while still coordinating with 243 other nearby oxygen groups ${ }^{34}$. The simulated activation energy barrier for $\mathrm{Li}-\mathrm{Cu}-\mathrm{CNF}$ is $0.31 \mathrm{eV}$, 
244 which is as low as that in inorganic materials $(\sim 0.3 \mathrm{eV})^{34}$, suggesting the $\mathrm{Li}^{+}$transport in $\mathrm{Li}-\mathrm{Cu}-$

$245 \mathrm{CNF}$ is likely following the similar mechanism in inorganic ion conductors. Therefore, these 246 abundant oxygen atoms in the open molecular channels effectively stabilize the $\mathrm{Li}^{+}$during its 247 partial dissociation for transport.

248 We employed MD simulations to further understand the $\mathrm{Li}^{+}$transport mechanism in $\mathrm{Li}-\mathrm{Cu}-$ 249 CNF. A fast-moving $\mathrm{Li}^{+}$travels across the AGUs along or between the cellulose molecular chains 250 with a displacement of $18.8 \AA$ in $5.0 \mathrm{~ns}$, while the cellulose backbone moves little (Fig. 3g). The 251 counter-anions $\left(\mathrm{COO}^{-}\right.$and $\left.\mathrm{RO}^{-}\right)$in the cellulose backbone move much less than the $\mathrm{Li}^{+}$, as 252 indicated by their small mean square displacements (MSD, Extended Data Fig. 7a), resulting in a 253 high transference number $(0.80$ by simulation, close to the experimental value 0.78$)$. The MSD 254 plots for additional $\mathrm{Li}^{+}$(Extended Data Fig. 7b) further indicate $\mathrm{Li}^{+}$hopping between $\mathrm{COO}^{-}$and $255 \mathrm{RO}^{-}$sites in $\mathrm{Li}-\mathrm{Cu}-\mathrm{CNF}$, instead of moving with its local solvation cage formed by the polymer 256 chain segment. This represents a typical "structural diffusion" behavior, i.e., the $\mathrm{Li}^{+}$moves 257 independent from its local solvation environment ${ }^{31}$. Due to the abundance of $\mathrm{COO}^{-}$and $\mathrm{RO}^{-}$ 258 groups in $\mathrm{Li}-\mathrm{Cu}-\mathrm{CNF}$, the average distance between these functionalities provides a $\mathrm{Li}^{+}$hopping 259 distance of $\sim 3.0 \AA$ (Extended Data Fig. 7c), which is close to the hopping distance in fast inorganic 260 ion conductors, such as $\mathrm{Li}_{1.33} \mathrm{Ti}_{1.67} \mathrm{Al}_{0.33}\left(\mathrm{PO}_{4}\right)_{3}, \mathrm{Li}_{10} \mathrm{GeP}_{2} \mathrm{~S}_{12}$, and $\mathrm{LLZO}^{32}$. Thus, the rich oxygen 261 groups in $\mathrm{Li}-\mathrm{Cu}-\mathrm{CNF}\left(\mathrm{COO}^{-}, \mathrm{RO}^{-}\right.$, etc.) are likely to form a continuous hopping pathway that 262 enables high $\mathrm{Li}^{+}$mobility independent of the polymer chain motion.

263 MD simulations also reveal the critical importance of $\mathrm{H}_{2} \mathrm{O}$ molecules for the fast $\mathrm{Li}^{+}$ 264 movement. We found the fast-moving $\mathrm{Li}^{+}$in the system are coordinated with more water molecules 265 (1.6), as compared with the slower moving $\mathrm{Li}^{+}(0.7)$, despite the fact that all of them have almost 266 the same total Li-O coordination number ( 4.5) (Fig. 3h). This difference strongly suggests that 
267 the fast-moving $\mathrm{H}_{2} \mathrm{O}$ molecules, as indicated by the large MSD (Extended Data Fig. 7d) and high 268 diffusion coefficient ( $D_{\mathrm{H}}=9.5 \times 10^{-7} \mathrm{~cm}^{2} \mathrm{~s}^{-1}$ vs. $D_{\mathrm{Li}}=6.1 \times 10^{-7} \mathrm{~cm}^{2} \mathrm{~s}^{-1}$ by NMR), effectively 269 assist the $\mathrm{Li}^{+}$transport, possibly by knocking the $\mathrm{Li}^{+}$out of the coordination sites (i.e., the $\mathrm{COO}^{-}$, $270 \mathrm{RO}^{-}, \mathrm{EO}$, and $\mathrm{ROH}$ groups of cellulose) for fast $\mathrm{Li}^{+}$diffusion. Indeed, we see a dramatic increase 271 in the $\mathrm{Li}^{+}$displacement and diffusivity for $\mathrm{Li}-\mathrm{Cu}-\mathrm{CNF}$ featuring bound water molecules compared 272 to $\mathrm{Li}-\mathrm{Cu}-\mathrm{CNF}$ without water and Li-CNF (Fig. 3i). Thus, the unprecedentedly high ionic 273 conductivity in $\mathrm{Li}-\mathrm{Cu}-\mathrm{CNF}$ can be attributed to the decoupled $\mathrm{Li}^{+}$hopping mechanism, which is 274 jointly enabled by the open cellulose molecular channels, local environment rich in Li-O 275 coordination, and the assistance of bound water molecules.

276 Upon closer examination of the bound water molecules in $\mathrm{Li}-\mathrm{Cu}-\mathrm{CNF}$, we found that they do 277 not exist as a condensed liquid phase, which contains electrochemically active species like $\mathrm{H}^{+}$, $278 \mathrm{H}_{3} \mathrm{O}^{+}$, and $\mathrm{OH}^{-}$, but instead are isolated neutral $\mathrm{H}_{2} \mathrm{O}$ molecules bound with the cellulose framework 279 (Extended Data Fig. 7e). Such isolated water molecules would differ from bulk water molecules 280 chemically and electrochemically. For example, they do not readily gain or lose electrons and are 281 thus electrochemically stable ${ }^{33}$. We confirmed the electrochemical stability by DFT calculations 282 (Extended Data Fig. 8), which predict the Li-Cu-CNF with bound water molecules has a wide 283 electrochemical stability window that is comparable to ethylene carbonate, a typical electrolyte 284 solvent used in commercial lithium-ion batteries. Additionally, the linear sweep voltammogram 285 shows the $\mathrm{Li}-\mathrm{Cu}-\mathrm{CNF}$ features a wide electrochemical stability window of $0-4.5 \mathrm{~V} \mathrm{vs.} \mathrm{Li}^{+} / \mathrm{Li}$ (Fig. $2863 \mathrm{j}$ ), which would allow for the reversible operation of the Li metal anode and high-voltage cathodes 287 needed for high-energy-density solid-state batteries. 

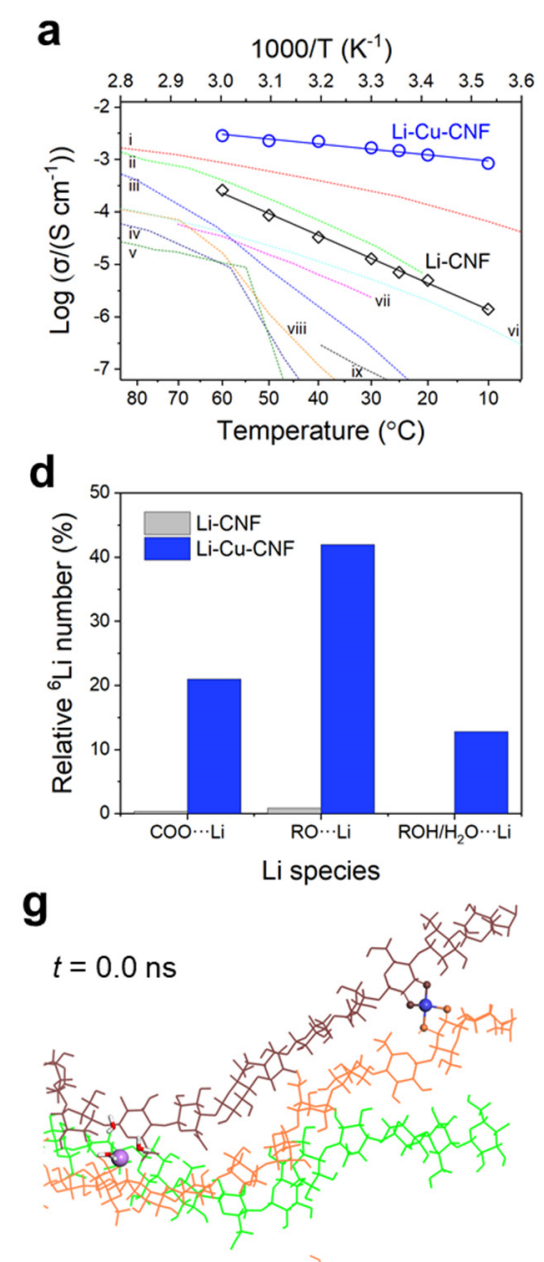

Cellulose

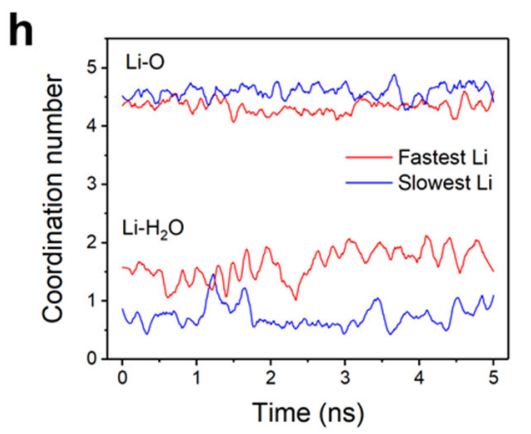

b

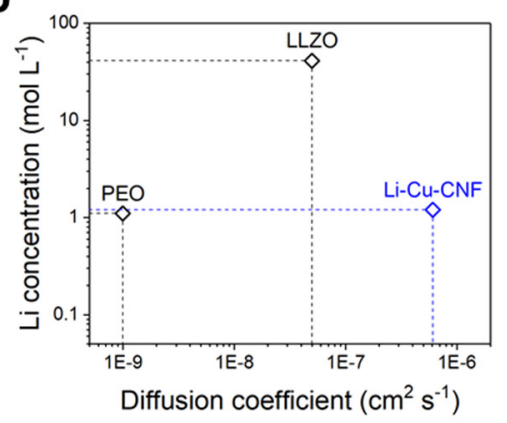

e
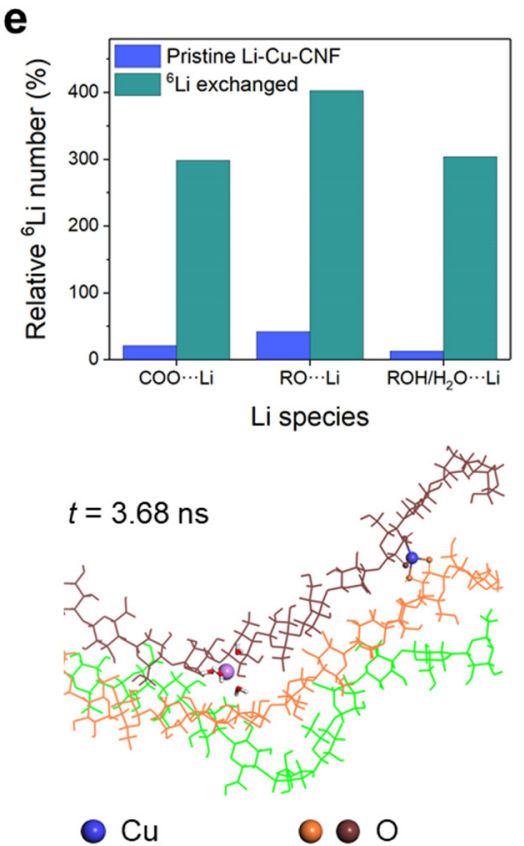

i

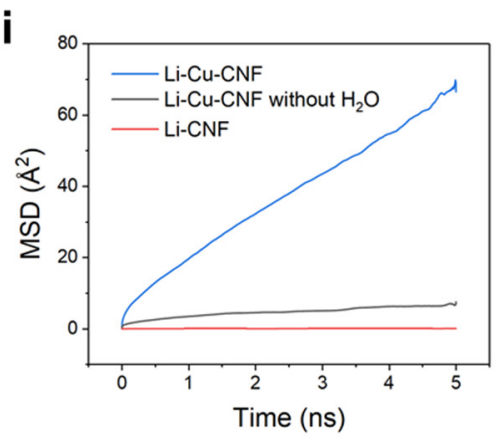

C

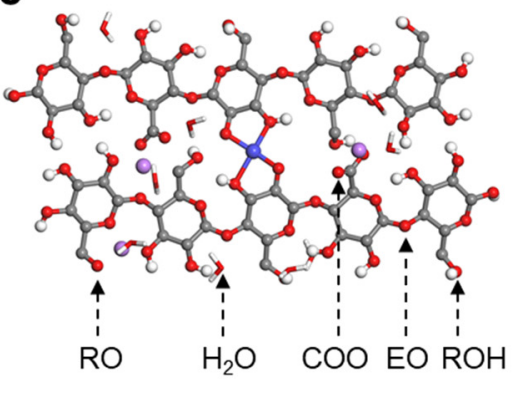

f
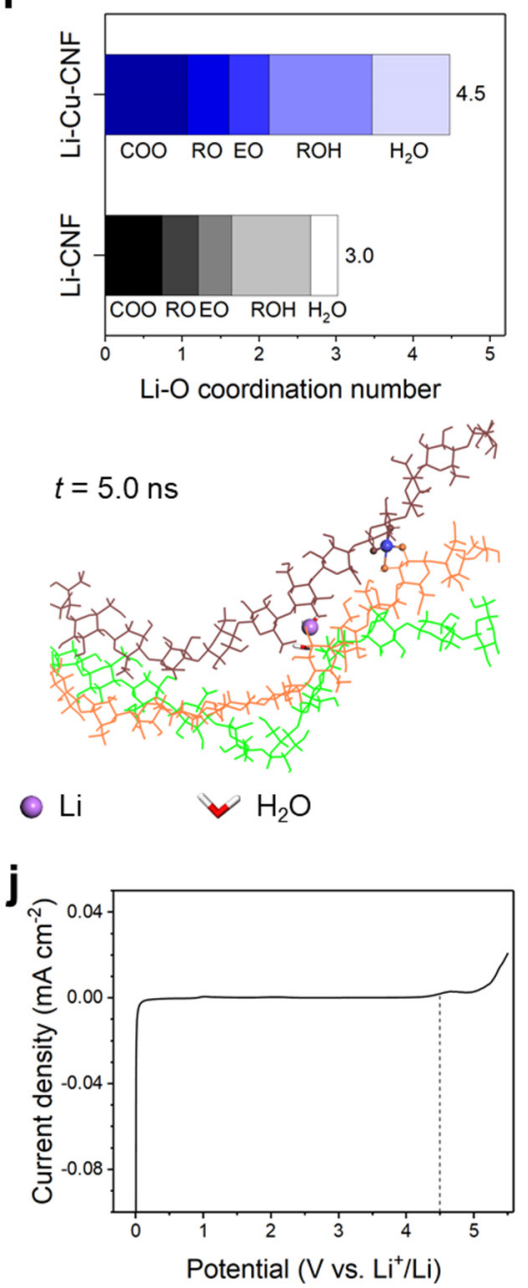

Fig. $3 \mid \mathrm{Li}^{+}$conductivity and transport mechanism in $\mathbf{L i - C u}-\mathrm{CNF}$. a, The temperaturedependent conductivity of $\mathrm{Li}-\mathrm{Cu}-\mathrm{CNF}$ and $\mathrm{Li}-\mathrm{CNF}$ (without $\mathrm{Cu}^{2+}$ coordination) and linear fitting according to the Arrhenius equation, the slope of which indicates the activation energy. The temperature-dependent conductivity plots (i-ix) of typical SPEs are included for comparison ( $\mathrm{i}^{12}$, ii-iv $\left.{ }^{7}, v^{15}, v^{13}, v_{i i}{ }^{24}, v i i i^{16}, \mathrm{ix}^{3}\right)$. b, Comparison of the $\mathrm{Li}^{+}$diffusion coefficient and $\mathrm{Li}^{+}$ 
294 concentration of Li-Cu-CNF with other solid-state electrolytes (PEO and LLZO). c, Schematic of 295 the chemical environment of $\mathrm{Li}^{+}$in the $\mathrm{Li}-\mathrm{Cu}-\mathrm{CNF}$ system with different types of oxygen atoms. 296 The $\mathrm{C}, \mathrm{H}, \mathrm{O}, \mathrm{Cu}$, and $\mathrm{Li}$ atoms are denoted by grey, white, red, blue, and purple spheres, 297 respectively. The hydrogen atoms that are bonded with carbon are not shown for clarity. d, Relative $298{ }^{6} \mathrm{Li}$ number in different $\mathrm{Li}$ chemical environments in Li-CNF and $\mathrm{Li}-\mathrm{Cu}-\mathrm{CNF}$, derived from NMR 299 (Extended Data Fig. 5) by normalizing the mass-specific ${ }^{6} \mathrm{Li}$ number in $\mathrm{Li}-\mathrm{Cu}-\mathrm{CNF}$ to $100 \%$. e, 300 Relative ${ }^{6} \mathrm{Li}$ number for different $\mathrm{Li}$ chemical environments in the $\mathrm{Li}-\mathrm{Cu}-\mathrm{CNF}$ before and after $301 \quad{ }^{6} \mathrm{Li} \rightarrow{ }^{7} \mathrm{Li}$ tracer exchange. f, The average Li-O coordination numbers from MD simulations for Li$302 \mathrm{CNF}$ and Li-Cu-CNF. g, Structural snapshots from MD simulations of a fast-moving $\mathrm{Li}^{+}$ 303 transporting in $\mathrm{Li}-\mathrm{Cu}-\mathrm{CNF}$ for $5 \mathrm{~ns}$. $\mathbf{h}$, The coordination numbers $\mathrm{of}^{\mathrm{Li}^{+}}$coordinating with all 304 available oxygen atoms ( $\mathrm{Li}-\mathrm{O}$, including the oxygen atoms in cellulose and bound water 305 molecules) and just water molecules $\left(\mathrm{Li}-\mathrm{H}_{2} \mathrm{O}\right)$ in $\mathrm{Li}-\mathrm{Cu}-\mathrm{CNF}$ for the 6 fastest and 6 slowest $\mathrm{Li}^{+}$ 306 ions in the Li-Cu-CNF model. i, MSD plots for the $\mathrm{Li}-\mathrm{Cu}-\mathrm{CNF}$ systems with/without water 307 molecules and the Li-CNF system with water molecules on the surface of the CNFs. $\mathbf{j}$, 308 Electrochemical stability window of the Li-Cu-CNF measured by linear sweep voltammogram 309 from $0 \mathrm{~V}$ to $5.5 \mathrm{~V}\left(\mathrm{vs} . \mathrm{Li}^{+} / \mathrm{Li}\right)$ at $0.1 \mathrm{mV} \mathrm{s}^{-1}$. 
The 1D, nanoscale Li-Cu-CNF ion conductor can be applied as both an independent solid-state

311 electrolyte when densely packaged into a freestanding film and an effective ion-conducting

312 additive for constructing continuous $\mathrm{Li}^{+}$transport networks in electrodes, which is particularly

313 important for high energy density cathode materials that feature intrinsically low ionic

314 conductivity, such as $\mathrm{LiFePO}_{4}$ and $\mathrm{LiNi}_{x} \mathrm{Mn}_{y} \mathrm{Co}_{z} \mathrm{O}_{2}$. Both functions (electrolyte and additive) are

315 crucial for building high-performance all-solid-state batteries (Fig. 4a). We first demonstrated the

316 Li-Cu-CNF can be assembled and pressed into a thin $(\sim 50 \mu \mathrm{m})$ yet dense film with three-

317 dimensionally, randomly distributed nanofibrils (Fig. 4b and Extended Data Fig. 9a, 9b) to form a

318 solid-state film electrolyte with low resistance (Extended Data Fig. 9c). The Li-Cu-CNF film

319 electrolyte shows a through-plane ionic conductivity of $3.4 \times 10^{-4} \mathrm{~S} \mathrm{~cm}^{-1}$ at room temperature

320 (Extended Data Fig. 9d), still much higher than other SPEs reported in the literature $3,7,12,13,15,16,19,24$.

321 Additionally, the dense and highly conductive Li-Cu-CNF film electrolyte enables stable Li

322 cycling performance at $0.5 \mathrm{~mA} \mathrm{~cm}^{-2}$ for $400 \mathrm{~h}$ in a Li metal symmetric cell without dendrite-

323 induced short-circuiting (Extended Data Fig. 9e).

324 The individual $\mathrm{Li}-\mathrm{Cu}-\mathrm{CNF}$ fibrils were also applied as an effective ion-conducting additive for

325 battery electrodes. To overcome low ionic conductivity, a general approach in fabricating solid-

326 state electrodes has involved blending the material with flammable liquid electrolytes or using a

327 significant amount of polymer electrolyte (e.g., 25-30 wt\% PEO/LiTFSI ${ }^{19,20}$ ) due to the poor ionic

328 percolation of bulk polymers, which inevitably drives down the energy density of the battery. As

329 an alternative, $\mathrm{Li}-\mathrm{Cu}-\mathrm{CNF}$ has the following advantages as an ion-conducting additive, including:

330 (1) the high aspect ratio ( 200) of the CNFs, which should enable a low percolation threshold ${ }^{34}$;

331 (2) compatibility with the traditional slurry-casting method for scalable electrode manufacturing;

332 and (3) the ability to serve as both an ionic conductor and polymer binder for fabricating thick 
333 electrodes with good mechanical integrity. As a proof-of-concept, we selected $\mathrm{LiFePO}_{4}$ as a 334 cathode material to demonstrate the incorporation of $\mathrm{Li}-\mathrm{Cu}-\mathrm{CNF}$ as a $1 \mathrm{D}$ additive to form an ion 335 percolation network within the solid-state cathode (Fig. 4c). The resulting cathode featured a 336 percolation threshold of $15 \mathrm{vol} \%$ (Fig. $4 \mathrm{~d}$ ), which corresponds to $<5 \mathrm{wt} \%$ of the $\mathrm{Li}-\mathrm{Cu}-\mathrm{CNF}$ 337 additive in the composite. Moreover, the use of the $\mathrm{Li}-\mathrm{Cu}-\mathrm{CNF}$ ion-conducting additive is 338 compatible with the traditional slurry-casting method for electrode preparation (Fig. 4e and 339 Extended Data Fig. 10a), which allows large-scale, roll-to-roll manufacturing of all-solid-state 340 batteries.

341 We also demonstrated the effective $\mathrm{Li}^{+}$transport enabled by $\mathrm{Li}-\mathrm{Cu}-\mathrm{CNF}$ in an all-solid-state 342 full battery featuring both the Li-Cu-CNF film electrolyte and a thick $\left(120 \mu \mathrm{m}, 10-11 \mathrm{mg} \mathrm{cm}^{-2}\right.$ $343 \mathrm{LiFePO}_{4}$ ) solid-state $\mathrm{LiFePO}_{4}$ cathode composite containing the $\mathrm{Li}-\mathrm{Cu}-\mathrm{CNF}$ additive (Fig. $4 \mathrm{f}$ ). The $344 \mathrm{LiFePO}_{4}$ solid-state cathode demonstrated in this work is 3-5-times thicker than other $\mathrm{LiFePO}_{4}$ 345 solid-state cathodes reported in the literature ${ }^{13,19,20,35}$. However, due to the excellent ionic 346 percolation made possible by the nanocellulose-based $\mathrm{Li}-\mathrm{Cu}-\mathrm{CNF}$ ion-conducting additive $(9 \mathrm{wt} \%$ 347 in the cathode), the impedance of such a thick cathode limited by ion transport was only $390 \Omega$ $348 \mathrm{~cm}^{2}, \sim 45$ times lower compared to the control $\mathrm{LiFePO}_{4}$ cathode made using the $\mathrm{Li}-\mathrm{CNF}$ additive $349\left(17680 \Omega \mathrm{cm}^{2}\right)$ (Extended Data Fig. 10b, 10c). With Li-Cu-CNF, the all-solid-state $\mathrm{LiFePO}_{4}$ 350 battery featured a high initial discharge capacity of $137 \mathrm{~mA} \mathrm{~h} \mathrm{~g}^{-1}$ and a relatively low overpotential 351 of $0.17 \mathrm{~V}$ (Fig. 4g). In contrast, the cathode made using the Li-CNF control showed an initial 352 capacity of $110 \mathrm{~mA} \mathrm{~h} \mathrm{~g}{ }^{-1}$, which declined rapidly to almost 0 within 5 cycles, as well as 353 demonstrating a high overpotential of $0.8 \mathrm{~V}$ (Fig. 4g). The cycling stability of the all-solid-state $354 \mathrm{LiFePO}_{4}$ battery was also significantly improved by using the $\mathrm{Li}-\mathrm{Cu}-\mathrm{CNF}$ electrolyte and ion355 conducting additive, successfully reaching 100 cycles at $0.2 \mathrm{C}\left(1 \mathrm{C}=170 \mathrm{~mA} \mathrm{~g}^{-1}\right)$ at room 
356 temperature (Fig. 4h). Additionally, the flexibility of the $\mathrm{Li}-\mathrm{Cu}-\mathrm{CNF}$ electrolyte and $\mathrm{LiFePO}_{4}$

357 composite cathode allowed us to fabricate an all-solid-state battery that remained operational when

358 folded (inset in Fig. 4h and Extended Data Fig. 10d). A rechargeable LiNio.6 Mn0.2 $\mathrm{Co}_{0.2} \mathrm{O}_{2}$ (NMC)

359 high-voltage cathode was also made to further demonstrate the capability of Li-Cu-CNF as a film

360 electrolyte and ion-conducting additive in an all-solid-state battery, which showed lower

361 interfacial resistance, reduced overpotential, and increased capacity $\left(180 \mathrm{~mA} \mathrm{~h} \mathrm{~g}^{-1}\right.$ initial discharge

362 capacity) (Extended Data Fig. 10e, 10f), demonstrating the stability of the Li-Cu-CNF at high

363 voltage and its compatibility with high-energy-density all-solid-state batteries. 
a
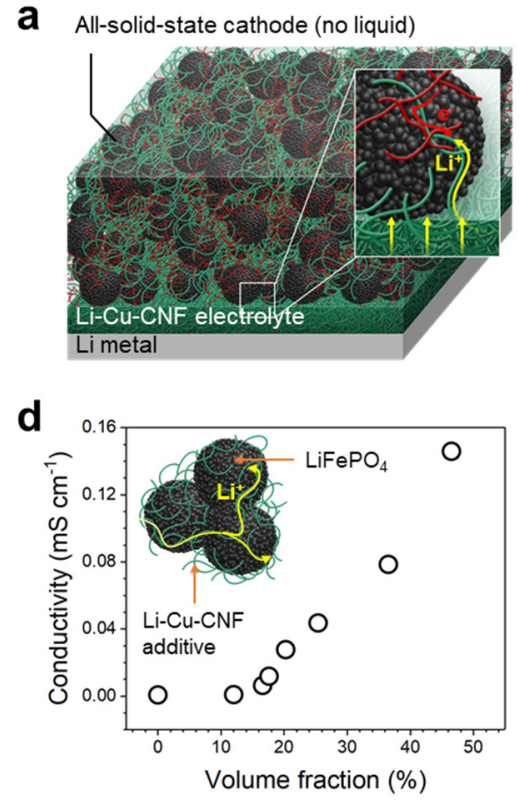

g

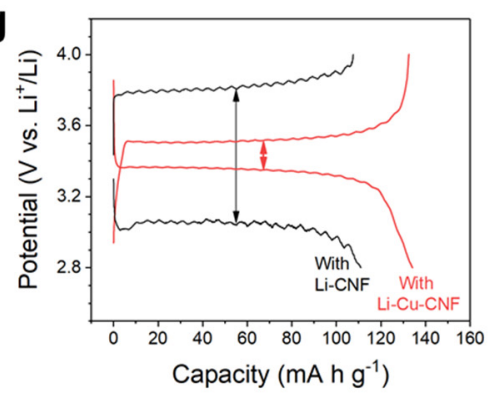

j

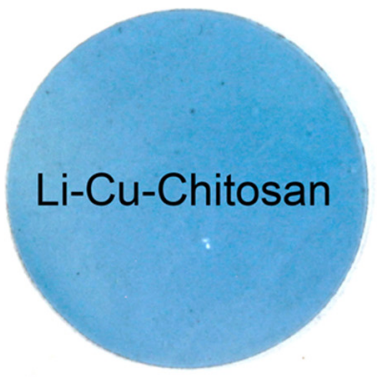

b

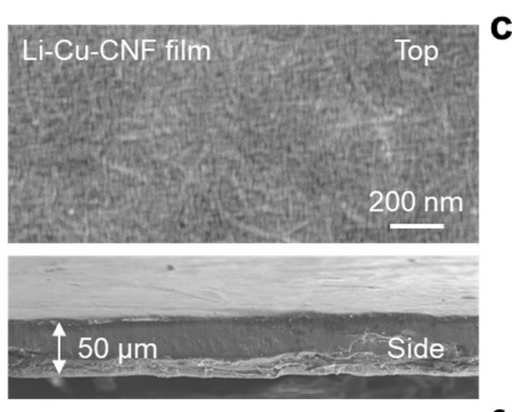

e

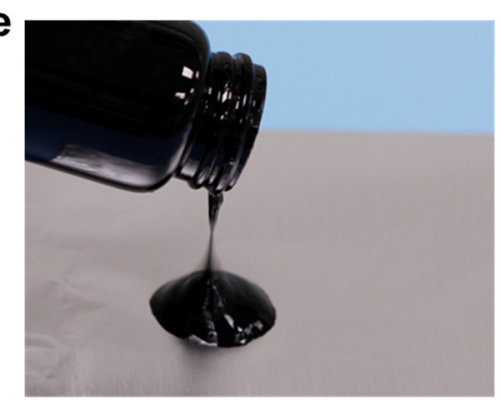

h

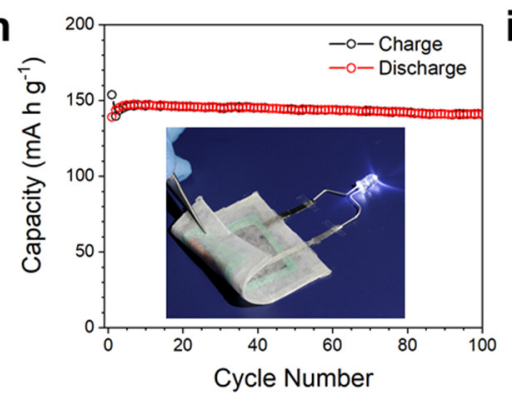

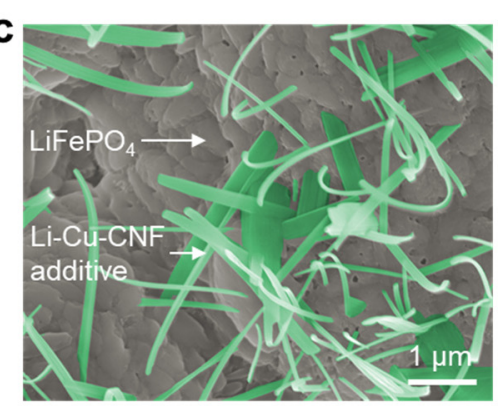

f
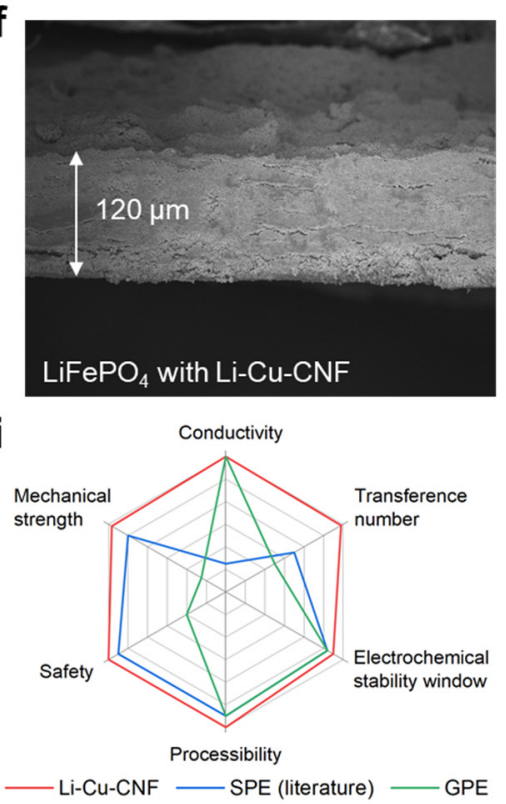
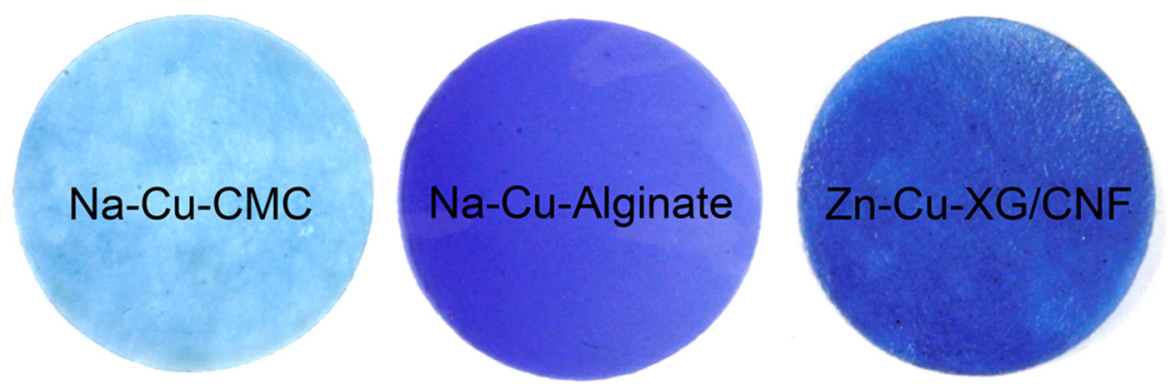

365 Fig. 4 | Demonstration of all-solid-state batteries using the Li-Cu-CNF ion conductor. a,

366 Schematic of an all-solid-state full battery consisting of a Li metal anode, the Li-Cu-CNF film

367 SPE, and the solid-state cathode (black spheres) featuring the Li-Cu-CNF as an ion-conducting

368 additive (green fibers). b, Top-view and side-view SEM images of the dense electrolyte made of

369 the 1D Li-Cu-CNF. c, SEM image of the $\mathrm{LiFePO}_{4}$ cathode with the $\mathrm{Li}-\mathrm{Cu}-\mathrm{CNF}$ ion-conducting

370 additive (false color: grey, $\mathrm{LiFePO}_{4}$; green, $\mathrm{Li}-\mathrm{Cu}-\mathrm{CNF}$ ). d, The ionic conductivity of $\mathrm{LiFePO}_{4}$ 
371 cathodes made with different amounts of Li-Cu-CNF to achieve ion percolation. e, Photo of the 372 cathode slurry consisting of $\mathrm{LiFePO}_{4}$ and $\mathrm{Cu}-\mathrm{CNF}$ additive for casting the electrode and 373 subsequent $\mathrm{Li}^{+}$intercalation. f, Cross-sectional SEM images of a $120 \mu \mathrm{m}$ thick $\mathrm{LiFePO}_{4}$ cathode 374 made using Li-Cu-CNF and carbon nanotube additives. g, Galvanostatic charge/discharge voltage 375 profiles of the thick $\mathrm{LiFePO}_{4}$ solid-state cathodes made by filtration-pressing with $\mathrm{Li}-\mathrm{Cu}-\mathrm{CNF}$ or 376 Li-CNF additive and Li-Cu-CNF electrolyte. The arrows indicate the overpotentials at half 377 capacity. $\mathbf{h}$, The cycle performance $(0.2 \mathrm{C})$ of an all-solid-state $\mathrm{LiFePO}_{4}$ cell made using $\mathrm{Li}-\mathrm{Cu}$ 378 CNF ion-conducting additive in the cathode, the Li-Cu-CNF film electrolyte, and Li metal anode.

379 Inset: digital photo of the folded all-solid-state battery based on the $\mathrm{LiFePO}_{4}$ cathode and $\mathrm{Li}-\mathrm{Cu}$ 380 CNF as both the solid-state electrolyte and ion-conducting additive. i, Comparing the performance 381 of the Li-Cu-CNF electrolyte with SPEs and GPEs reported in the literature. $\mathbf{j}$, Digital photos of 382 M-Cu-polymer electrolytes (analogue to $\mathrm{Li}-\mathrm{Cu}-\mathrm{CNF}$ ), where $\mathrm{M}=\mathrm{Li}, \mathrm{Na}$, or $\mathrm{Zn}$, and the polymers 383 include chitosan, carboxymethyl cellulose (CMC), alginate acid, and xanthan gum (XG). 
As a 1D solid-state ion conductor, Li-Cu-CNF demonstrates a record-high ionic conductivity $\left(1.5 \times 10^{-3} \mathrm{~S} \mathrm{~cm}^{-1}\right)$ and high transference number $(0.78)$ at room temperature, which was made

387 possible by decoupling the $\mathrm{Li}^{+}$transport from the local solvation environment. $\mathrm{The}^{+} \mathrm{i}^{+}$transport 388 follows a rapid ion hopping mechanism via the polar functional groups and bound water molecules 389 available in the cellulose molecular channels that have been opened by simple $\mathrm{Cu}^{2+}$ coordination 390 chemistry. The Li-Cu-CNF ion conductor provides exceptional safety, stability, scalability, facile391 processibility, and good mechanical strength for high-energy-density batteries, which are 392 significant advantages over conventional polymer electrolytes (solid or gel), as shown in Fig. 4i. 393 This 1D ion conductor can also function as an ionic building block to form solid-state ionic 394 conducting networks, providing a unique opportunity to enable thick cathodes and achieve high395 energy-density all-solid-state batteries. The success of this new design strategy creates a new class 396 of polymer ion conductors that enable fast conduction by various cations (e.g., $\mathrm{H}^{+}, \mathrm{Na}^{+}$, and $\mathrm{Zn}^{2+}$ ) 397 with high room-temperature ionic conductivities that have been impossible from traditional 398 polymer electrolytes. For example, we investigated this same approach for the synthesis of ion 399 conductors made of chitosan, alginate acid, carboxymethyl cellulose (CMC), and xanthan gum 400 (XG) (Fig. 4j), all of which showed record-high room-temperature ionic conductivities $\left(\sigma_{\mathrm{Li}}=\right.$ $4013 \times 10^{-4} \mathrm{~S} \mathrm{~cm}^{-1}$ for Li-Cu-chitosan, $\sigma_{\mathrm{Na}}=2 \times 10^{-4} \mathrm{~S} \mathrm{~cm}^{-1}$ for Na-Cu-alginate, and $\sigma_{\mathrm{Zn}}=9 \times 10^{-4} \mathrm{~S}$ $402 \mathrm{~cm}^{-1}$ for $\mathrm{Zn}-\mathrm{Cu}-\mathrm{XG} / \mathrm{CNF}$ ). This novel design approach provides both material and conceptual 403 breakthroughs for the development of many other high-performance solid-state ion conductors that 404 could have a broad impact beyond just safe solid-state batteries, examples of which could include 405 electrochemical synaptic devices, solid-state sensors, or redox-controlled information processing 406 and storage. 


\section{References}

4081 Xu, K. Nonaqueous Liquid Electrolytes for Lithium-Based Rechargeable Batteries. Chem. 409 Rev. 104, 4303-4418 (2004).

4102 Long, L., Wang, S., Xiao, M. \& Meng, Y. Polymer electrolytes for lithium polymer batteries. J. Mater. Chem. A 4, 10038-10069 (2016).

413

3 Gadjourova, Z., Andreev, Y. G., Tunstall, D. P. \& Bruce, P. G. Ionic conductivity in crystalline polymer electrolytes. Nature 412, 520-523 (2001).

4144 Manthiram, A., Yu, X. \& Wang, S. Lithium battery chemistries enabled by solid-state electrolytes. Nat. Rev. Mater. 2, 16103 (2017). Lopez, J., Mackanic, D. G., Cui, Y. \& Bao, Z. Designing polymers for advanced battery chemistries. Nat. Rev. Mater. 4, 312-330 (2019). Zhao, W., Yi, J., He, P. \& Zhou, H. Solid-State Electrolytes for Lithium-Ion Batteries: Fundamentals, Challenges and Perspectives. Electrochem. Energ. Rev. 2, 574-605 (2019). 7 Croce, F., Appetecchi, G. B., Persi, L. \& Scrosati, B. Nanocomposite polymer electrolytes for lithium batteries. Nature 394, 456-458 (1998).

8 Diederichsen, K. M., McShane, E. J. \& McCloskey, B. D. Promising Routes to a High Li ${ }^{+}$ Transference Number Electrolyte for Lithium Ion Batteries. ACS Energy Lett. 2, 25632575 (2017).

9 Xue, Z., He, D. \& Xie, X. Poly(ethylene oxide)-based electrolytes for lithium-ion batteries. J. Mater. Chem. A 3, 19218-19253 (2015).

10 Molinari, N., Mailoa, J. P. \& Kozinsky, B. Effect of Salt Concentration on Ion Clustering and Transport in Polymer Solid Electrolytes: A Molecular Dynamics Study of PEOLiTFSI. Chem. Mater. 30, 6298-6306 (2018).

11 Timachova, K., Watanabe, H. \& Balsara, N. P. Effect of Molecular Weight and Salt Concentration on Ion Transport and the Transference Number in Polymer Electrolytes. Macromolecules 48, 7882-7888 (2015).

12 Khurana, R., Schaefer, J. L., Archer, L. A. \& Coates, G. W. Suppression of Lithium Dendrite Growth Using Cross-Linked Polyethylene/Poly(ethylene oxide) Electrolytes: A New Approach for Practical Lithium-Metal Polymer Batteries. J. Am. Chem. Soc. 136, 7395-7402 (2014).

13 Mackanic, D. G. et al. Crosslinked Poly(tetrahydrofuran) as a Loosely Coordinating Polymer Electrolyte. Adv. Energy Mater. 8, 1800703 (2018).

14 Pan, Q., Smith, D. M., Qi, H., Wang, S. \& Li, C. Y. Hybrid Electrolytes with Controlled Network Structures for Lithium Metal Batteries. Adv. Mater. 27, 5995-6001 (2015).

Bouchet, R. et al. Single-ion BAB triblock copolymers as highly efficient electrolytes for lithium-metal batteries. Nat. Mater. 12, 452-457 (2013).

16 Ma, Q. et al. Single Lithium-Ion Conducting Polymer Electrolytes Based on a SuperDelocalized Polyanion. Angew. Chem. Int. Ed. 55, 2521-2525 (2016).

17 Croce, F., Persi, L., Ronci, F. \& Scrosati, B. Nanocomposite polymer electrolytes and their impact on the lithium battery technology. Solid State Ionics 135, 47-52 (2000).

18 Liu, W., Lin, D., Sun, J., Zhou, G. \& Cui, Y. Improved Lithium Ionic Conductivity in Composite Polymer Electrolytes with Oxide-Ion Conducting Nanowires. ACS Nano 10, 11407-11413 (2016).

Wan, J. et al. Ultrathin, flexible, solid polymer composite electrolyte enabled with aligned nanoporous host for lithium batteries. Nat. Nanotechnol. 14, 705-711 (2019). 
$20 \mathrm{Xu}, \mathrm{H}$. et al. High-performance all-solid-state batteries enabled by salt bonding to perovskite in poly(ethylene oxide). Proc. Natl. Acad. Sci. U.S.A. 116, 18815-18821 (2019). Lv, D. et al. Pure cellulose lithium-ion battery separator with tunable pore size and improved working stability by cellulose nanofibrils. Carbohydr. Polym. 251, 116975 (2021).

22 Zhao, D. et al. Cellulose-Based Flexible Functional Materials for Emerging Intelligent Electronics. Adv. Mater., 2000619 (2020).

23 Dahlström, C. et al. Ion conductivity through TEMPO-mediated oxidated and periodate oxidated cellulose membranes. Carbohydr. Polym. 233, 115829 (2020). Kimura, K., Motomatsu, J. \& Tominaga, Y. Correlation between Solvation Structure and Ion-Conductive Behavior of Concentrated Poly(ethylene carbonate)-Based Electrolytes. $J$. Phys. Chem. C 120, 12385-12391 (2016).

25 Zugenmaier, P. Crystalline Cellulose and Derivatives. 1 edn, (Springer-Verlag Berlin Heidelberg, 2008).

26 Ogawa, Y. et al. Formation and stability of cellulose-copper-NaOH crystalline complex. Cellulose 21, 999-1006 (2014).

27 Quartarone, E. \& Mustarelli, P. Electrolytes for solid-state lithium rechargeable batteries: recent advances and perspectives. Chem. Soc. Rev. 40, 2525-2540 (2011).

28 Evans, J., Vincent, C. A. \& Bruce, P. G. Electrochemical measurement of transference numbers in polymer electrolytes. Polymer 28, 2324-2328 (1987).

29 Nair, J. R., Imholt, L., Brunklaus, G. \& Winter, M. Lithium Metal Polymer Electrolyte Batteries: Opportunities and Challenges. Electrochem. Soc. Interface 28, 55-61 (2019).

30 Zheng, J., Tang, M. \& Hu, Y.-Y. Lithium Ion Pathway within Li7La3Zr2 $\mathrm{O}_{12}-$ Polyethylene Oxide Composite Electrolytes. Angew. Chem. Int. Ed. 55, 12538-12542 (2016).

31 Self, J., Fong, K. D. \& Persson, K. A. Transport in Superconcentrated LiPF6 and LiBF4/Propylene Carbonate Electrolytes. ACS Energy Lett. 4, 2843-2849 (2019).

32 He, X., Zhu, Y., Epstein, A. \& Mo, Y. Statistical variances of diffusional properties from ab initio molecular dynamics simulations. npj Comput. Mater. 4, 18 (2018).

$33 \mathrm{Ng}, \mathrm{C}$. Y. et al. Photoionization of dimeric polyatomic molecules: Proton affinities of $\mathrm{H}_{2} \mathrm{O}$ and HF. J. Chem. Phys. 67, 4235-4237 (1977).

34 Kim, B., Lee, J. \& Yu, I. Electrical properties of single-wall carbon nanotube and epoxy composites. J. Appl. Phys. 94, 6724-6728 (2003).

35 Zeng, X.-X. et al. Reshaping Lithium Plating/Stripping Behavior via Bifunctional Polymer Electrolyte for Room-Temperature Solid Li Metal Batteries. J. Am. Chem. Soc. 138, $15825-$ 15828 (2016). 


\section{Methods}

\section{Fabrication process}

490 The Li-Cu-CNF was fabricated by the following three steps: (1) CNFs, which were produced

491 by (2,2,6,6-tetramethylpiperidin-1-yl)oxidanyl (TEMPO) oxidation of pulp (International 492 Paper $)^{36}$, were immersed in $\mathrm{Cu}^{2+}$-saturated alkaline solution $(20 \% \mathrm{NaOH})$ for $1-2$ weeks. The 493 CNFs gradually turned blue (indicating $\mathrm{Cu}^{2+}$ coordination with the $\mathrm{CNFs}$ ), with the product 494 referred to as $\mathrm{Cu}-\mathrm{CNF}-\mathrm{NaOH}$. (2) The free water in the $\mathrm{Cu}-\mathrm{CNF}-\mathrm{NaOH}$ was then replaced by 495 DMF solvent exchange, which was then evaporated to produce the $\mathrm{Cu}-\mathrm{CNF}$. (3) After soaking the $496 \mathrm{Cu}-\mathrm{CNF}$ in a Li salt solution $\left(1 \mathrm{M} \mathrm{LiPF}_{6}\right.$ dissolved in ethylene carbonate/dimethyl carbonate, $1 / 1$ 497 volumetric ratio) in an argon-filled glovebox and evaporating the solvent in vacuum, the $\mathrm{Li}-\mathrm{Cu}-$ 498 CNF solid-state ion conductor was obtained. For the Li-CNF control sample, the CNFs were 499 treated using the same steps except the material was immersed in the $\mathrm{NaOH}$ solution without $\mathrm{Cu}^{2+}$ 500 in Step 1.

501 For different uses of the Li-Cu-CNF, the materials or synthesis process described above were 502 slightly changed. To obtain the Li-Cu-CNF with aligned orientation for measuring the intrinsic 503 conductivity, mechanical strength, and fiber XRD along the fibril direction, basswood was cut 504 along the longitudinal direction (i.e., the growth direction of the tree), delignified, pressed, and 505 directly used as the cellulose source without further TEMPO-treatment in Step 1. To fabricate the 506 Li-Cu-CNF thin-film electrolyte, the Cu-CNF-NaOH obtained in Step 1 (derived from TEMPO507 oxidized CNFs, as described previously) was vacuum filtrated and pressed into a film and further 508 processed in Steps 2 and 3. To mix the $\mathrm{Li}-\mathrm{Cu}-\mathrm{CNF}$ with the $\mathrm{LiFePO}_{4}(\mathrm{BTR}$ New Material Group 509 Co.) or NMC (ANL) cathode materials, the $\mathrm{Cu}-\mathrm{CNF}-\mathrm{NaOH}$ obtained in Step 1 was washed and 510 mixed with the cathode material and carbon nanotubes (CNT, XFNANO) (typical mass ratio of 
511 cathode material:CNT:Cu-CNF $=8: 1: 1)$ in water solution and then either filtrated as a free-

512 standing cathode or cast on Al foil with the addition of $9 \mathrm{wt} \%$ sodium alginate binder, followed

513 by the same treatment in Steps 2 and 3.

514 The Li-Cu-CNF system was extended to other M-Cu-polymer systems via slightly modified 515 synthesis methods. In this work, aqueous solutions of chitosan, sodium alginate, and sodium CMC 516 (all from Sigma Aldrich) were cast-dried and pressed into thin films. The XG (TCI) was mixed 517 with the TEMPO-oxidized CNF material (XG/CNF, mass ratio 1:1) in solution, filtrated, and also 518 pressed into a thin film. The polymer films were coordinated with $\mathrm{Cu}^{2+}$ to form $\mathrm{Cu}$-polymer via a 519 similar method in Step 1. The Cu-chitosan was further similarly treated with Steps 2 and 3 for $\mathrm{Li}^{+}$ 520 intercalation. The $\mathrm{Cu}-\mathrm{CMC}$ was soaked in a $\mathrm{Na}^{+}$ion electrolyte $\left(3 \mathrm{M} \mathrm{NaClO}_{4}\right.$ in $\left.\mathrm{DMF}\right)$ for 521 intercalating $\mathrm{Na}^{+}$and forming $\mathrm{Na}-\mathrm{Cu}-\mathrm{CMC}$. The $\mathrm{Cu}$-alginate was treated with a $\mathrm{Na}^{+}$ion electrolyte 522 (4 $\mathrm{M} \mathrm{NaClO}_{4}$ aqueous solution) to form $\mathrm{Na}-\mathrm{Cu}$-alginate for $\mathrm{Na}^{+}$conduction. The $\mathrm{Cu}-\mathrm{XG} / \mathrm{CNF}$ was 523 treated with a $\mathrm{Zn}^{2+}$ ion electrolyte $\left(2 \mathrm{M} \mathrm{ZnSO}_{4}\right.$ aqueous solution) to form $\mathrm{Zn}-\mathrm{Cu}-\mathrm{XG} / \mathrm{CNF}$ for $\mathrm{Zn}^{2+}$ 524 conduction. All samples were dried in vacuum before electrochemical testing.

525 The solid-state batteries were assembled in an argon-filled glovebox. The Li symmetric cells 526 were assembled by sandwiching the Li-Cu-CNF electrolyte between two Li metals. The solid-state 527 full cells were made with a $\mathrm{Li}$ metal anode, $\mathrm{Li}-\mathrm{Cu}-\mathrm{CNF}$ electrolyte, and a $\mathrm{LiFePO}_{4}$ cathode or 528 NMC cathode containing Li-Cu-CNF additive (9 wt $\%)$. To measure the ion percolation behavior 529 of $\mathrm{Li}-\mathrm{Cu}-\mathrm{CNF}$ in the cathode, the $\mathrm{LiFePO}_{4}$ cathode was fabricated with the same method using 530 different ratios of Li-Cu-CNF (Li-CNF was used as the "zero" Li-Cu-CNF control) and without 531 CNTs. The all-solid-state flexible cell was assembled using a thin $\mathrm{Li}$ metal anode, Li-Cu-CNF 532 electrolyte, and $\mathrm{LiFePO}_{4}$ cathode with $\mathrm{Li}-\mathrm{Cu}-\mathrm{CNF}$ additive in a paper pouch. 


\section{Characterization}

534 A Hitachi SU-70 field emission SEM coupled with an energy-dispersive X-ray spectroscopy 535 system was employed for SEM and elemental analysis. FTIR was conducted on a Nexus 670 made 536 by Thermo Electron with a "Smart Endurance" Attenuated Total Reflectance accessory. The fiber 537 XRD measurements were conducted on a Xenocs Xeuss SAXS/WAXS system with a $\mathrm{Cu} \mathrm{K} \alpha(\lambda=$ $5381.5418 \AA$ ) source and Detris Pilatus 300k detector. A home-made sample holder was used to bring 539 samples close to the detector. The content of $\mathrm{Li}$ and $\mathrm{Cu}$ in $\mathrm{Li}-\mathrm{Cu}-\mathrm{CNF}$ was analyzed by dissolving 540 the sample in nitric acid, the metal concentration of which was measured using a multi-collector

541 ICP mass spectrometer (Thermo-Finnigan Element 2). The stress-strain measurement of the Li$542 \mathrm{Cu}-\mathrm{CNF}$ (along the cellulose fiber direction) was performed with a Tinius Olsen H5KT testing 543 machine.

544 XAS measurements were performed at the 8-ID Beamline of the National Synchrotron Light

545 Source II at Brookhaven National Laboratory (BNL). X-ray absorption near-edge spectroscopy 546 (XANES) and extended X-ray absorption fine structure (EXAFS) data were collected at the Cu K-

547 edge in transmission mode. The samples were placed between two Kapton tapes, which allow for 548 high transmissivity for X-ray measurements. The spectra of the standards were obtained from $\mathrm{Cu}$ 549 foil (provided by BNL), commercial copper (I) oxide $\left(\mathrm{Cu}_{2} \mathrm{O}\right)$ powder, and copper (II) oxide $(\mathrm{CuO})$ 550 powder (Sigma Aldrich). XAS data were analyzed using the IFEFFIT package, which included 551 ATHENA and ARTEMIS ${ }^{37}$.

552 For isotope tracing, the tracer exchange $\left({ }^{6} \mathrm{Li} \rightarrow{ }^{7} \mathrm{Li}\right)$ was driven by electrochemical cycling using $553{ }^{6} \mathrm{Li}$-enriched metal (95 atom\%, Sigma-Aldrich) as electrode foils. The Li-Cu-CNF (or Li-CNF as 554 a control) electrolyte was assembled between two ${ }^{6} \mathrm{Li}$ foils to form a symmetric cell $\left({ }^{6} \mathrm{Li} \mid \mathrm{Li}-\mathrm{Cu}-\right.$ $\left.555 \mathrm{CNF} \mid{ }^{6} \mathrm{Li}\right)$. The cell was galvanically polarized for 50 cycles with a current density of $32 \mu \mathrm{A} \mathrm{cm}{ }^{-2}$ 
556 and the current switched the direction every $30 \mathrm{~min}$. After cycling, the electrolyte was removed

557 from the cell for ${ }^{6} \mathrm{Li} \mathrm{NMR}$ measurements. ${ }^{6} \mathrm{Li}$ magic-angle-spinning NMR experiments were

558 performed on a Bruker Avance III-500 spectrometer with a ${ }^{6} \mathrm{Li}$ Larmor frequency of $73.6 \mathrm{MHz}$.

559 Samples were packed in $2.5 \mathrm{~mm}$ rotors and spun at a speed of $25 \mathrm{kHz}$. A single pulse was employed

560 to acquire the ${ }^{6} \mathrm{Li}$ NMR spectra with a $90^{\circ}$ pulse length of $2.5 \mu$ s and a recycle delay of $10 \mathrm{~s} .{ }^{6} \mathrm{Li}$

561 NMR chemical shifts were referenced to solid $\mathrm{LiCl}$ at $-1.1 \mathrm{ppm}$.

$562 \quad{ }^{7} \mathrm{Li}$ and ${ }^{1} \mathrm{H}$ pulsed-field gradient NMR measurements were performed on $300 \mathrm{MHz}$ and 400

$563 \mathrm{MHz}$ NMR spectrometers on a double resonance probe equipped with a maximum gradient of

$5641200 \mathrm{G} \mathrm{cm}^{-1}$ and $50 \mathrm{G} \mathrm{cm}^{-1}$, respectively. Double-stimulated echo or spin-echo pulse sequences

565 were used to measure the diffusion coefficients. The signal was accumulated by using a minimum

566 of 64 up to a maximum of 1536 transients with 2 s recycling delay. The gradient strength was

567 varied from $2-50 \mathrm{G} / \mathrm{cm}$ or $2-700 \mathrm{G} / \mathrm{cm}$ over 16 increments. The diffusion time $(\Delta)$ and the

568 diffusion pulse length $(\delta)$ were in the range of 50-400 $\mathrm{ms}$ and 2-9 ms, respectively. The diffusion

569 coefficients $(D)$ were calculated using the Stejskal-Tanner equation,

$$
\frac{I}{I_{0}}=\exp \left[-(G \gamma \delta)^{2}\left(\Delta-\frac{\delta}{3}\right) D\right]
$$

571 in which $\gamma$ is the gyromagnetic ratio and $G$ is the gradient strength.

\section{Electrochemical test}

573 The electrochemical tests (EIS, DC polarization, and linear sweep voltammogram) were done

574 on a Biologic electrochemical working station. The EIS spectra were measured in a frequency

575 range of $1 \mathrm{MHz}-1 \mathrm{~Hz}$ with a voltage amplitude of $20 \mathrm{mV}$. Electrochemical stripping and plating

576 for Li symmetric cells and galvanostatic cycling tests for solid-state cells were conducted on a

577 LAND electrochemical testing system with galvanostatic conditions. 
DFT calculations were performed using the Gaussian 16 code (Revision AVX2) ${ }^{38}$. The hybrid PBE0 functional ${ }^{39}$ and the basis set $6-311+\mathrm{G}^{* *}$ were used for geometry optimizations, energy 581 calculations, and frequency calculations. The D3 version of Grimme's dispersion with Becke582 Johnson damping $(\mathrm{GD} 3 \mathrm{BJ})^{40}$ was adopted to correct for the weak interactions.

\section{Molecular dynamics simulations}

The crystalline $\mathrm{Cu}-\mathrm{CNF}-\mathrm{NaOH}$ was built using the Materials Studio (MS, version 7.0) ${ }^{41}$ Visualizer with experimental input for the lattice constant and crystal symmetry ${ }^{26}$. The Forcite module in MS was used to conduct classical molecular dynamics (MD) simulations. The COMPASS II forcefield ${ }^{42}$, which is extended for polymer systems, was adopted to account for 588 both the bonded and non-bonded interactions. The force field type and charges listed in Extended Data Fig. 2a result in Li-O interactions for different functional groups comparing well with DFT 590 calculations (Extended Data Fig. 2b). Since the $\mathrm{Cu}^{2+}$ did not diffuse in experiments, an additional 591 Harmonic potential with a force constant of $25,000 \mathrm{kcal} \mathrm{mol}^{-1} \AA^{-2}$ was applied to the $\mathrm{Cu}-\mathrm{O}$ bond 592 term to keep the $\mathrm{Cu}-\mathrm{O}$ distances at the values obtained from DFT calculations (Extended Data Fig.

593 2c). The Nosé method ${ }^{43}$ was used for constant temperature dynamics and the Berendsen method ${ }^{44}$ 594 was used for NPT (constant particle number, pressure, and temperature) dynamics. The Ewald 595 summation method was used to calculate the Coulombic interactions with an accuracy of 0.001 $596 \mathrm{kcal} / \mathrm{mol}$ and a cutoff distance of $12.5 \AA$. A total simulation time of $5.0 \mathrm{~ns}$ with a timestep of 1.0 597 fs was applied to typical production MD runs.

\section{Computational model for the $\mathrm{Li}-\mathrm{Cu}-\mathrm{CNF}$ system and the procedure for the MD simulations}

599 We started by building the atomic structure of the crystalline $\mathrm{Cu}-\mathrm{CNF}-\mathrm{NaOH}$ based on the 600 experimental inputs on the lattice parameters and crystal symmetry. The $2 \times 2$ supercell of the $\mathrm{Cu}-$ 
601 CNF backbone structure (Extended Data Fig. 2d) was assigned with lattice parameters of $a=b=$

$60215.0 \AA$ with a hexagonal symmetry, which agrees with the experimental measurements. Every two 603 nearby cellulose chains were connected by one $\mathrm{Cu}$ atom through the hydroxyl $\mathrm{O}$ atoms in the 604 simulation cell. A long cell was built with $\mathrm{c}=90.0 \AA$. In our MD simulations, the $2 \times 2$ supercell 605 was used to avoid the interactions between periodic images. An appropriate number of $\mathrm{H}_{2} \mathrm{O}$ 606 molecules were added by the Amorphous Cell module in MS (Extended Data Fig. 2e). Our 607 simulated cell contains 144 AGUs, 1600 water molecules, and $12 \mathrm{Cu}$ atoms. $24 \mathrm{CH}_{2} \mathrm{OH}$ groups 608 were replaced by $\mathrm{COOH}$ groups. Room temperature $(298 \mathrm{~K})$ and a pressure of 1 bar were kept 609 constant during NPT dynamics for $1.0 \mathrm{~ns}$ to obtain the density at this stage. Next, we removed 610 most water molecules to model the drying process with only $144 \mathrm{H}_{2} \mathrm{O}$ molecules left in the system.

611 The $\mathrm{Li}^{+}$intercalation was achieved by replacing the $24-\mathrm{COOH}$ groups with $24-\mathrm{COOLi}$ groups 612 and the $24-\mathrm{CH}_{2} \mathrm{O}$ groups with $24-\mathrm{CH}_{2} \mathrm{OLi}$ groups, as shown in Extended Data Fig. $2 \mathrm{~g}$. There 613 were $48 \mathrm{Li}^{+}$ions in the modeling system, and the $\mathrm{Li}$ :AGU ratio was set to $1: 3$, which is the value 614 estimated by the ICP experiment. Then NPT dynamics simulations were performed to obtain the 615 equilibrated amorphous Li-Cu-CNF (Extended Data Fig. 2g). A high temperature of $600 \mathrm{~K}$ was 616 used to accelerate the dynamics; compared with room temperature simulations no mechanism 617 change was observed. Finally, production runs for $5.0 \mathrm{~ns}$ were performed at $600 \mathrm{~K}$ under NVT 618 (constant particle number, volume, and temperature) ensemble to investigate the Li transport 619 mechanism. The Li-Cu-CNF without any $\mathrm{H}_{2} \mathrm{O}$ molecules was also simulated for comparison.

\section{XANES calculations}

621 The $\mathrm{Cu}$ K-edge theoretical XANES calculations for the $\mathrm{Cu}-(\mathrm{AGU}) 2$ system (Extended Data

622 Fig. 2c) were conducted in the framework of the real-space full multiple scattering scheme with 623 the muffin-tin approximation for the potential as implemented in the FDMNES code ${ }^{45}$. 


\section{References}

62536 Saito, T., Kimura, S., Nishiyama, Y. \& Isogai, A. Cellulose Nanofibers Prepared by

626 TEMPO-Mediated Oxidation of Native Cellulose. Biomacromolecules 8, 2485-2491 (2007).

37 Ravel, B. \& Newville, M. ATHENA, ARTEMIS, HEPHAESTUS: data analysis for X-ray absorption spectroscopy using IFEFFIT. J. Synchrotron Rad. 12, 537-541 (2005). Frisch, M. J. et al., Gaussian 16 Rev. AVX2, Wallingford, CT (2016).

634 Adamo, C. \& Barone, V. Toward reliable density functional methods without adjustable parameters: The PBE0 model. J. Chem. Phys. 110, 6158-6170 (1999). corrected density functional theory. J. Comput. Chem. 32, 1456-1465 (2011). BIOVIA, Materials Studio 7.0, Dassault Systèmes, San Diego (2013). Sun, H. et al. COMPASS II: extended coverage for polymer and drug-like molecule databases. J. Mol. Model. 22, 47 (2016).

3 Nosé, S. A molecular dynamics method for simulations in the canonical ensemble. Mol. Phys. 52, 255-268 (1984).

44 Berendsen, H. J. C., Postma, J. P. M., Gunsteren, W. F. v., DiNola, A. \& Haak, J. R. Molecular dynamics with coupling to an external bath. J. Chem. Phys. 81, 3684-3690 (1984).

660

662 Joly, Y. X-ray absorption near-edge structure
approximation. Phys. Rev. B 63, 125120 (2001).

46 Sharma, A. et al. XANES, EXAFS and photocatalytic investigations on copper oxide nanoparticles and nanocomposites. RSC Adv. 5, 21762-21771 (2015).

47 Persson, I. et al. EXAFS Study on the Coordination Chemistry of the Solvated Copper(II) Ion in a Series of Oxygen Donor Solvents. Inorg. Chem. 59, 9538-9550 (2020).

8 Schmidt, D. A. \& Miki, K. Structural Correlations in Liquid Water: A New Interpretation of IR Spectroscopy. J. Phys. Chem. A 111, 10119-10122 (2007).

49 Wallace, V. M., Dhumal, N. R., Zehentbauer, F. M., Kim, H. J. \& Kiefer, J. Revisiting the Aqueous Solutions of Dimethyl Sulfoxide by Spectroscopy in the Mid- and Near-Infrared: Experiments and Car-Parrinello Simulations. J. Phys. Chem. B 119, 14780-14789 (2015).

50 Torres, J. et al. A neutron scattering and electron microscopy study of the structure, wetting, and freezing behavior of water near hydrophilic CuO-nanostructured surfaces. $J$. Appl. Phys. 125, 025302 (2019).

1 Fan, M., Dai, D. \& Huang, B. Fourier Transform Infrared Spectroscopy for Natural Fibres. in Fourier Transform - Materials Analysis (ed Salih Salih) Ch. 3, (IntechOpen, 2012).

52 Yuan, M., Erdman, J., Tang, C. \& Ardebili, H. High performance solid polymer electrolyte with graphene oxide nanosheets. RSC Adv. 4, 59637-59642 (2014).

53 Tao, C. et al. A promising TPU/PEO blend polymer electrolyte for all-solid-state lithium ion batteries. Electrochim. Acta 257, 31-39 (2017).

54 Shin, I., Nam, J., Lee, K., Kim, E. \& Kim, T.-H. Poly(ethylene glycol) (PEG)-crosslinked poly(vinyl pyridine)-PEG-poly(vinyl pyridine)-based triblock copolymers prepared by RAFT polymerization as novel gel polymer electrolytes. Polym. Chem. 9, 5190-5199 (2018). 
66755 Lu, Q. et al. A novel solid composite polymer electrolyte based on poly(ethylene oxide) 668 segmented polysulfone copolymers for rechargeable lithium batteries. J. Membr. Sci. 425669 426, 105-112 (2013).

67056 Liang, B., Jiang, Q., Tang, S., Li, S. \& Chen, X. Porous polymer electrolytes with high 671 ionic conductivity and good mechanical property for rechargeable batteries. J. Power $672 \quad$ Sources 307, 320-328 (2016).

673 


\section{Data availability}

675 The data that support the findings of this study are available from the corresponding author on 676 reasonable request.

\section{Acknowledgements}

678 L. Hu acknowledges support from the University of Maryland A. James Clark School of 679 Engineering. Q. Wu and Y. Qi acknowledge the support from the Nanostructures for Electrical 680 Energy Storage (NEES) center, an Energy Frontier Research Center funded by the U.S. 681 Department of Energy, Office of Science, Basic Energy Sciences under Award number 682 DESC0001160. Y.-Y. Hu acknowledges the support from the National Science Foundation under 683 Grant No. DMR-1847038. Solid-state NMR experiments were performed at the National High 684 Magnetic Field Laboratory, which is supported by the National Science Foundation through 685 NSF/DMR-1644779 and the State of Florida. Access to the High Flux Backscattering 686 Spectrometer was provided by the Center for High Resolution Neutron Scattering, a partnership 687 between the NIST and the National Science Foundation under Agreement No. DMR-1508249. 688 Certain commercial equipment, instruments, or materials are identified in this paper in order to 689 specify the experimental procedure adequately. Such identification is not intended to imply 690 recommendation or endorsement by the NIST.

\section{Author contributions}

692 L. Hu conceived the SPE concept and supervised the project. C. Yang, W. Xie, and S. He designed

693 the experiments and conducted the material synthesis, characterization, and electrochemical tests.

694 Y. Qi and Q. Wu carried out the density functional theory and molecular dynamics simulations.

695 X. Zhang and R. Briber contributed to the structural analysis. J. Zheng, Y.-Y. Hu, M. Garaga, and 
696 S. Greenbaum conducted the NMR analysis and determination of the ion diffusion coefficient. Y.

697 Mao and M. Tyagi performed the XANE characterization. B.H. Ko and F. Jiao contributed to the

698 XAS analysis. J. Dai drew the schematic of the battery. L. Hu, C. Yang, Y. Qi, Q. Wu, A. Brozena,

699 A. Isogai, and K. Xu collectively wrote the paper. All authors commented on the final manuscript.

\section{Competing interests}

701 The authors declare no competing interest.

\section{Additional information}

703 Supplementary information is available for this paper.

704 Correspondence and requests for materials should be addressed to L.H. and Y.Q.

705 Reprints and permissions information is available at http://www.nature.com/reprints. 

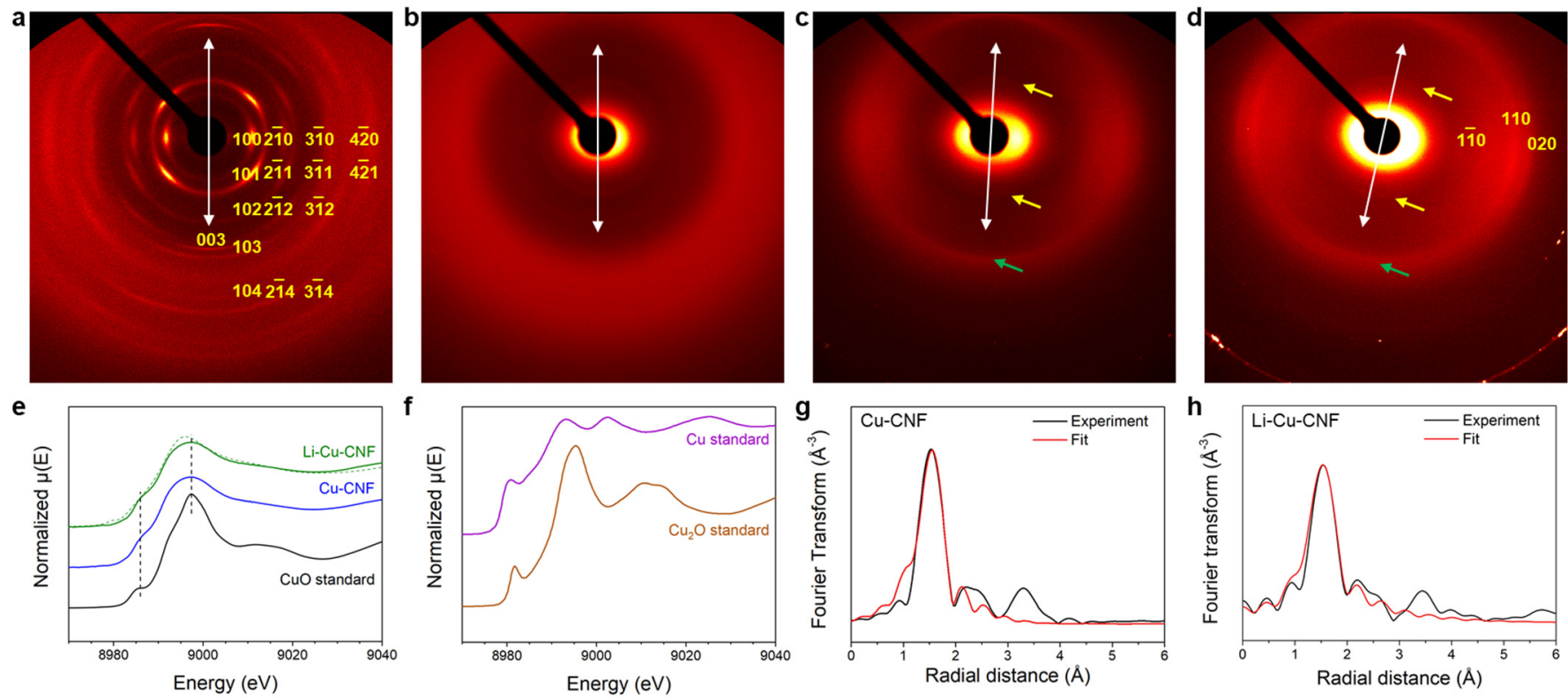

707 Extended Data Fig. 1 | Structural characterization during the synthesis of Li-Cu-CNF. a-d, The fiber

708 XRD patterns of the CNFs after the following treatment steps: a, $\mathrm{Cu}-\mathrm{CNF}-\mathrm{NaOH}$ obtained from $\mathrm{Cu}^{2+}$ 709 saturated $\mathrm{NaOH}$ aqueous solution. The peaks are indexed based on the literature ${ }^{26}$. The $(003)$ reflection is 710 observed with a spacing of $0.51 \mathrm{~nm}$ while the (001) and (002) reflections are absent, indicating the Cu-CNF$711 \mathrm{NaOH}$ features a threefold symmetric structure along the cellulose molecular chain direction. b, The Cu$712 \mathrm{CNF}$ washed with water to remove $\mathrm{NaOH}$, demonstrating an amorphous structure. $\mathbf{c}, \mathrm{Cu}-\mathrm{CNF}$ after removing 713 water by DMF exchange and evaporating DMF. The fiber XRD pattern shows a mostly amorphous structure 714 with a small angle peak at $\sim 2 \mathrm{~nm}$ corresponding to cellulose $\mathrm{II}^{25}$, possibly due to a small number of cellulose 715 chains without coordinated $\mathrm{Cu}$ forming cellulose II after $\mathrm{NaOH}$ is removed. A high $q$ peak at $\sim 0.4 \mathrm{~nm}$ in the 716 equatorial direction indicates the average molecular chain-to-chain distance of cellulose II. The green arrow 717 in the meridian direction shows a peak corresponding to $0.47 \mathrm{~nm}$ in real space. The yellow arrows are 718 pointing to peaks indicating the repeating unit of the $\mathrm{Cu}-\mathrm{CNF}$ is $\sim 1 \mathrm{~nm}$ along the cellulose chain. Both 0.47 $719 \mathrm{~nm}$ and $1 \mathrm{~nm}$ repeating distances are absent in all known cellulose structures and therefore we attribute them 720 to the unique structure of the $\mathrm{Cu}-\mathrm{CNF}$. $\mathbf{d}$, The $\mathrm{Li}-\mathrm{Cu}-\mathrm{CNF}$ after intercalating $\mathrm{Li}^{+}$in $\mathrm{Cu}-\mathrm{CNF}$ and evaporating 721 the solvent. The amorphous cellulose structure is maintained with some weak diffraction peaks of cellulose 
II. The yellow and green arrows indicate the same peaks as in $\mathbf{c} . \mathbf{e}-\mathbf{h}, \mathrm{XAS}$ analysis of the $\mathrm{Cu}-\mathrm{CNF}$ and Li-

$723 \mathrm{Cu}-\mathrm{CNF}$ samples: the $\mathrm{Cu} \mathrm{K}$-edge $\mathrm{X}$-ray absorption near edge structure (XANES) spectra of $\mathbf{e}, \mathrm{Cu}-\mathrm{CNF}, \mathrm{Li}-$

$724 \mathrm{Cu}-\mathrm{CNF}$, and a $\mathrm{CuO}$ standard, as well as $\mathbf{f}, \mathrm{Cu}_{2} \mathrm{O}$ and $\mathrm{Cu}$ standard samples. $\mathbf{g}-\mathbf{h}$, The Fourier-transformed $725 \mathrm{Cu}$ K-edge extended X-ray absorption fine structure (EXAFS) spectra of $\mathbf{g}, \mathrm{Cu}-\mathrm{CNF}$ and $\mathbf{h}, \mathrm{Li}-\mathrm{Cu}-\mathrm{CNF}$. standards, the $\mathrm{Cu}-\mathrm{CNF}$ and $\mathrm{Li}-\mathrm{Cu}-\mathrm{CNF}$ show similar yet broadened pre-edge peaks as $\mathrm{CuO}$ at $8986 \mathrm{eV}$ (1s $\rightarrow 3 \mathrm{~d}$ transition). The characteristic $\mathrm{Cu}(\mathrm{I})$ peak $\left(\mathrm{Cu}_{2} \mathrm{O}\right)$ at $\sim 8981 \mathrm{eV}$ and the $\mathrm{Cu}$ metal peaks are not observed in the $\mathrm{Cu}-\mathrm{CNF}$ and $\mathrm{Li}-\mathrm{Cu}-\mathrm{CNF}$ samples. Thus, the $\mathrm{Cu}^{2+}$ is coordinated in the $\mathrm{CNF}$ (with or without $\mathrm{Li}$ ) in a $730+2$ chemical valence state. By fitting the $\mathrm{Cu}$ K-edge EXAFS spectra of $\mathrm{Cu}-\mathrm{CNF}$ and $\mathrm{Li}-\mathrm{Cu}-\mathrm{CNF}$, we 731 obtained the structural parameters for the first coordination shell of the $\mathrm{Cu}$ atoms. In $\mathrm{Cu}-\mathrm{CNF}$, the $\mathrm{Cu}^{2+}$ is 732 bonded with $\mathrm{O}$ atoms, with an average bonding distance of $1.97 \AA$. The $\mathrm{Cu}-\mathrm{O}$ bonding distance is longer 733 than that in $\mathrm{CuO}(1.91 \AA)^{46}$ and consistent with $\mathrm{Cu}$-organic complexes reported in the literature ${ }^{47}$, indicating 734 that the $\mathrm{Cu}^{2+}$ is coordinated with the $\mathrm{O}$ in the AGUs of the cellulose molecules. The calculated XANES 735 spectrum of the Li-Cu-CNF material (the green dashed line in Extended Data Fig. 1e) is in good agreement 736 with the experimentally measured system, showing that the theoretical model for the $\mathrm{Cu}-\mathrm{O}$ complex structure 737 described in Extended Data Fig. 2c is reasonable.

738 The structural parameter values for the first coordination shell of the $\mathrm{Cu}$ atom, obtained from the EXAFS.

\begin{tabular}{lllll}
\hline & $\mathrm{CN}_{\mathrm{Cu}-\mathrm{O}}$ & $R_{\mathrm{Cu}-\mathrm{O}}(\AA)$ & $\sigma^{2} \mathrm{Cu}-\mathrm{O}\left(10^{-3} \AA^{2}\right)$ & $\Delta E_{0}(\mathrm{eV}), \mathrm{Cu} \mathrm{K}$-edge \\
\hline $\mathrm{Cu}-\mathrm{CNF}$ & $2.1(3)$ & $1.96(1)$ & $2.1(1.8)$ & $2.8(1.5)$ \\
\hline $\mathrm{Li}-\mathrm{Cu}-\mathrm{CNF}$ & $2.1(3)$ & $1.97(2)$ & $3.7(2.4)$ & $5.7(1.8)$ \\
\hline
\end{tabular}

$739 \mathrm{CN}$ : coordination number, $R$ : bond distance, $\sigma^{2}$ : mean-square disorder, and $\Delta E_{0}$ : energy shift. The single740 digit numbers in the parentheses for $\mathrm{CN}$ and $R$ are the last digit errors and the numbers in parentheses for $\sigma^{2}$ 741 and $\Delta E_{0}$ are full errors. 

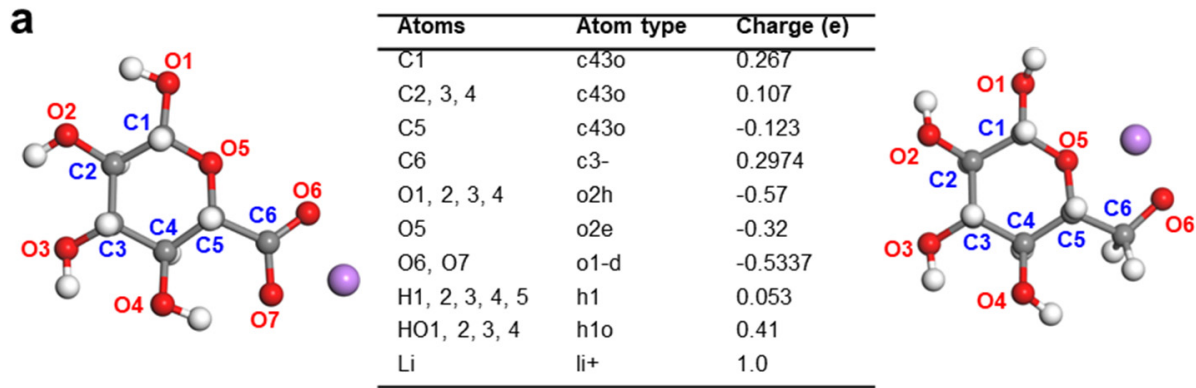

\begin{tabular}{lll}
\hline Atoms & Atom type & Charge (e) \\
\hline C1 & c430 & 0.027 \\
$\mathrm{C} 2,3,4,5$ & $\mathrm{c} 430$ & 0.027 \\
$\mathrm{C} 6$ & $\mathrm{c} 3-$ & 0.054 \\
$\mathrm{O} 1,2,3,4$ & o2h & -0.57 \\
$\mathrm{O} 5$ & o2e & -0.32 \\
$\mathrm{O} 6$ & o1 & -0.60 \\
$\mathrm{H} 1,2,3,4,5$ & $\mathrm{~h} 1$ & 0.053 \\
$\mathrm{HC} 61,62$ & $\mathrm{~h} 1$ & 0.053 \\
$\mathrm{HO} 1,2,3,4$ & $\mathrm{~h} 1 \mathrm{o}$ & 0.41 \\
$\mathrm{Li}$ & li+ & 1.0 \\
\hline
\end{tabular}

b
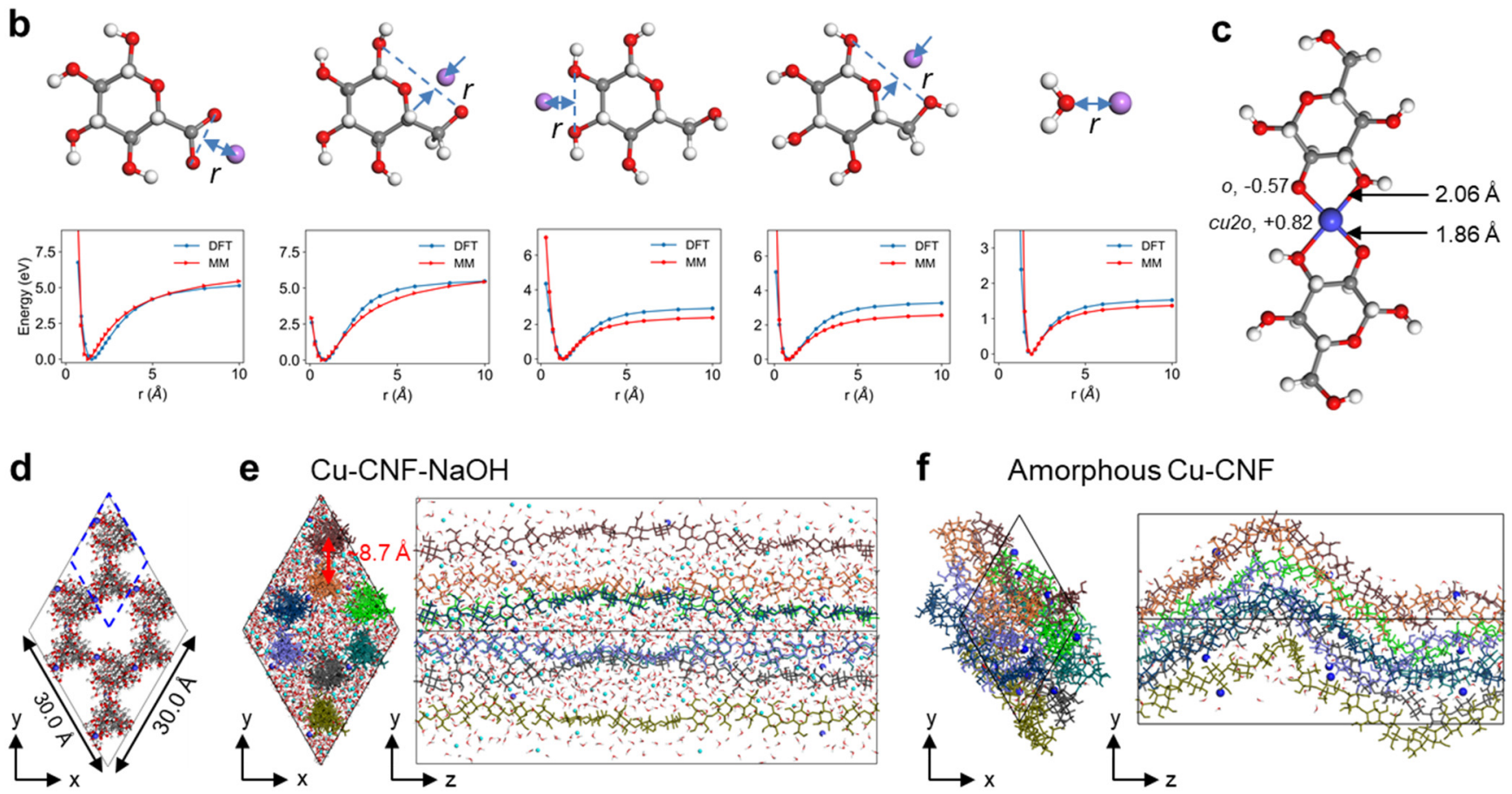

f Amorphous Cu-CNF
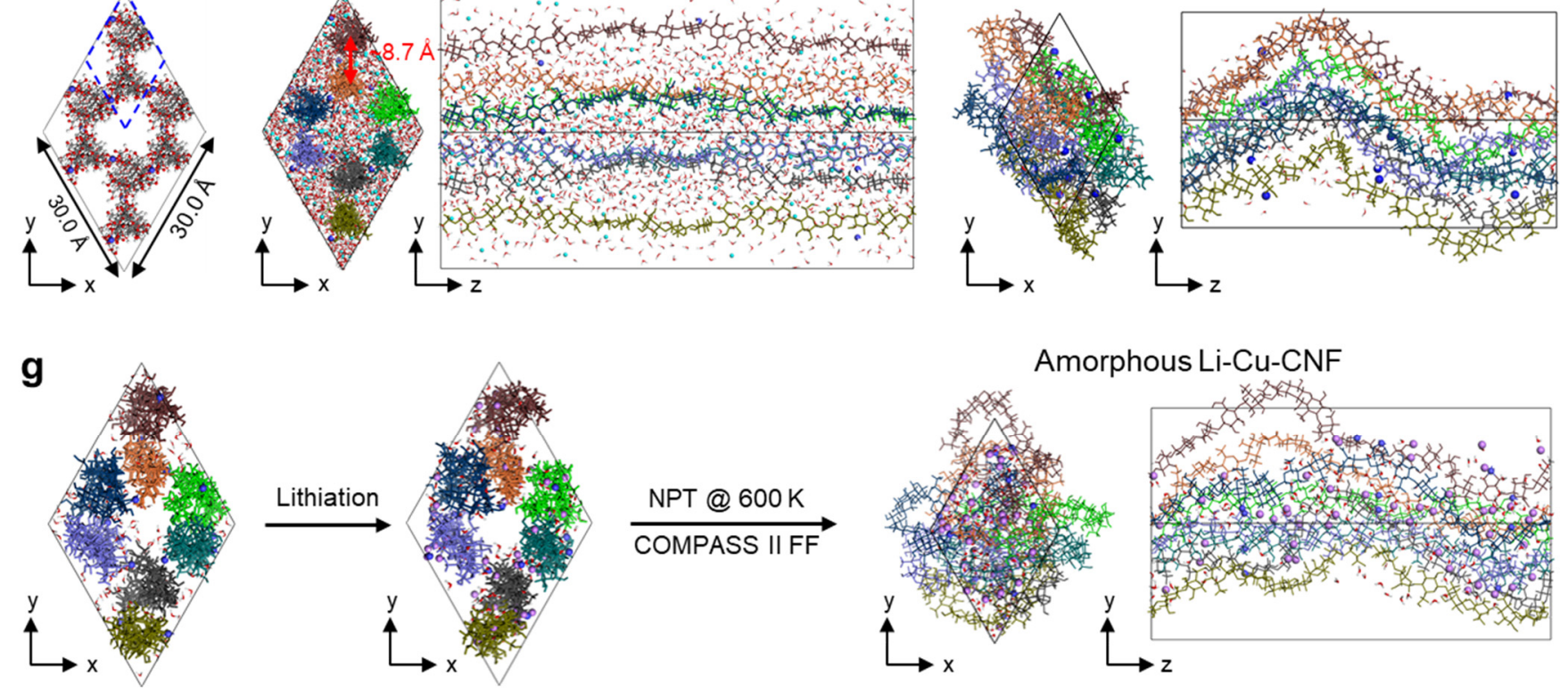

$\odot \mathrm{COH} \odot \mathrm{O} \odot \mathrm{Cu} \odot \mathrm{Li} \bigcirc \mathrm{Na} \rightleftharpoons \mathrm{H}_{2} \mathrm{O}=\mathrm{OH}$

Extended Data Fig. 2 | DFT calculations and MD simulations of the Li-Cu-CNF structure. a, The assigned COMPASS II force field types and atomic charges in typical cellulose units for MD simulations. b, The optimized atomic structures of the representative systems of Li-Cu-CNF used to evaluate interactions between $\mathrm{Li}^{+}$and different oxygen-containing functional groups and water molecules, and corresponding 
energy-distance relationships for different $\mathrm{Li}^{+}$bonding environments given by molecular mechanics 748 calculations using COMPASS II FF and by DFT calculations. The difference between the total system 749 energy at $r=10.0 \AA$ and minimum energy is taken as the $\mathrm{Li}^{+}$dissociation energy. The $\mathrm{Li}^{+}$is strongly bonded 750 with both anionic $\mathrm{COO}^{-}$and $\mathrm{RO}^{-}$groups with dissociation energies of $>5.0 \mathrm{eV}$. The dissociation energy of 751 the $\mathrm{Li}^{+}$is $\sim 3.0 \mathrm{eV}$ for $\mathrm{ROH}$ and $\mathrm{EO}$ groups and $1.5 \mathrm{eV}$ for $\mathrm{H}_{2} \mathrm{O}$ molecules. The strong interactions between 752 the $\mathrm{Li}^{+}$and 1 or 2 oxygen species in cellulose suggest slow $\mathrm{Li}^{+}$movements in the absence of multiple Li-O 753 coordination. In the $\mathrm{H}_{2} \mathrm{O}$ molecule, the $\mathrm{O}$ atom has an atom type of $o 2 *$ and charge of $-0.82 e$, while the $\mathrm{H}$ atom has an atom type of $h l o$ and a charge of $+0.41 e$ for force field calculations. c, To simulate $\mathrm{Cu}^{2+}$ coordination in cellulose, we optimized the atomic structure of two AGUs connected by one $\mathrm{Cu}^{2+}(\mathrm{Cu}-$ $(\mathrm{AGU})_{2}$ system) to serve as a structural building block. Two $\mathrm{H}$ atoms are deprotonated by the $\mathrm{Cu}$. The average optimized $\mathrm{Cu}-\mathrm{O}$ bond length $(1.96 \AA)$ is close to that observed in the experiment $(1.97 \AA)$, and the calculated XANES of the $\mathrm{Cu}-(\mathrm{AGU})_{2}$ system is also in good agreement with the experimental measurement (Extended Data Fig. 1e), showing that our computational model for the structure of the $\mathrm{Cu}-\mathrm{O}$ complex is reasonable. Atom types and atomic charges in force field calculations are given for $\mathrm{Cu}$ and its connected $\mathrm{O}$ atoms, which are categorized as $\mathrm{ROH}$ for statistics (Fig. $3 \mathrm{c}$ in the main text). d, Top view of a $2 \times 2$ supercell of the periodic $\mathrm{Cu}$-coordinated $\mathrm{CNF}$ structure as a starting structure for the simulation, built with the most reasonable model that we proposed based on the fiber XRD pattern (Fig. 2d). Every two nearby cellulose chains are connected by one $\mathrm{Cu}$ atom through the hydroxyl oxygen atoms. The unit cell is denoted by dashed blue lines. e, Top and side views of the $\mathrm{Cu}-\mathrm{CNF}-\mathrm{NaOH}$. f, Top and side views of the $\mathrm{Cu}-\mathrm{CNF}$ obtained by removing $\mathrm{NaOH}$ aqueous solution from $\mathrm{Cu}-\mathrm{CNF}-\mathrm{NaOH}$ and then equilibrating the system with NPT dynamics simulations. In $\mathrm{Cu}-\mathrm{CNF}$, we reserved $144 \mathrm{H}_{2} \mathrm{O}$ molecules to keep an $\mathrm{H}_{2} \mathrm{O}$ :AGU ratio of 1:1. g, Schematic of the computational approach used to obtain the atomic structure of the final amorphous $\mathrm{Li}-\mathrm{Cu}-$ CNF model (top and side views). 

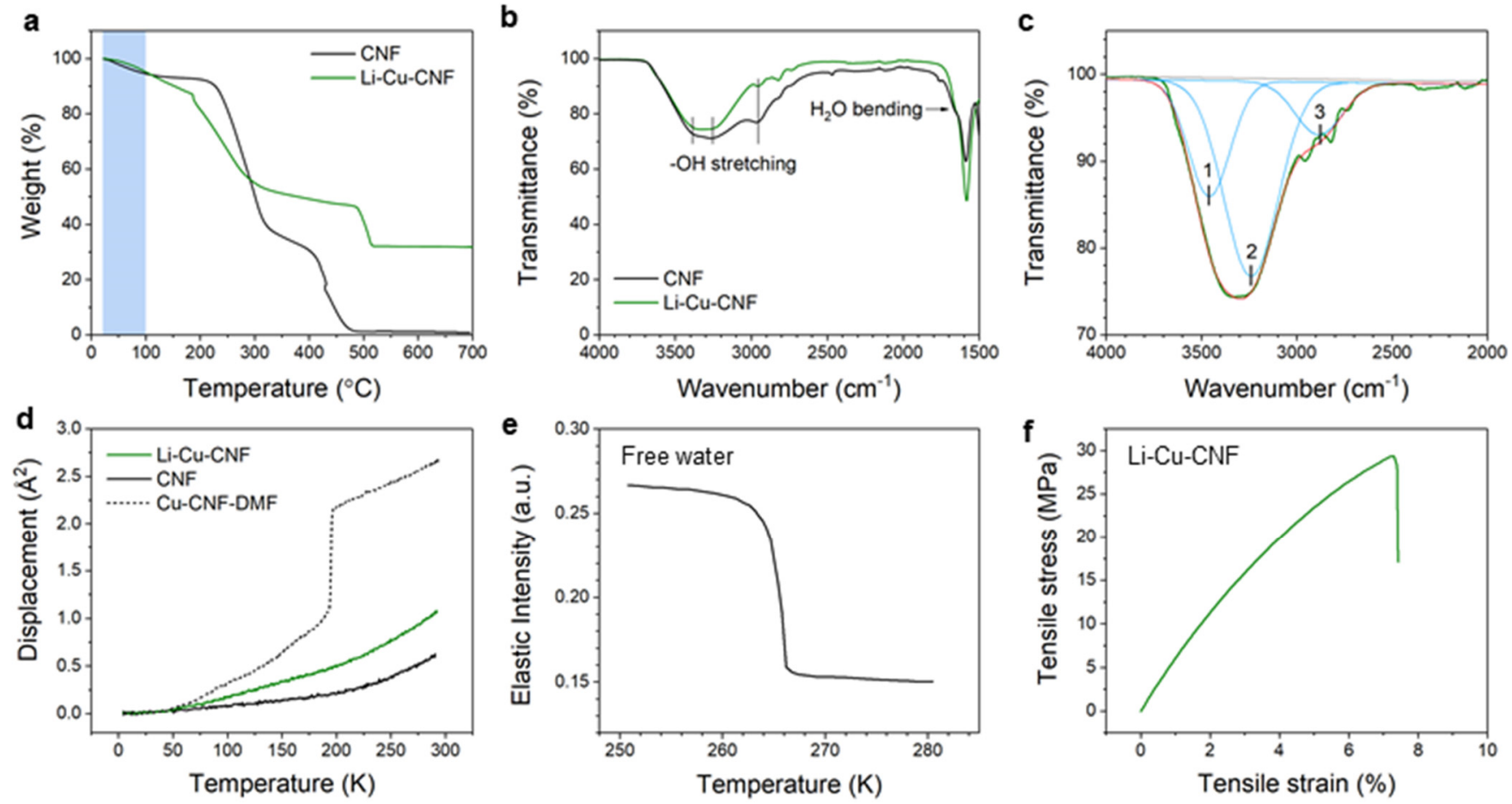

771 Extended Data Fig. 3 | Bound water and mechanical property analysis of Li-Cu-CNF. a,

772 Thermogravimetric analysis (TGA) curves of the CNF starting material and Li-Cu-CNF. b, FTIR of the 773 pristine $\mathrm{CNFs}$ and solid-state $\mathrm{Li}-\mathrm{Cu}-\mathrm{CNF}$ electrolyte. Both the pristine CNFs and Li-Cu-CNF show a broad $774-\mathrm{OH}$ stretching peak at $\sim 3300 \mathrm{~cm}^{-1}$. c, The $-\mathrm{OH}$ stretching peak of Li-Cu-CNF deconvoluted into three bands 775 at 3464,3235 , and $2886 \mathrm{~cm}^{-1}$, which can be assigned to bound water molecules in different hydrogen-

776 bonding states ${ }^{48,49}$. d, The atomic mean-square displacement change in $\mathrm{CNF}$ and Li-Cu-CNF as a function 777 of temperature measured by QENS. The Cu-CNF sample after DMF solvent exchange with some residual DMF (Cu-CNF-DMF) is also shown for comparison. e, The elastic neutron scattering intensity versus the 779 temperature of free water $\left(60 \mu \mathrm{L} \mathrm{H}_{2} \mathrm{O}\right.$ on $\mathrm{Cu}$ foil $)$ upon cooling, obtained from the literature ${ }^{50}$. f, The stress780 strain curve of $\mathrm{Li}-\mathrm{Cu}-\mathrm{CNF}$ along the $\mathrm{CNF}$ fiber direction.

The TGA curves of CNF and Li-Cu-CNF both display $6 \%$ weight loss at $100{ }^{\circ} \mathrm{C}$ (highlighted in blue in 782 Extended Data Fig. 3a), indicating they contain the same amount of bound water. We characterized the 783 bound water by FTIR and QENS. The FTIR spectra of the CNFs and Li-Cu-CNF electrolyte (Extended Data 
784 Fig. 3b) do not show a peak at $3629 \mathrm{~cm}^{-1}$ that would be attributed to "free water" not participating in 785 hydrogen-bonding interactions with the cellulose, nor do the samples feature a peak at $3535 \mathrm{~cm}^{-1}$ due to 786 weakly hydrogen-bonded water ${ }^{48,49}$. Compared with the $-\mathrm{OH}$ stretching peak of free water at $3629 \mathrm{~cm}^{-1}$, the 787 -OH stretching bands of Li-Cu-CNF shift to much lower wavenumbers $\left(3464,3235\right.$, and $2886 \mathrm{~cm}^{-1}$, 788 Extended Data Fig. 3c), which indicates stronger water-cellulose interactions through multiple hydrogen 789 bonding. In addition, we attribute the weak peak at $1640 \mathrm{~cm}^{-1}$ to $-\mathrm{OH}$ bending of bound water in the 790 cellulose,$^{51}$ further suggesting that water is bound in the CNFs and Li-Cu-CNF electrolyte.

791 The QENS spectra (Extended Data Fig. 3d) show that the Cu-CNF with a small amount of residual DMF 792 solvent (Cu-CNF-DMF) features a drastic decrease of the displacement near $195 \mathrm{~K}$, slightly below the 793 freezing point of DMF (212 K). This characteristic change due to DMF is not seen in $\mathrm{Li}-\mathrm{Cu}-\mathrm{CNF}$, indicating 794 the Li-Cu-CNF is DMF-free. Meanwhile, the elastic scan of free water when cooling shows an abrupt 795 intensity increase near $266 \mathrm{~K}$ (Extended Data Fig. 3e). In contrast, no sharp change near $266 \mathrm{~K}$ is observed 796 in the CNF or Li-Cu-CNF samples (Extended Data Fig. 3d), indicating there is no free water in the Li-Cu797 CNF electrolyte.

798 The amorphous Li-Cu-CNF material without free water or DMF solvent displays good mechanical 799 properties as a solid-state electrolyte. A high tensile stress of 29.2 MPa is achieved in Li-Cu-CNF (Extended 800 Data Fig. 3f), which is stronger than most reported SPEs ${ }^{52-56}$. 

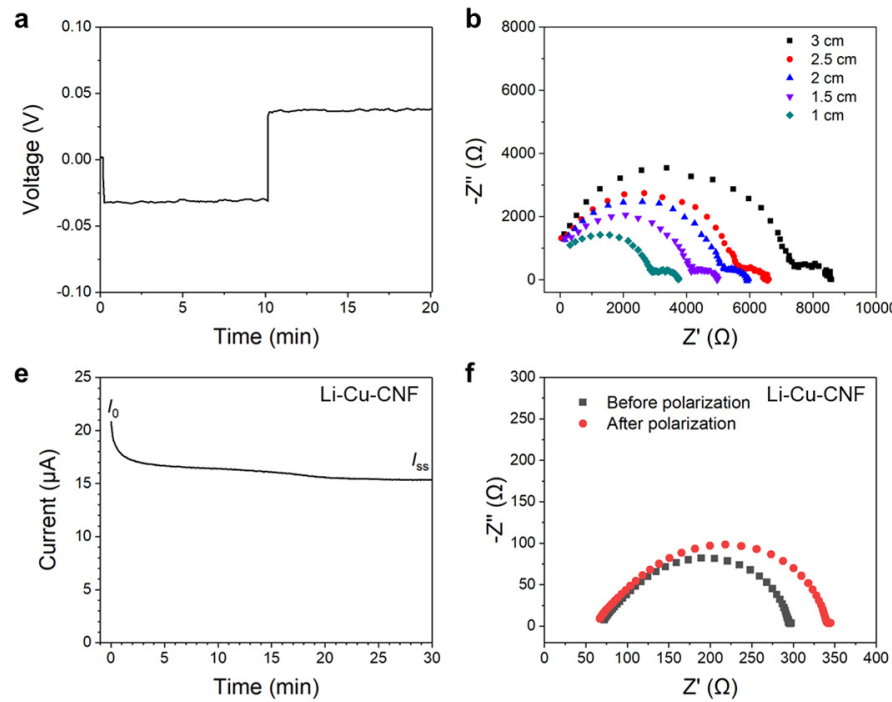

i

$\begin{array}{llllll}\Delta V(\mathrm{mV}) & I_{0}(\mu \mathrm{A}) & l_{\mathrm{ss}}(\mu \mathrm{A}) & R_{0}(\Omega) & R_{\mathrm{ss}}(\Omega) & t_{\mathrm{Li}}\end{array}$

801 10 20.8

Li-CNF

10

7.96

5.19
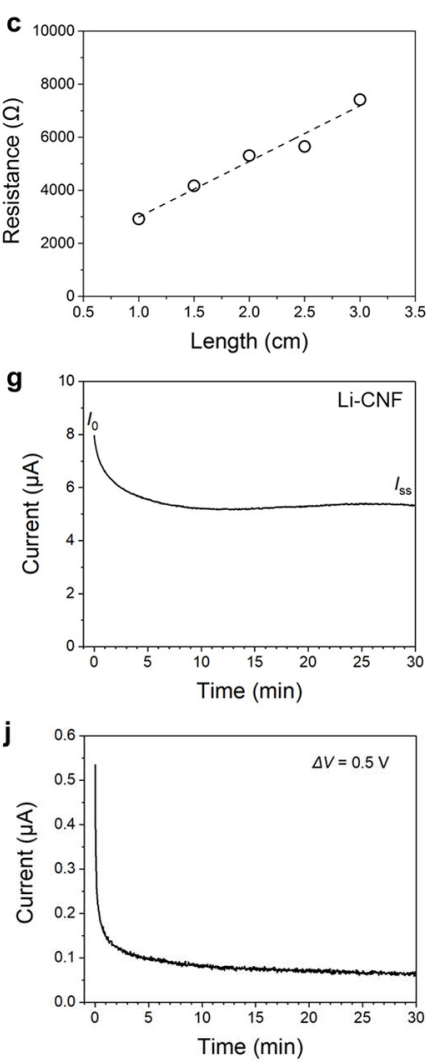

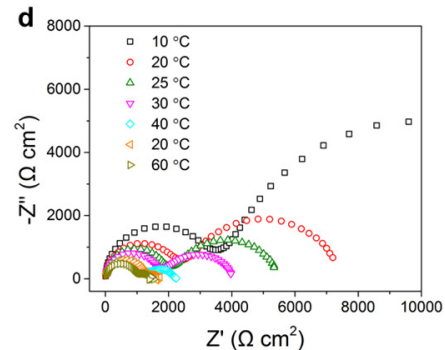

h
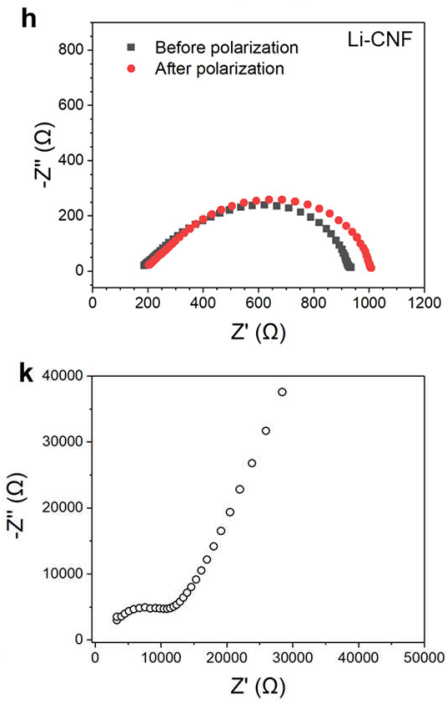

\section{Extended Data Fig. 4 | The ionic conductivities and transference numbers of Li-Cu-CNF and Li-CNF.}

a, Voltage profile of the galvanostatic Li plating and stripping between two ends of the Li-Cu-CNF with aligned cellulose fibers (length: $1 \mathrm{~cm}$ ) at $0.01 \mathrm{~mA}$. b, EIS Nyquist plots of aligned Li-Cu-CNF materials of different lengths, ranging from $1 \mathrm{~cm}$ to $3 \mathrm{~cm}$, for measuring the intrinsic conductivity of Li-Cu-CNF along the cellulose molecular chain direction. $\mathbf{c}$, The resistance corresponding to the high-frequency semi-circle in b of the aligned Li-Cu-CNF with different lengths. d, EIS Nyquist plots of the aligned Li-Cu-CNF with a length of $3 \mathrm{~cm}$ and cross-sectional area of $0.03 \mathrm{~cm}^{2}$ at different temperatures, ranging from $10{ }^{\circ} \mathrm{C}$ to $60{ }^{\circ} \mathrm{C}$. e, DC polarization curve and $\mathbf{f}$, EIS Nyquist plots before and after polarization of the $\mathrm{Li}|\mathrm{Li}-\mathrm{Cu}-\mathrm{CNF}| \mathrm{Li}$ cell. g, DC polarization curve and $\mathbf{h}$, EIS Nyquist plots before and after polarization of the Li|Li-CNF $\mid \mathrm{Li}$ cell. $\mathbf{i}$, Table showing the parameters measured by DC polarization and EIS for calculating the $\mathrm{Li}^{+}$transference 812 number. $\mathbf{j}, \mathbf{k}$, The conductivity of the $\mathrm{Cu}^{2+}$ in the $\mathrm{Li}-\mathrm{Cu}-\mathrm{CNF}$ electrolyte measured by $\mathbf{j}$, DC polarization and $813 \mathbf{k}$, AC (EIS) methods in a $\mathrm{Cu}|\mathrm{Cu}-\mathrm{CNF}| \mathrm{Cu}$ cell. 
We first confirmed the $\mathrm{Li}^{+}$transport along the direction of the $\mathrm{Li}-\mathrm{Cu}-\mathrm{CNF}$ ion conductor by the 815 galvanostatic Li plating/stripping cycling (Extended Data Fig. 4a) between two ends of the aligned Li-Cu816 CNF membrane (length: $1 \mathrm{~cm}$ ) at room temperature. To distinguish the resistances of the electrolyte and Li817 electrolyte interface, we measured the EIS of the same Li-Cu-CNF membrane at different lengths (Extended 818 Data Fig. 4b). The EIS spectra of the Li-Cu-CNF ion conductor shows two semi-circles, which are attributed 819 to the electrolyte and interface resistance. The semi-circle at the high-frequency region increases linearly as 820 we increase the electrolyte length from $1 \mathrm{~cm}$ to $3 \mathrm{~cm}$ (Extended Data Fig. 4c). Thus, the high-frequency 821 semi-circle is attributed to the resistance of the $\mathrm{Li}-\mathrm{Cu}-\mathrm{CNF}$ electrolyte. The calculated $\mathrm{Li}^{+}$conductivity of 822 Li-Cu-CNF at different temperatures (Extended Data Fig. 4d) is plotted in Fig. 3a, following the Arrhenius823 type relationship.

$824 \quad \mathrm{The}^{+} \mathrm{i}^{+}$transference numbers $\left(t_{\mathrm{Li}}\right)$ in $\mathrm{Li}-\mathrm{Cu}-\mathrm{CNF}$ and $\mathrm{Li}-\mathrm{CNF}$ (without $\mathrm{Cu}$ coordination) were measured 825 based on the Bruce-Vincent method ${ }^{28}$. The DC polarization measurements were conducted with a potential 826 of $\Delta V=10 \mathrm{mV}$ in the $\mathrm{Li}|\mathrm{Li}-\mathrm{Cu}-\mathrm{CNF}| \mathrm{Li}$ and $\mathrm{Li}|\mathrm{Li}-\mathrm{CNF}| \mathrm{Li}$ cells until the current reached a steady state, 827 and the corresponding EIS measurements were collected before and after the DC polarization (Extended 828 Data Fig. 4e-h). $t_{\mathrm{Li}}$ was calculated according to $t_{\mathrm{Li}}=\frac{I_{\mathrm{SS}}\left(\Delta V-I_{0} R_{0}\right)}{I_{0}\left(\Delta V-I_{\mathrm{SS}} R_{\mathrm{SS}}\right)}$, where $\Delta V$ is the applied potential, $I_{0}$ is the 829 initial current, $R_{0}$ is the initial resistance, $I_{\mathrm{ss}}$ is the steady-state current, and $R_{\mathrm{ss}}$ is the steady-state resistance. 830 The measured results of these parameters are listed in Extended Data Fig. 4i.

831 We measured the $\mathrm{Cu}$-ion conductivity in a $\mathrm{Cu}|\mathrm{Cu}-\mathrm{CNF}| \mathrm{Cu}$ cell to enable only $\mathrm{Cu}^{2+}$ transport, which 832 was $1 \times 10^{-8} \mathrm{~S} \mathrm{~cm}^{-1}$ using the DC method (Extended Data Fig. $4 \mathrm{j}$ ) and $5 \times 10^{-7} \mathrm{~S} \mathrm{~cm}^{-1}$ as measured by the 833 AC technique (Extended Data Fig. 4k), much lower than the $\mathrm{Li}^{+}$conductivity in Li-Cu-CNF. Therefore, the 834 ionic conductivity of Li-Cu-CNF is contributed by the material's $\mathrm{Li}^{+}$rather than $\mathrm{Cu}^{2+}$. 

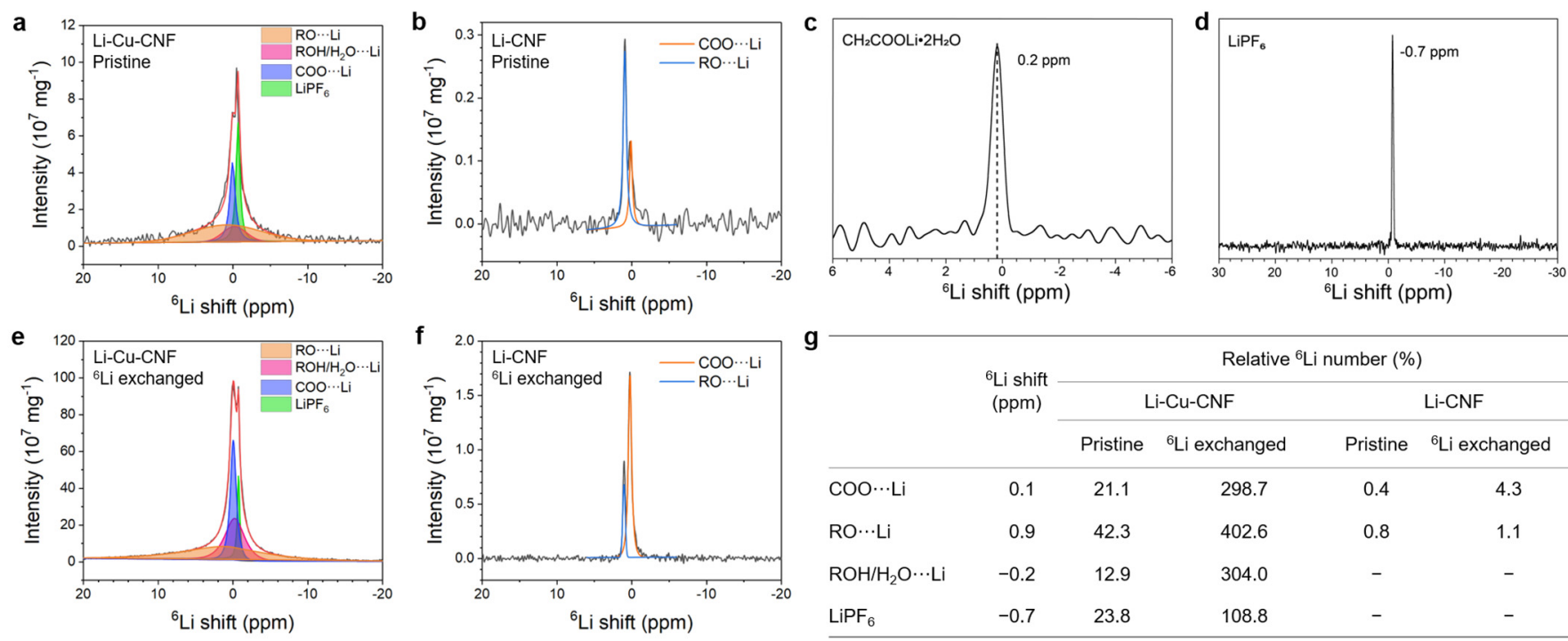

\begin{tabular}{|c|c|c|c|c|c|}
\hline & \multirow{3}{*}{$\begin{array}{l}{ }^{6} \text { Li shift } \\
\text { (ppm) }\end{array}$} & \multicolumn{4}{|c|}{ Relative ${ }^{6} \mathrm{Li}$ number $(\%)$} \\
\hline & & \multicolumn{2}{|c|}{ Li-Cu-CNF } & \multicolumn{2}{|r|}{ Li-CNF } \\
\hline & & Pristine & ${ }^{6} \mathrm{Li}$ exchanged & Pristine & ${ }^{6}$ Li exchanged \\
\hline $\mathrm{COO} \cdots \mathrm{Li}$ & 0.1 & 21.1 & 298.7 & 0.4 & 4.3 \\
\hline $\mathrm{RO} \cdots \mathrm{Li}$ & 0.9 & 42.3 & 402.6 & 0.8 & 1.1 \\
\hline $\mathrm{ROH} / \mathrm{H}_{2} \mathrm{O} \cdots \mathrm{Li}$ & -0.2 & 12.9 & 304.0 & - & - \\
\hline $\mathrm{LiPF}_{6}$ & -0.7 & 23.8 & 108.8 & - & - \\
\hline
\end{tabular}

Extended Data Fig. 5 | NMR analysis of the Li coordination environment and diffusion pathway. a, b,

837 The ${ }^{6} \mathrm{Li}$ NMR spectra and simulations of $\mathbf{a}, \mathrm{Li}-\mathrm{Cu}-\mathrm{CNF}$ and $\mathbf{b}, \mathrm{Li}-\mathrm{CNF}$. c, d, The ${ }^{6} \mathrm{Li}$ NMR spectra of $\mathbf{c}$, $838 \mathrm{CH}_{2} \mathrm{COOLi} \cdot 2 \mathrm{H}_{2} \mathrm{O}$ and $\mathbf{d}, \mathrm{LiPF}_{6}$ as references for the $\mathrm{COO} \cdots \mathrm{Li}$ and $\mathrm{LiPF} 6$ peak assignments in $\mathrm{Li}-\mathrm{Cu}-\mathrm{CNF}$.

e, $\mathbf{f}$, The ${ }^{6} \mathrm{Li}$ NMR spectra and simulations of $\mathbf{e}, \mathrm{Li}-\mathrm{Cu}-\mathrm{CNF}$ and $\mathbf{f}, \mathrm{Li}-\mathrm{CNF}$ after ${ }^{6} \mathrm{Li} \rightarrow{ }^{7} \mathrm{Li}$ tracer exchange,

840 which was performed by cycling Li-Cu-CNF or Li-CNF electrolyte (natural abundance: $92.4 \%{ }^{7} \mathrm{Li}$ and $7.6 \%$

$841{ }^{6} \mathrm{Li}$ ) between two ${ }^{6} \mathrm{Li}$-enriched metal electrodes (i.e., symmetric ${ }^{6} \mathrm{Li}|\mathrm{Li}-\mathrm{Cu}-\mathrm{CNF}|{ }^{6} \mathrm{Li}$ cells). g, Table

842 showing the amount of $\mathrm{Li}^{+}$in different chemical environments in $\mathrm{Li}-\mathrm{Cu}-\mathrm{CNF}$ and $\mathrm{Li}-\mathrm{CNF}$ before and after $843{ }^{6} \mathrm{Li} \rightarrow{ }^{7} \mathrm{Li}$ tracer exchange, derived from the relative spectral areal integral of the ${ }^{6} \mathrm{Li}$ resonances in the NMR 844 spectra shown in $\mathbf{a}, \mathbf{b}, \mathbf{e}$, and $\mathbf{f}$. 


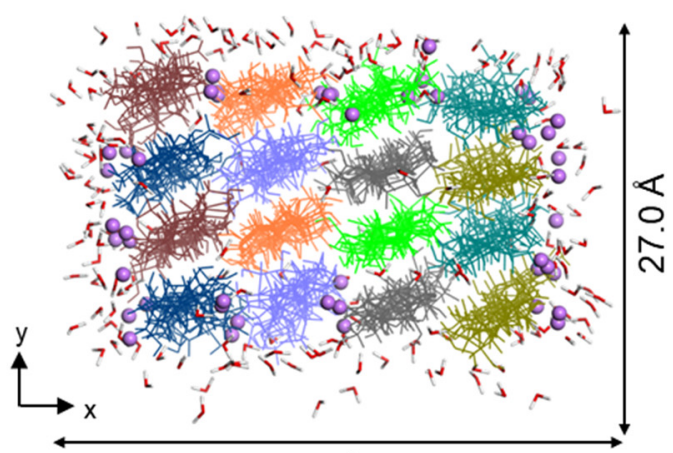

$37.0 \AA$

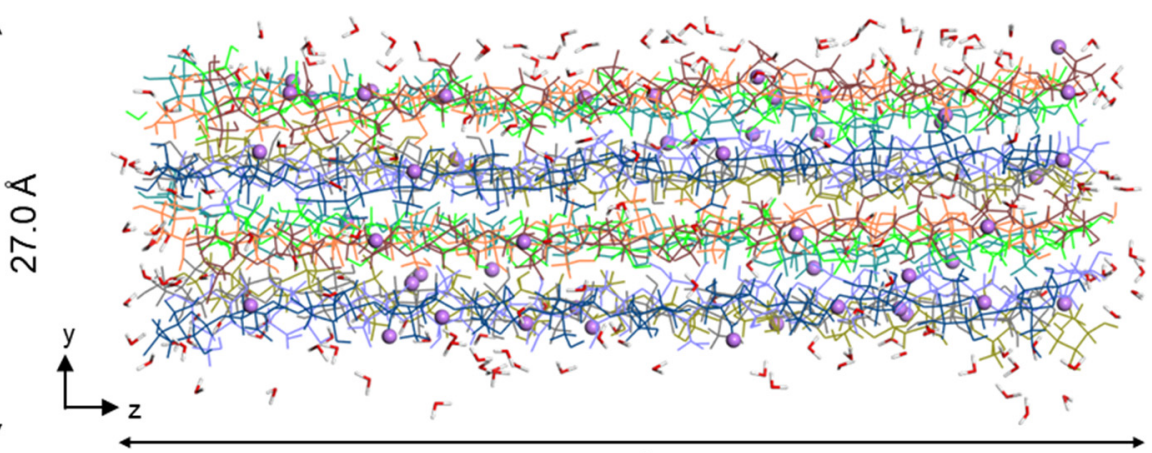

$62.0 \AA$

846 Extended Data Fig. 6 | Simulated structure of Li-CNF by MD. The Li-CNF system consists of 16 847 cellulose chains surrounded by $\mathrm{Li}^{+}$and water molecules. Different chains are denoted by different colors.

$848 \mathrm{Li}^{+}$ions are indicated by purple spheres and water molecules are presented as stick models. The size of the

849 Li-CNF system is given roughly. The simulations show that without the participation of $\mathrm{Cu}^{2+}, \mathrm{the}^{+} \mathrm{ind}^{+}$and 850 water molecules only adsorb on the surface of the cellulose structures. This structure leads to the low MSD 851 of the $\mathrm{Li}^{+}$in $\mathrm{Li}-\mathrm{CNF}$, as shown in Fig $3 \mathrm{i}$. 

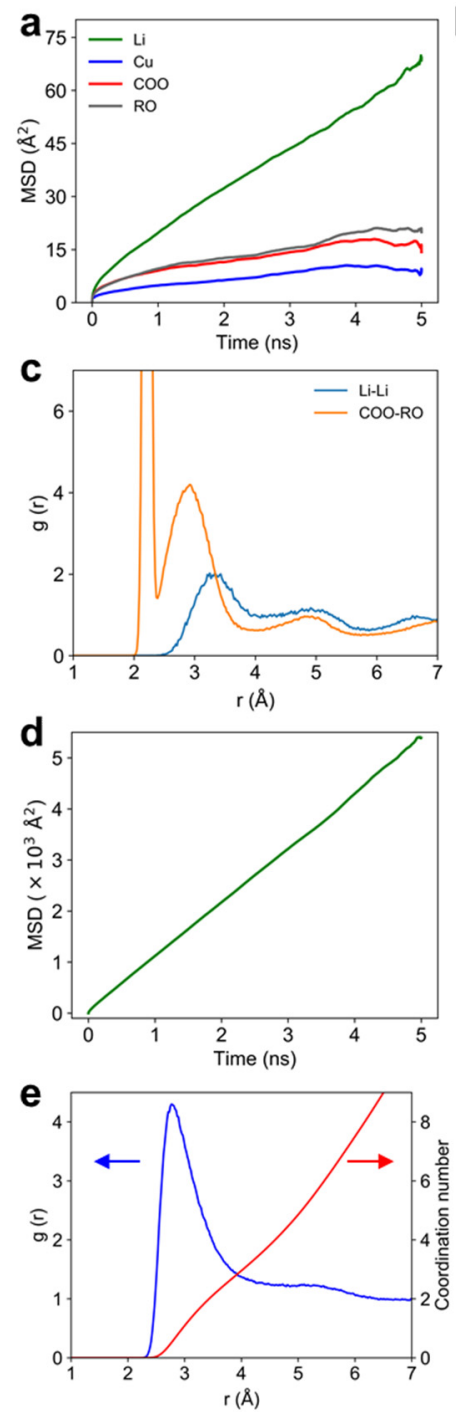
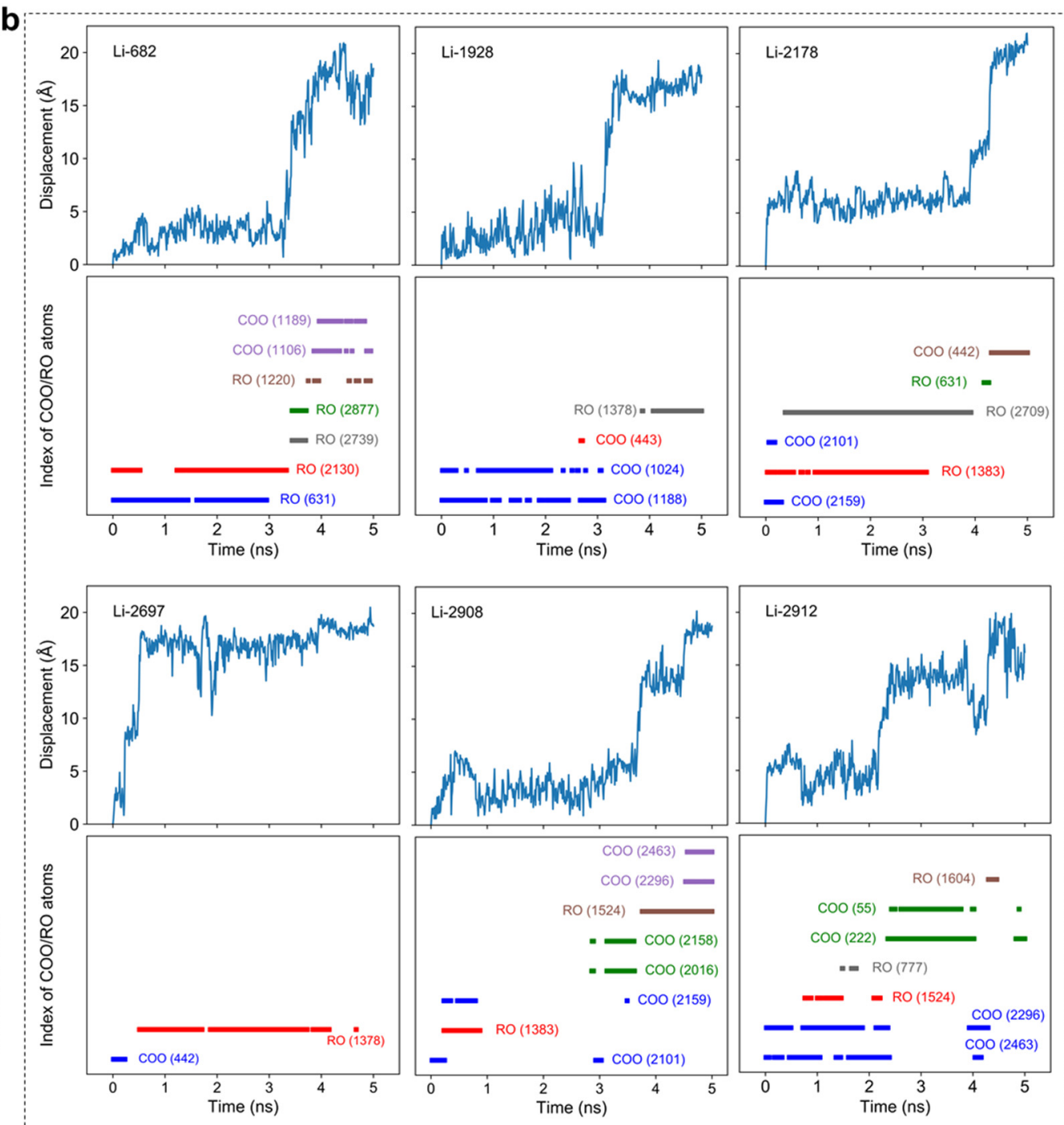

Extended Data Fig. 7 | Numerical analyses of molecular dynamics simulations. a, MSD plots for $\mathrm{Li}^{+}$,

$\mathrm{COO}^{-}$and $\mathrm{RO}^{-}$groups, and $\mathrm{Cu}^{2+}$ in the model (Fig. 2i and Extended Data Fig. 2g), which features an $\mathrm{H}_{2} \mathrm{O}$ :AGU ratio of 1:1 (obtained from TGA curves, as shown in Extended Data Fig. 3a). The average MSD plots show that $\mathrm{Li}^{+}$move fast while $\mathrm{COO}^{-}$and $\mathrm{RO}^{-}$groups and $\mathrm{Cu}^{2+}$ in the $\mathrm{Li}-\mathrm{Cu}-\mathrm{CNF}$ backbone move 857 much slower. $\mathbf{b}$, Displacement plots of six $\mathrm{Li}^{+}$in the simulation that have displacements of $>15.0 \AA$, and the 858 index of $\mathrm{COO} / \mathrm{RO}$ atoms that are bonded to the $\operatorname{six~} \mathrm{Li}^{+}$( $\mathrm{Li}-\mathrm{O}$ distance $<2.5 \AA$ ). $\mathbf{c}$, Radial distribution 859 functions (RDF) for $\mathrm{Li}-\mathrm{Li}$ and $\mathrm{COO}-\mathrm{RO}$ pairs in $\mathrm{Li}-\mathrm{Cu}-\mathrm{CNF}$ with an $\mathrm{H}_{2} \mathrm{O}: \mathrm{AGU}$ ratio of 1:1. The locations 860 of the first peak of the Li-Li pair and the second peak of the COO-RO pair indicate the hopping distance 
861 ( $\sim 3.0 \AA)$ between the residence sites. The first peak of the COO-RO pair indicates the distance between the 862 two $\mathrm{O}$ atoms within the same $\mathrm{COO}$ group. d, MSD plot of water molecules for the $\mathrm{Li}-\mathrm{Cu}-\mathrm{CNF}$ system, which

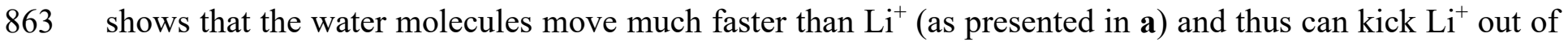
864 the residence sites. e, Radial distribution function and coordination number plots for the $\mathrm{H}_{2} \mathrm{O}-\mathrm{H}_{2} \mathrm{O}$ pairs of 865 the bound water in $\mathrm{Li}-\mathrm{Cu}-\mathrm{CNF}$.

866 The diffusion coefficients of $\mathrm{Li}^{+}, \mathrm{COO}^{-}$, and $\mathrm{RO}^{-}$were computed according to $D=\frac{\mathrm{MSD}}{6 \Delta t}$, where the 867 linear diffusion region of the MSD plot (Extended Data Fig. 7a) was used ${ }^{32}$ and $\Delta t$ was the time interval. 868 The calculated diffusion coefficients in the simulated $\mathrm{Li}-\mathrm{Cu}-\mathrm{CNF}$ for the $\mathrm{Li}^{+}, \mathrm{COO}^{-}$, and $\mathrm{RO}^{-}$were $D_{\mathrm{Li}^{+}}=$ 869 $2.03 \times 10^{-7} \mathrm{~cm}^{2} \mathrm{~s}^{-1}, D_{\mathrm{COO}^{-}}=0.49 \times 10^{-7} \mathrm{~cm}^{2} \mathrm{~s}^{-1}$, and $D_{\mathrm{RO}^{-}}=0.56 \times 10^{-7} \mathrm{~cm}^{2} \mathrm{~s}^{-1}$, respectively, at $600 \mathrm{~K}$. The 870 transference number was calculated to be 0.80 based on its definition $t_{\mathrm{Li}^{+}}=D_{\mathrm{Li}^{+}} /\left(D_{\mathrm{Li}^{+}}+D_{\text {anion }}\right)$, where $871 D_{\text {anion }}$ is the average diffusion coefficient for the $\mathrm{COO}^{-}$and $\mathrm{RO}^{-}$anions. The calculated transference number 872 is in good agreement with the experimental value of 0.78 . The $\mathrm{Li}^{+}$conductivities at temperatures of $500 \mathrm{~K}$, $873600 \mathrm{~K}$, and $700 \mathrm{~K}$ were calculated based on $\sigma=\frac{n e^{2} D}{k T}$, where $n$ is the volume concentration of $\mathrm{Li}^{+}, e$ is the 874 electron charge, $k$ is the Boltzmann constant, and $T$ is the absolute temperature. Then, the ionic conductivities 875 were fitted with the Arrhenius equation $\sigma=A e^{\frac{-E a}{k T}}$, where $A$ is a pre-exponential factor (constant), $k$ is the 876 Boltzmann constant, and $E_{\mathrm{a}}$ is the activation energy. The calculated activation energy in Li-Cu-CNF was $8770.31 \mathrm{eV}$, slightly larger than the experimental value $(0.19 \mathrm{eV})$, likely due to overestimation of the Li-O 878 interactions by the force field.

Our computational modeling system of Li-Cu-CNF (as shown in Fig. 2i and Extended Data Fig. 2g) 880 contains a total of 3420 atoms, among which there are $48 \mathrm{Li}$ atoms and $888 \mathrm{O}$ atoms. Each atom is labeled 881 with a number between 1 and 3420 . For example, the $\mathrm{Li}^{+}$labeled with the number 682 is denoted as $\mathrm{Li}-682$. $882 \mathrm{Six} \mathrm{Li}^{+}$ions (Li-682, Li-1928, Li-2178, Li-2697, Li-2908, and Li-2912) have displacements of > $15.0 \AA$, 
883 and their MSD plots are given in Extended Data Fig. 7b. All the MSD plots show an abrupt increase at 884 certain moments, indicating the hopping of the $\mathrm{Li}^{+}$. The $\mathrm{COO}$ and $\mathrm{RO}$ atoms that are bonded with the selected $885 \mathrm{Li}^{+}$are shown in Extended Data Fig. $7 \mathrm{~b}$ as well. The simulation results indicate that $\mathrm{Li}^{+}$diffuses via hopping 886 between $\mathrm{COO}$ and $\mathrm{RO}$ groups instead of continuous movement coupled with chain segment motion.

887 The $\mathrm{COO} / \mathrm{RO}$ atoms are residence sites for $\mathrm{Li}^{+}$, and the $\mathrm{RDF}$ plot for the $\mathrm{COO} / \mathrm{RO}$ pairs is given in 888 Extended Data Fig. 7c. The first peak at $2.2 \AA$ represents the distance between the two oxygen atoms in one 889 COO group, while the second peak at $\sim 3.0 \AA$ gives the average distance between oxygen atoms in 890 neighboring COO/RO groups, which is indicative of the hopping distance. The RDF plot for the Li-Li pair 891 shows that the average Li-Li distance is $\sim 3.3 \AA$, close to the hopping distance.

892 The single coordination sphere in RDF and low coordination number $(<2)$ in Extended Data Fig. 7e 893 indicate the $\mathrm{H}_{2} \mathrm{O}$ molecules are isolated (gas-like) and do not form a liquid phase. The typical narrow 894 electrochemical window of bulk water $(<1.5 \mathrm{~V})$ is due to the presence of $\mathrm{H}^{+}\left(\mathrm{H}_{3} \mathrm{O}^{+}\right)$and $\mathrm{OH}^{-}$, as the $\mathrm{H}^{+}$and $895 \mathrm{H}_{3} \mathrm{O}^{+}$species are easily reduced, while $\mathrm{OH}^{-}$can be easily oxidized. In contrast, the isolated neutral $\mathrm{H}_{2} \mathrm{O}$ 896 molecules in Li-Cu-CNF do not easily gain or lose electrons and are thus electrochemically stable ${ }^{33}$. 


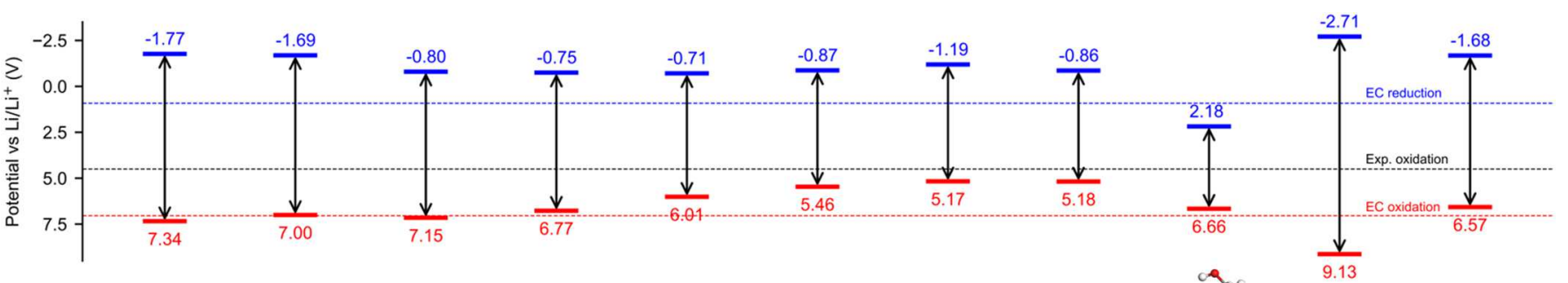

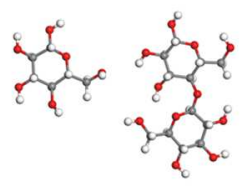

1

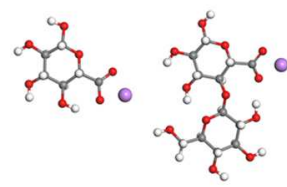

3

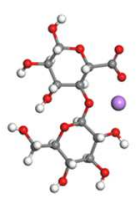

5

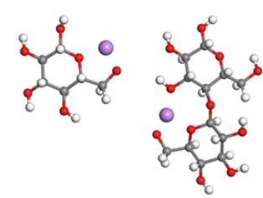

6

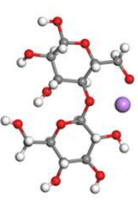

8

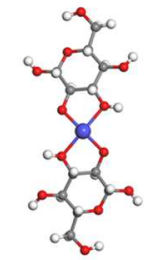

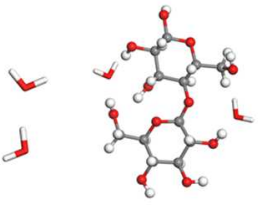

$10 \quad 11$

899 Extended Data Fig. 8 | Computations of the redox potentials. (Top) Reduction and oxidation potentials

900 (vs. $\mathrm{Li}^{+} / \mathrm{Li}$ ) obtained from DFT calculations for (bottom) different structures representative of the cellulose 901 and Li-Cu-CNF systems, including (1) glucose, (2) AGU dimer, (3) AGU-COOLi, (4) and (5) two isomers of (AGU) $2-\mathrm{COOLi},(6) \mathrm{AGU}-\mathrm{CH}_{2} \mathrm{Oli},(7)$ and (8) two isomers of (AGU) ${ }_{2}-\mathrm{CH}_{2} \mathrm{Oli}$, (9) $\mathrm{Cu}-(\mathrm{AGU})_{2},(10) \mathrm{H}_{2} \mathrm{O}$ 903 dimer, and (11) $(\mathrm{AGU})_{2}-\left(\mathrm{H}_{2} \mathrm{O}\right)_{2}$. The $\mathrm{C}, \mathrm{H}, \mathrm{O}, \mathrm{Li}$, and $\mathrm{Cu}$ atoms are represented by grey, white, red, purple, 904 and blue spheres, respectively. The experimental oxidation potential for the Li-Cu-CNF system (black) and the redox potentials for ethylene carbonate (EC, red and blue) are denoted with dashed lines for reference. 906 The water molecules are depicted with stick models. The redox potentials $\mathrm{vs} . \mathrm{Li}^{+} / \mathrm{Li}$ were calculated as $E_{\mathrm{re}}=$ $907-\frac{G_{A}-G_{N}}{F}-1.4$ and $E_{\mathrm{ox}}=\frac{G_{C}-G_{N}}{F}-1.4$, respectively. Here $G_{N}, G_{A}$, and $G_{C}$ denote the Gibbs free energies for 908 the optimized neutral species and corresponding anion and cation species, respectively. $F$ is the Faraday 909 constant. The temperature was set at $298 \mathrm{~K}$.

910 The calculation results show that almost all the representative structures have low reduction potentials 911 and high oxidation potentials. One exception is that the $\mathrm{Cu}-(\mathrm{AGU}) 2$ system could be reduced (with a 912 reduction potential of $2.18 \mathrm{~V}$ vs. $\mathrm{Li}^{+} / \mathrm{Li}$ ). Since the $\mathrm{Cu}^{2+}$ has a low concentration and are mainly coordinated 913 inside the $\mathrm{Li}-\mathrm{Cu}-\mathrm{CNF}$, the reduction of the $\mathrm{Cu}-\mathrm{O}$ complex is likely to be passivated by a solid electrolyte 914 interphase layer when contacting anode materials (e.g., a Li metal anode). 
a

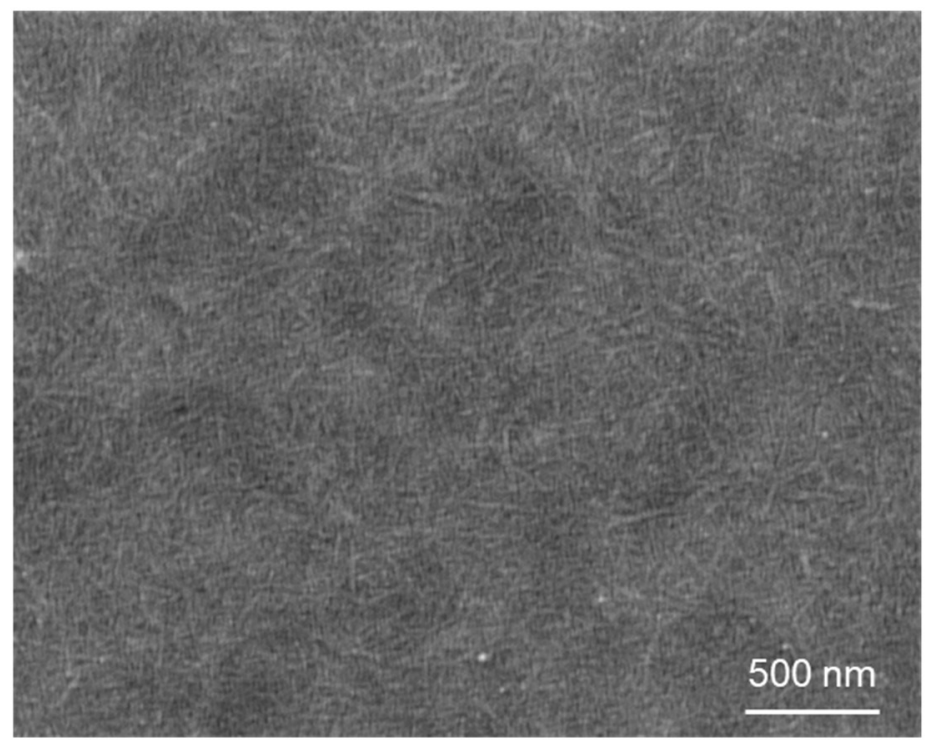

C

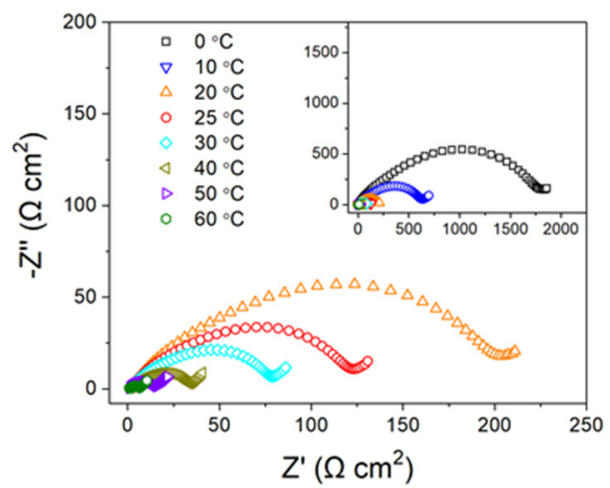

b

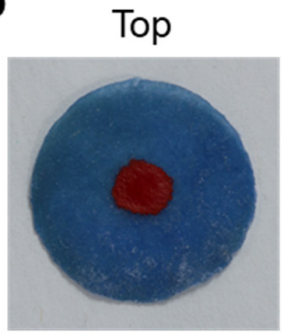

Back

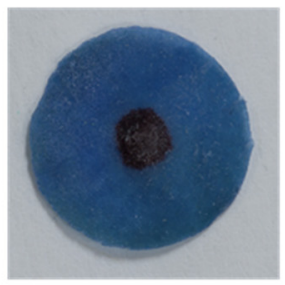

$1000 / \mathrm{T}\left(\mathrm{K}^{-1}\right)$
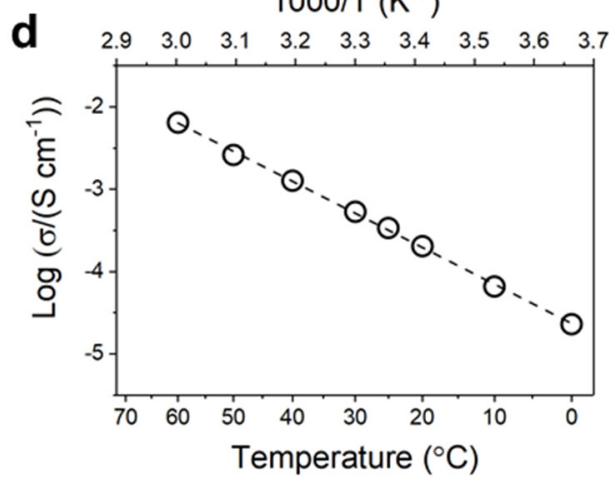

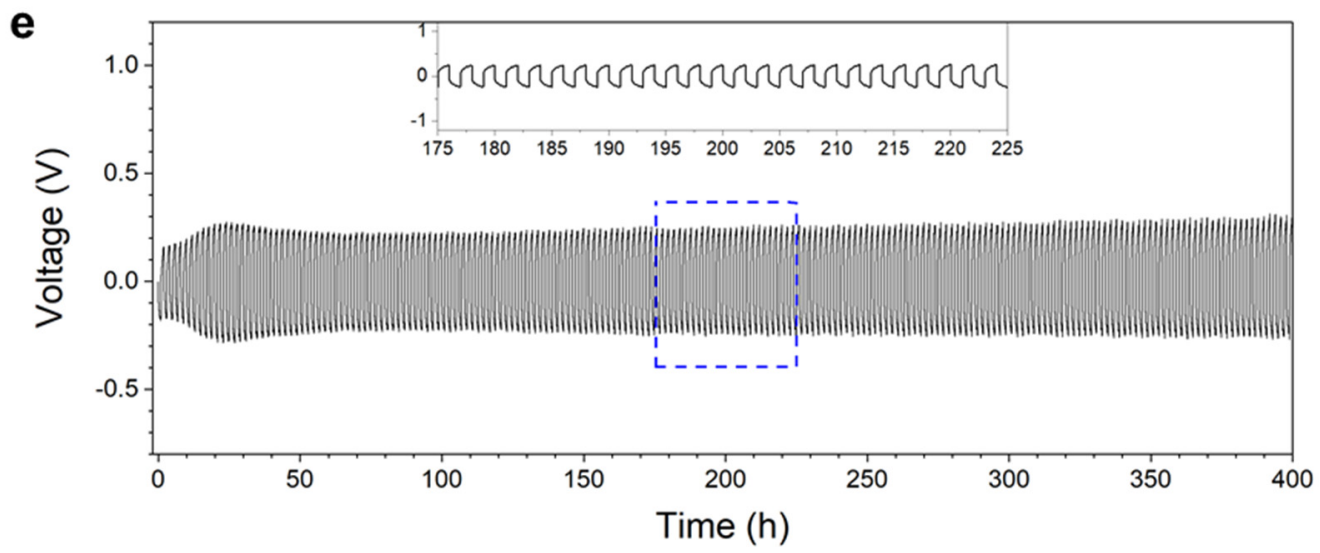

916 Extended Data Fig. 9 | Li-Cu-CNF film electrolyte and its electrochemical performance. a, Top view

917 SEM image of the Li-Cu-CNF film electrolyte. b, Digital photos (top and back) of a permeability test of the

918 Li-Cu-CNF film electrolyte to demonstrate the film's denseness. The electrolyte prevents liquid dye added 
919 to the top of the film from permeating to the back (from the back, only a dark shadow of the dye on top is 920 seen through the translucent film). c, EIS Nyquist plot of the Li-Cu-CNF film electrolyte at different 921 temperatures and d, the corresponding Arrhenius plot. The Li-Cu-CNF film electrolyte shows an overall 922 ionic conductivity of $3.4 \times 10^{-4} \mathrm{~S} \mathrm{~cm}^{-1}$ at room temperature. e, The Li plating/stripping cycling performance 923 of the Li-Cu-CNF film electrolyte at $0.5 \mathrm{~mA} \mathrm{~cm}^{-2}$, with $1 \mathrm{~h}$ for each plating/stripping half cycle, for a total 924 of $400 \mathrm{~h}$ at room temperature. 
a

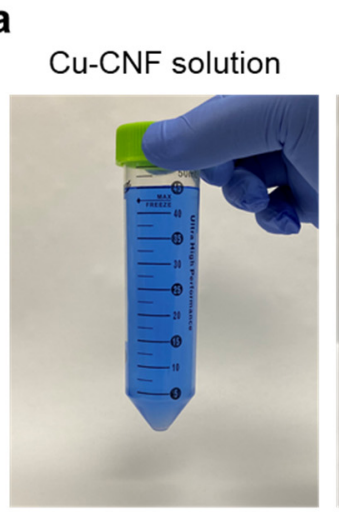

\section{b}

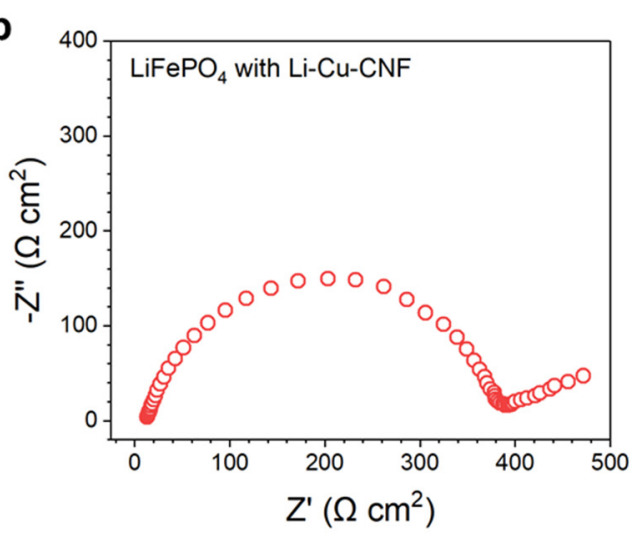

d

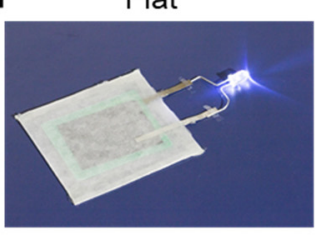

e

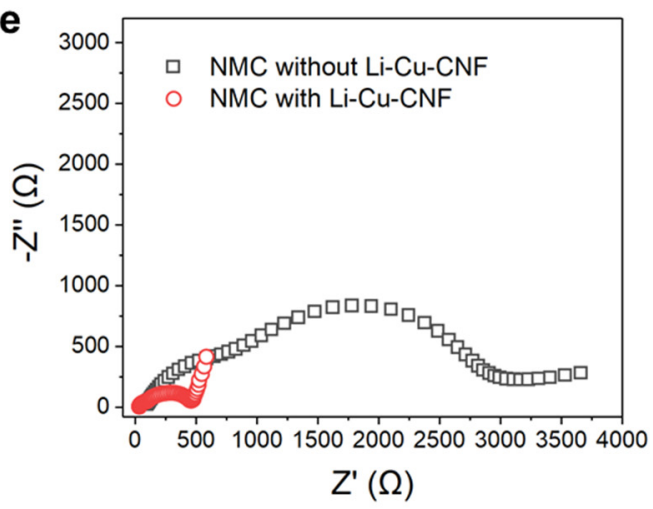

Cathode slurry with Cu-CNF
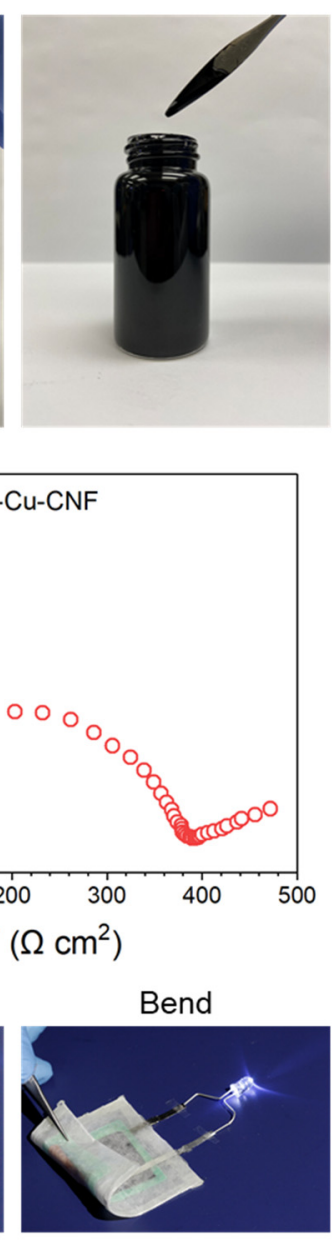

C

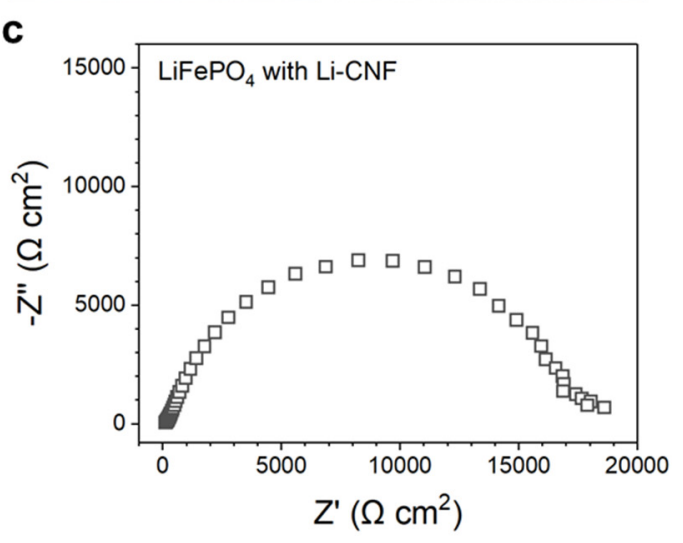

Fold
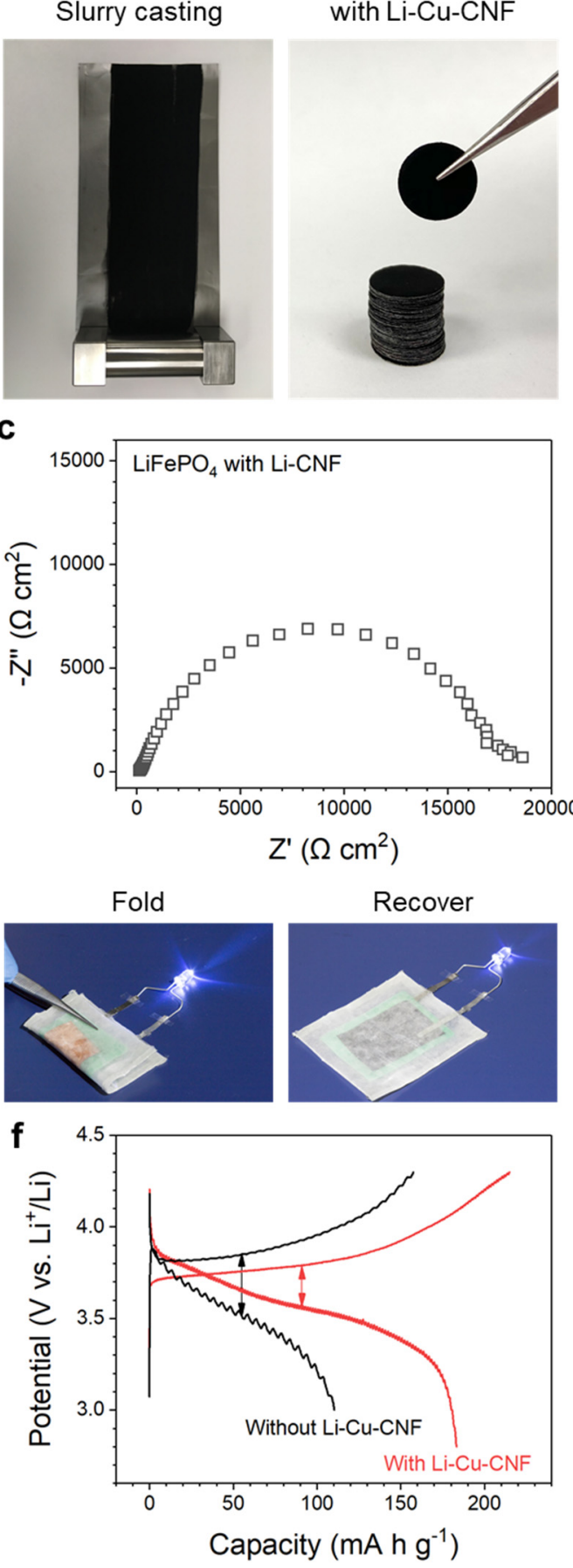

Cathode electrode

with Li-Cu-CNF

\section{Recover}

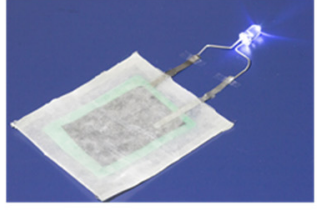

a

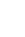


929 first mixed with the cathode material, a carbon additive (carbon nanotubes), and sodium alginate binder in 930 an aqueous solution to obtain the cathode slurry. The slurry is then cast on aluminum foil by a doctor blade 931 and vacuum dried at $35^{\circ} \mathrm{C}$. The cathode electrodes are then soaked in $\mathrm{Li}^{+}$electrolyte for $\mathrm{Li}^{+}$intercalation of 932 the $\mathrm{Cu}-\mathrm{CNF}$, followed by vacuum drying to obtain solid electrodes containing the Li-Cu-CNF additive. $\mathbf{b}$, 933 c, EIS of the solid-state batteries using thick $\mathrm{LiFePO}_{4}$ cathodes $(\sim 120 \mu \mathrm{m})$ made by filtration-pressing with 934 the addition of $\mathbf{b}, \mathrm{Li}-\mathrm{Cu}-\mathrm{CNF}$ and $\mathbf{c}, \mathrm{Li}-\mathrm{CNF}$. $\mathbf{d}$, A pouch all-solid-state battery made using a Li anode, the $935 \mathrm{Li}-\mathrm{Cu}-\mathrm{CNF}$ film SPE, and a $\mathrm{LiFePO}_{4}$ solid-state cathode containing the $\mathrm{Li}-\mathrm{Cu}-\mathrm{CNF}$ ion-conducting additive, 936 which shows good flexibility while still powering an LED light. e, EIS of solid-state batteries made using 937 the Li-Cu-CNF film electrolyte and the NMC cathodes $\left(9 \mathrm{mg} \mathrm{cm}^{-2}\right)$ with and without the addition of $\mathrm{Li}-\mathrm{Cu}-$ 938 CNF. f, Charge/discharge voltage profiles of the solid-state NMC cathode with and without the addition of 939 Li-Cu-CNF at $0.02 \mathrm{C}\left(1 \mathrm{C}=200 \mathrm{~mA} \mathrm{~g}^{-1}\right)$. 


\section{Figures}
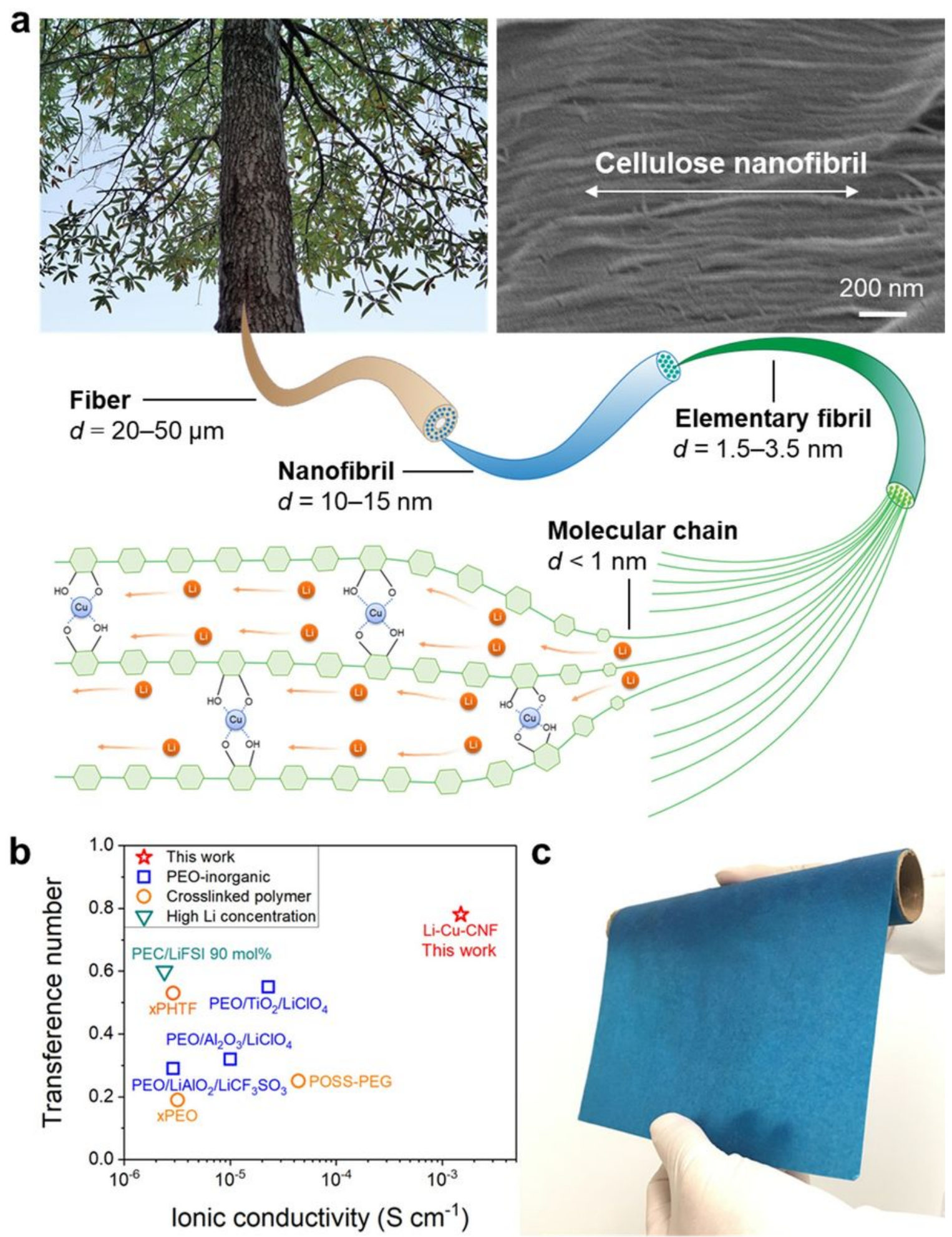

\section{Figure 1}

The structure and performance of the Li-Cu-CNF solid-state ion conductor. a, Schematic illustration of the hierarchical structure of CNFs, which are derived from wood cellulose fibers and are composed of elementary fibrils, each of which is comprised of individual cellulose molecular chains. Cu-ion 
coordination with the hydroxyl groups of cellulose opens the spacing between molecular chains, creating cellulose molecular channels in the CNFs that serve as Li+ conducting pathways in the resulting Li-CuCNF ion conductor. The scanning electron microscopy (SEM) image shows the morphology of the CNFs, which are naturally aligned in the cellulose fibers. $b, A$ plot of the transference number and ionic conductivity of Li-Cu-CNF and other SPEs13,14,17,24. c, A digital photo of a 1-meter long Li-Cu-CNF roll.

a
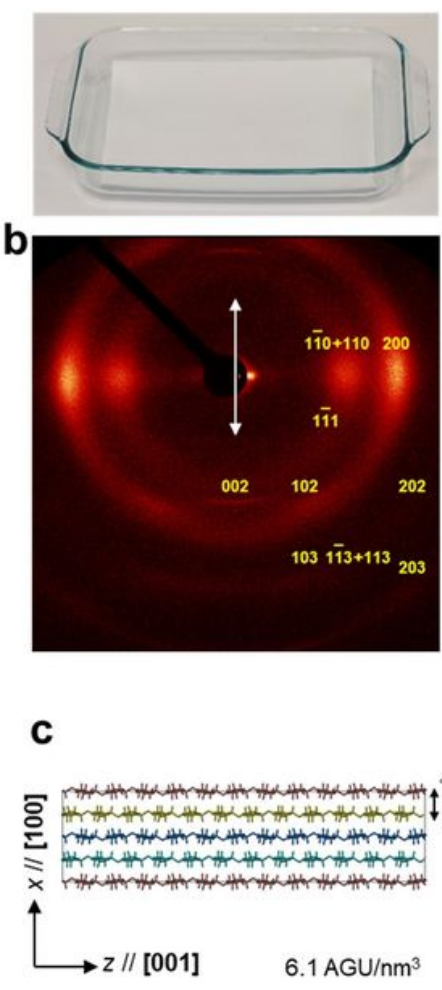

Cu-CNF-NaOH
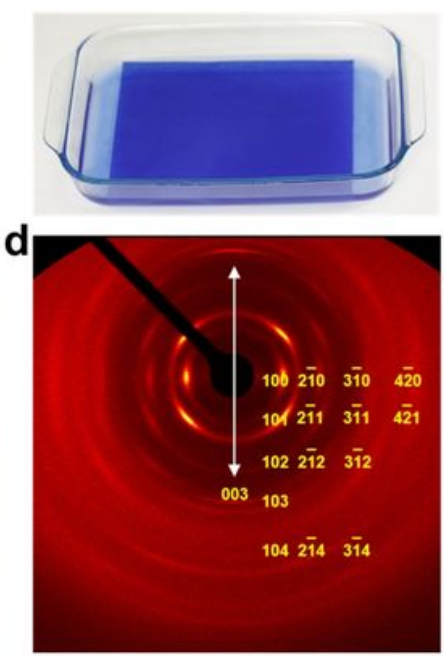

e

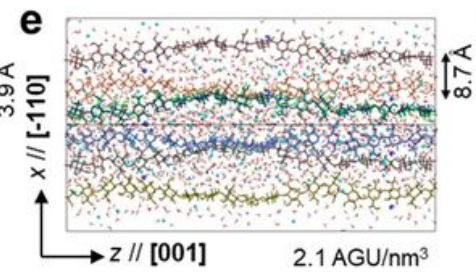

Br Cellulose $0 \mathrm{Cu} O \mathrm{Li}$
$\mathrm{Cu}-\mathrm{CNF}$
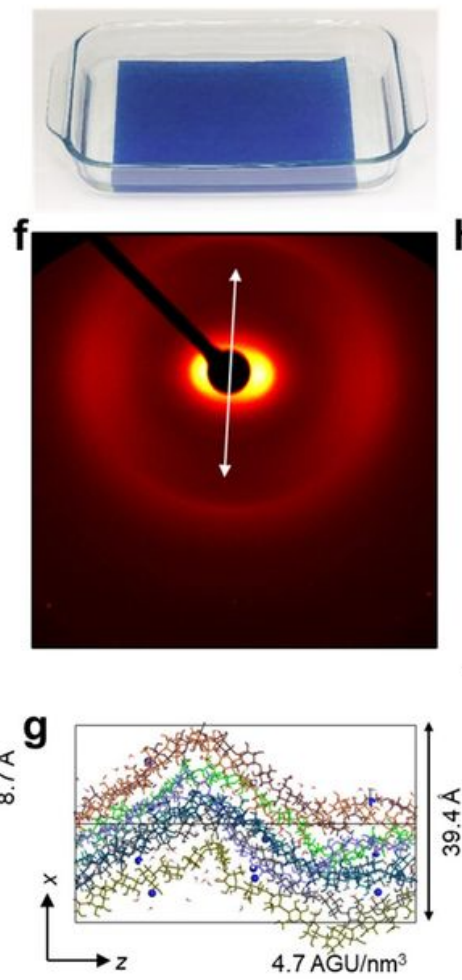

- $\mathrm{Na}=\mathrm{OH} \vee \mathrm{H}_{2} \mathrm{O}$
Li-Cu-CNF
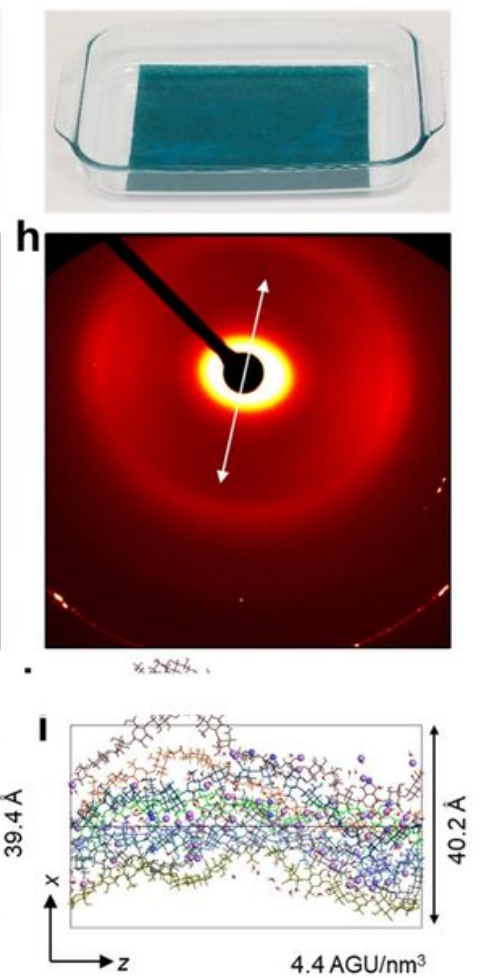

\section{Figure 2}

Structural evolution during the synthesis of Li-Cu-CNF. a, Digital images showing the fabrication process of $\mathrm{Li}-\mathrm{Cu}-\mathrm{CNF}$, during which the CNF starting material was immersed in $\mathrm{Cu} 2+$ alkaline solution to produce $\mathrm{Cu}-\mathrm{CNF}-\mathrm{NaOH}$. The aqueous solution in $\mathrm{Cu}-\mathrm{CNF}-\mathrm{NaOH}$ was then displaced with DMF to obtain $\mathrm{Cu}-\mathrm{CNF}$, and finally exchanged with LiPF6 organic electrolyte for Li+ intercalation and then dried to form Li-CuCNF. The fiber XRD patterns (middle row) and simulated structures (bottom row) of $b$ and $c$, the pristine CNFs showing cellulose I $\beta$ structure; $d$ and e, $\mathrm{Cu}-\mathrm{CNF}-\mathrm{NaOH}$, with coordinated cellulose chains packed in a hexagonal unit cell consistent with the literature26; $f$ and $g, C u-C N F$, in a largely amorphous state; and $h$ and i, Li-Cu-CNF, which features an amorphous structure (with some weak diffraction signals of cellulose II25). The white arrows in the fiber XRD patterns indicate the fiber direction. Different cellulose chains in the simulated structures are denoted by different colors. 

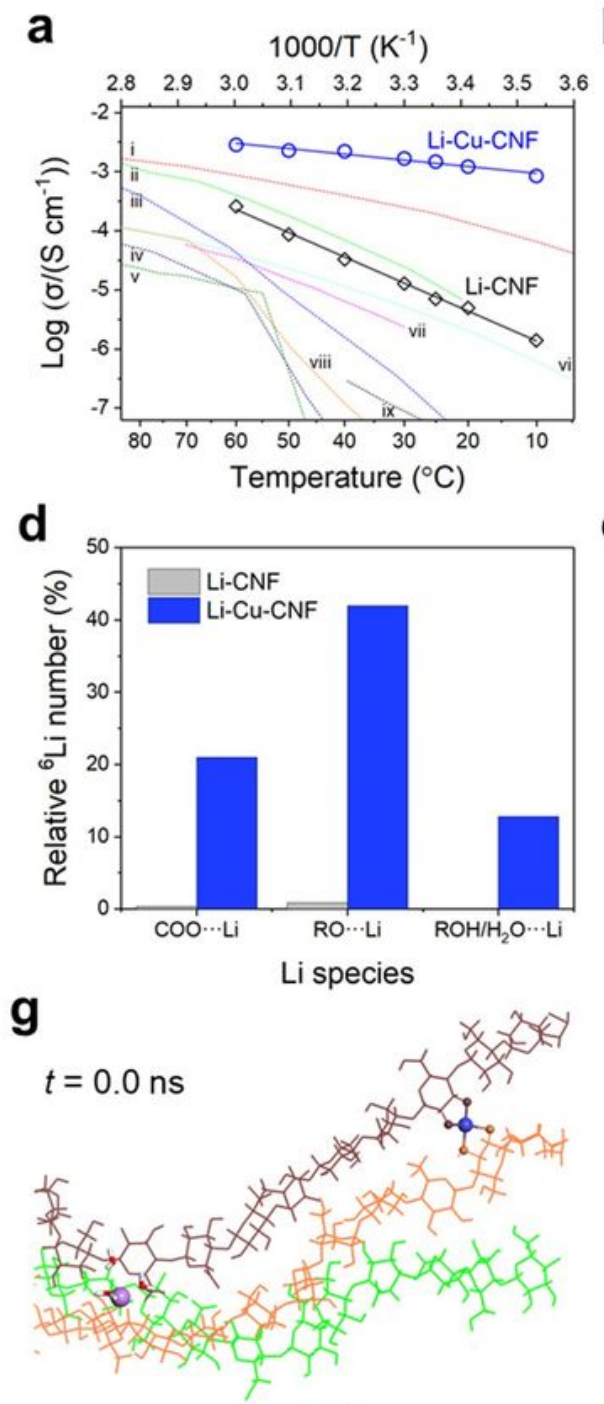

Cellulose

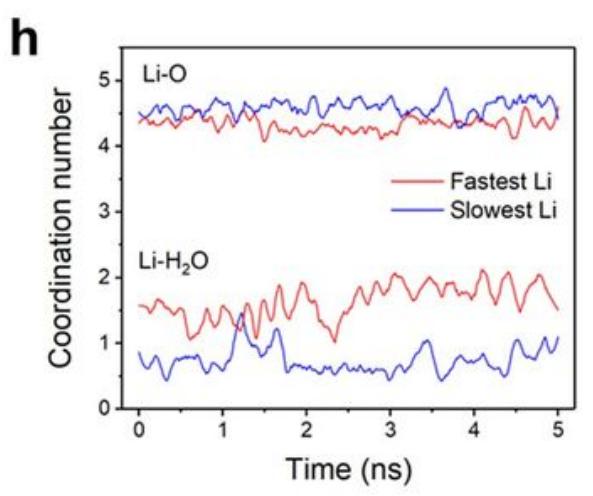

b

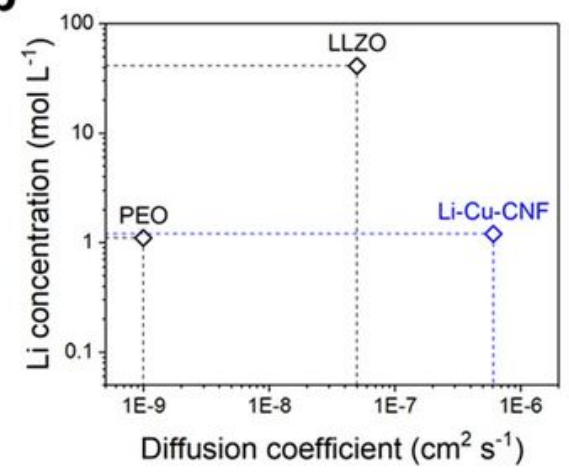

e
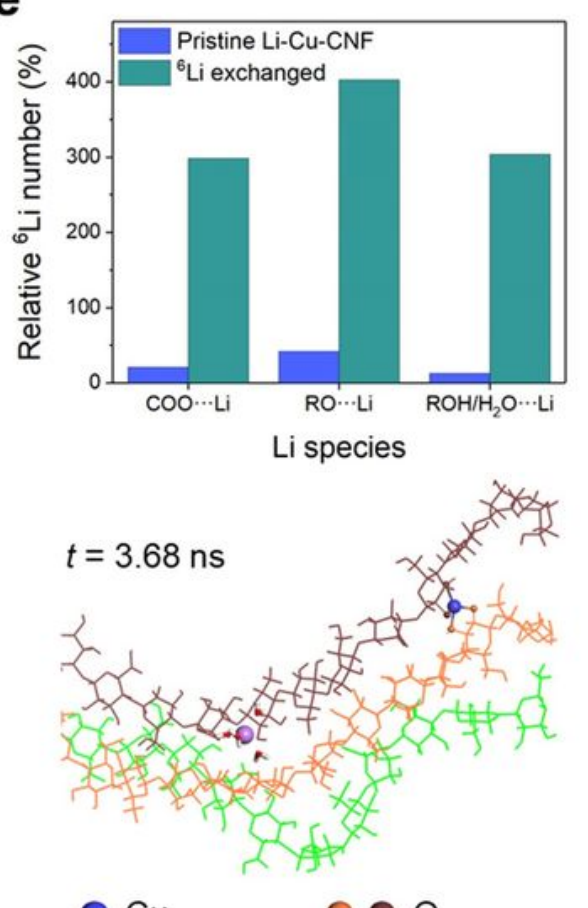

- $\mathrm{Cu}$

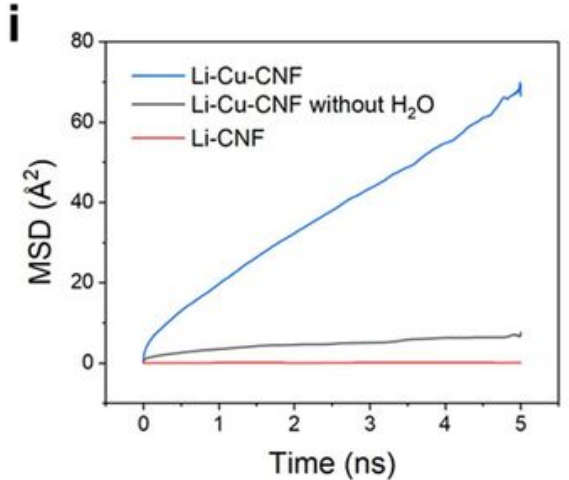

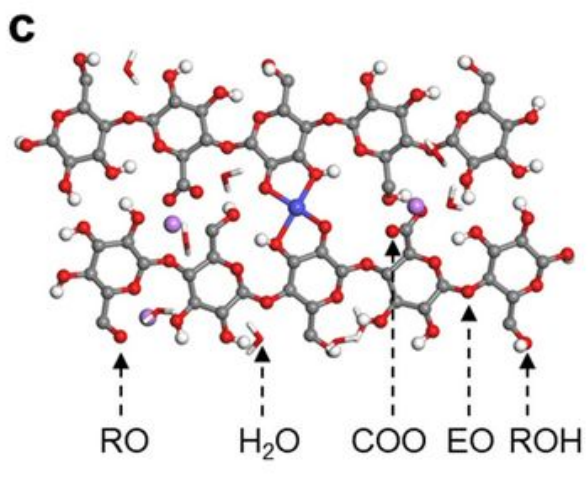

f
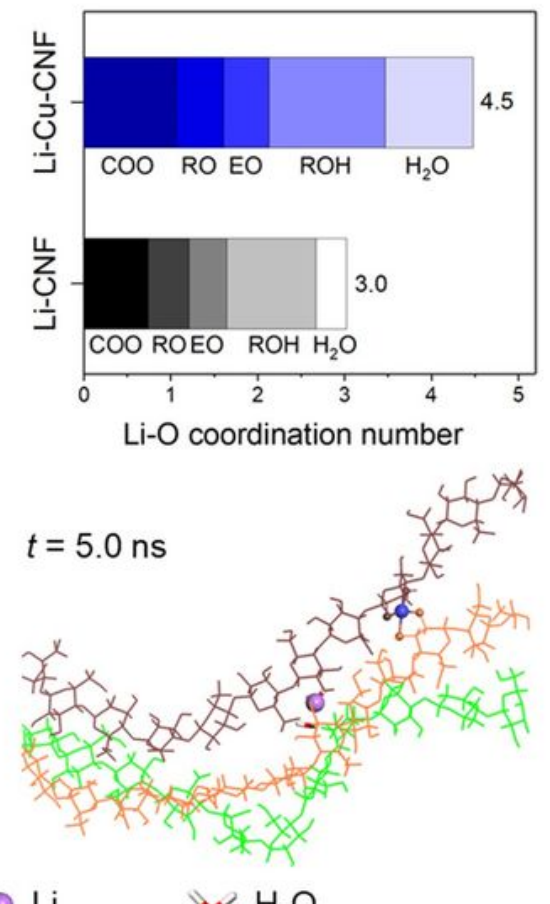

$\mathrm{Li} \vee \mathrm{H}_{2} \mathrm{O}$

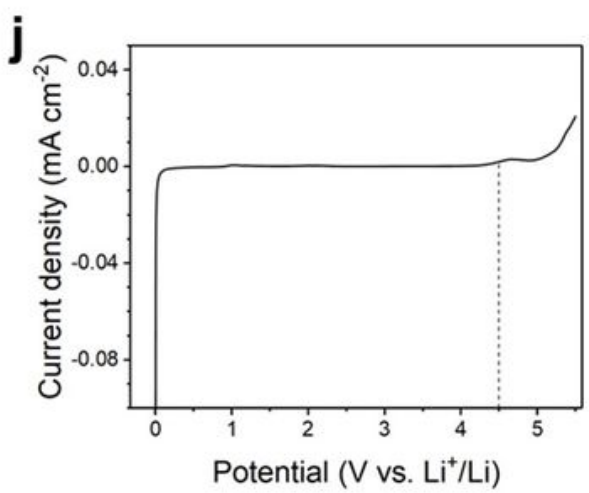

\section{Figure 3}

$\mathrm{Li}+$ conductivity and transport mechanism in Li-Cu-CNF. a, The temperature dependent conductivity of LiCu-CNF and Li-CNF (without Cu2+ coordination) and linear fitting according to the Arrhenius equation, the slope of which indicates the activation energy. The temperature-dependent conductivity plots (i-ix) of typical SPEs are included for comparison (i12, ii-iv7, v15, vi13, vii24, viii16, ix3). b, Comparison of the Li+ diffusion coefficient and Li+ concentration of Li-Cu-CNF with other solid-state electrolytes (PEO and 
LLZO). c, Schematic of the chemical environment of Li+ in the Li-Cu-CNF system with different types of oxygen atoms. The $\mathrm{C}, \mathrm{H}, \mathrm{O}, \mathrm{Cu}$, and $\mathrm{Li}$ atoms are denoted by grey, white, red, blue, and purple spheres, respectively. The hydrogen atoms that are bonded with carbon are not shown for clarity. d, Relative $6 \mathrm{Li}$ number in different Li chemical environments in Li-CNF and Li-Cu-CNF, derived from NMR (Extended Data Fig. 5) by normalizing the mass-specific $6 \mathrm{Li}$ number in Li-Cu-CNF to $100 \%$. e, Relative $6 \mathrm{Li}$ number for different Li chemical environments in the Li-Cu-CNF before and after $6 \mathrm{Li \otimes} 7 \mathrm{Li}$ tracer exchange. $\mathrm{f}$, The average Li-O coordination numbers from MD simulations for Li-CNF and Li-Cu-CNF. g, Structural snapshots from MD simulations of a fast-moving Li+ transporting in Li-Cu-CNF for $5 \mathrm{~ns}$. h, The coordination numbers of $\mathrm{Li}+$ coordinating with all available oxygen atoms ( $\mathrm{Li}-\mathrm{O}$, including the oxygen atoms in cellulose and bound water molecules) and just water molecules ( $\mathrm{Li}-\mathrm{H} 2 \mathrm{O})$ in $\mathrm{Li}-\mathrm{Cu}-\mathrm{CNF}$ for the 6 fastest and 6 slowest Li+ ions in the Li-Cu-CNF model. i, MSD plots for the Li-Cu-CNF systems with/without water molecules and the Li-CNF system with water molecules on the surface of the CNFs. $\mathrm{j}$, Electrochemical stability window of the Li-Cu-CNF measured by linear sweep voltammogram from $0 \mathrm{~V}$ to $5.5 \mathrm{~V}$ (vs. Li+/Li) at $0.1 \mathrm{mV} \mathrm{s}-1$. 
a
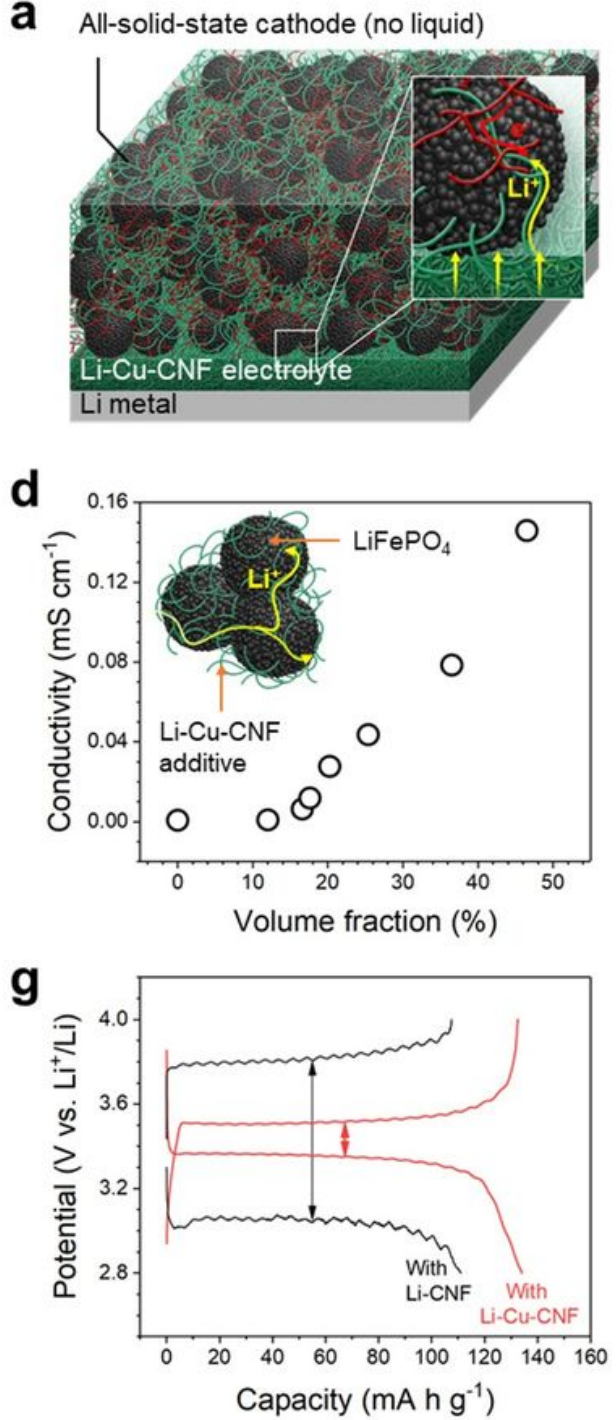

j

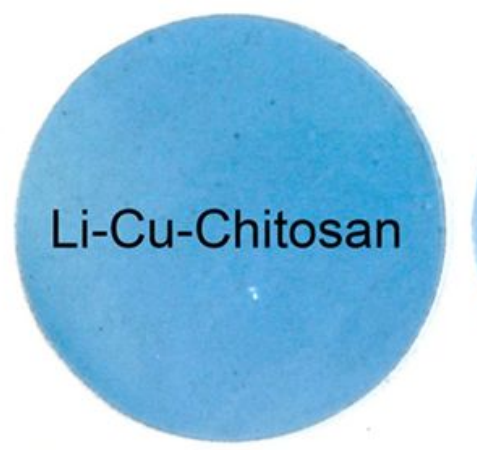

b

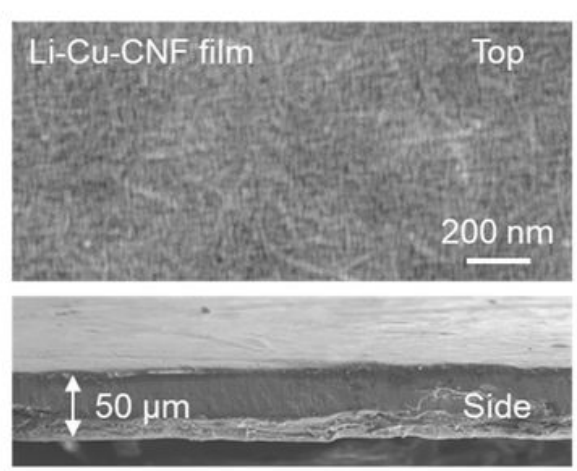

e

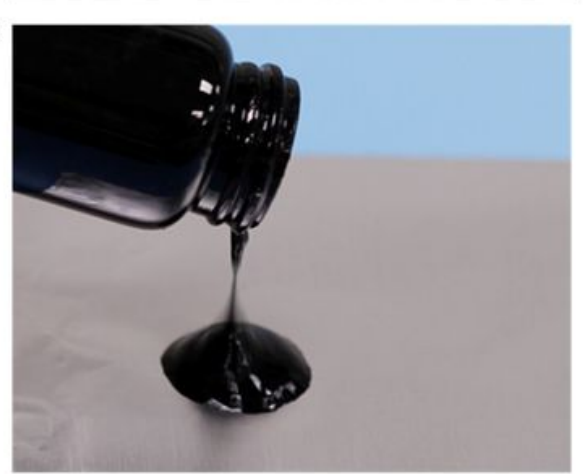

h

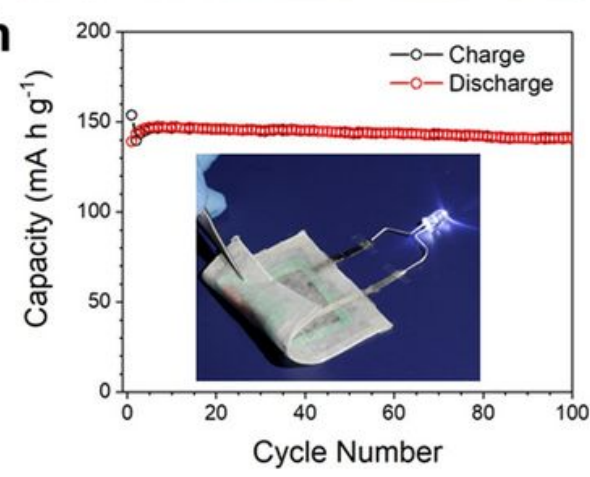

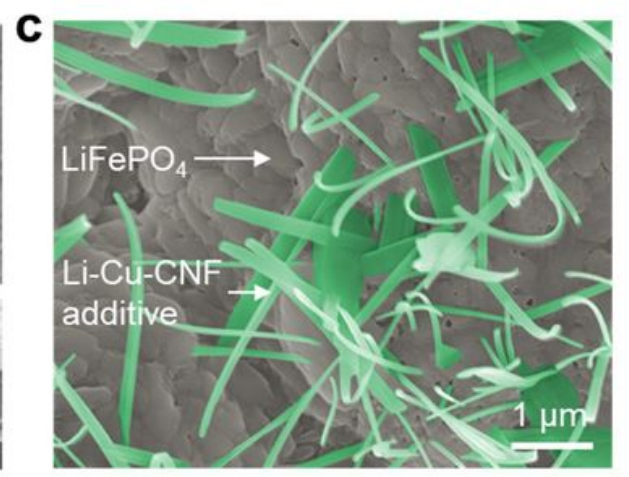

f

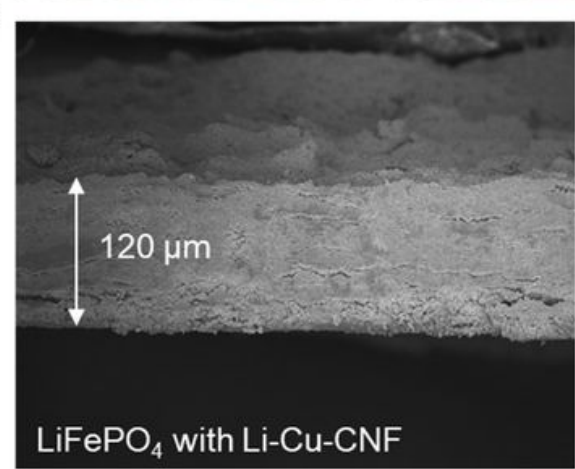

i

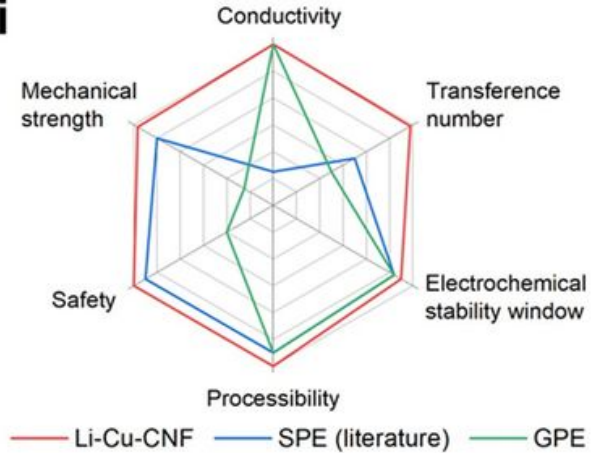

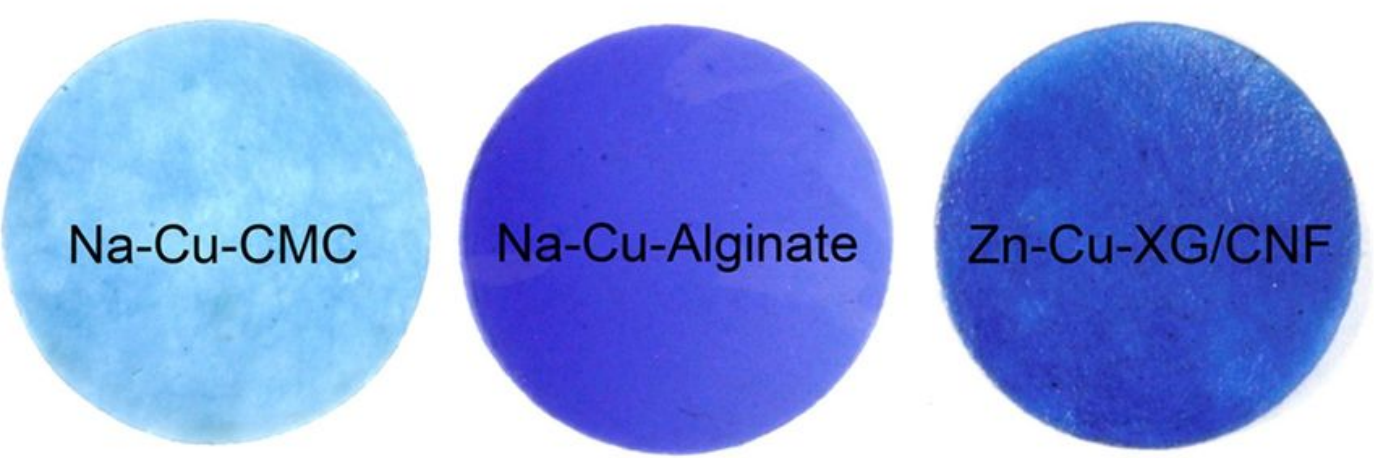

Figure 4

Demonstration of all-solid-state batteries using the Li-Cu-CNF ion conductor. a, Schematic of an all-solidstate full battery consisting of a Li metal anode, the Li-Cu-CNF film SPE, and the solid-state cathode (black spheres) featuring the Li-Cu-CNF as an ion-conducting additive (green fibers). b, Top-view and sideview SEM images of the dense electrolyte made of the 1D Li-Cu-CNF. c, SEM image of the LiFePO4 cathode with the Li-Cu-CNF ion-conducting additive (false color: grey, LiFeP04; green, Li-Cu-CNF). d, The ionic conductivity of LiFePO4 cathodes made with different amounts of Li-Cu-CNF to achieve ion 
percolation. e, Photo of the cathode slurry consisting of LiFePO4 and Cu-CNF additive for casting the electrode and subsequent $\mathrm{Li}+$ intercalation. f, Cross-sectional SEM images of a $120 \mu \mathrm{m}$ thick LiFePO4 cathode made using Li-Cu-CNF and carbon nanotube additives. g, Galvanostatic charge/discharge voltage profiles of the thick LiFePO4 solid-state cathodes made by filtration-pressing with $\mathrm{Li}-\mathrm{Cu}-\mathrm{CNF}$ or $\mathrm{Li}$ CNF additive and Li-Cu-CNF electrolyte. The arrows indicate the overpotentials at half capacity. $h$, The cycle performance (0.2 C) of an all-solid-state LiFePO4 cell made using Li-Cu- CNF ion-conducting additive in the cathode, the Li-Cu-CNF film electrolyte, and Li metal anode. Inset: digital photo of the folded all-solid-state battery based on the LiFePO4 cathode and Li-Cu- CNF as both the solid-state electrolyte and ion-conducting additive. i, Comparing the performance of the Li-Cu-CNF electrolyte with SPEs and GPEs reported in the literature. j, Digital photos of M-Cu-polymer electrolytes (analogue to Li-Cu$\mathrm{CNF}$ ), where $\mathrm{M}=\mathrm{Li}, \mathrm{Na}$, or $\mathrm{Zn}$, and the polymers include chitosan, carboxymethyl cellulose (CMC), alginate acid, and xanthan gum (XG). 